\title{
AVALIAÇÃO DO DESEMPENHO E COLESTEROL SÉRICO E MUSCULAR DE FRANGOS DE CORTE ALIMENTADOS COM NÍVEIS CRESCENTES DE CITRATO CÚPRICO NA DIETA
}

\author{
SÔNIA CRISTINA DARÓZ DE MORAIS \\ Médica Veterinária
}

Orientador: Prof. Dr. JOSÉ FERNANDO MACHADO MENTEN

Dissertação apresentada à Escola Superior de Agricultura "Luiz de Queiroz", Universidade de São Paulo, para a obtenção do título de Mestre em Agronomia, Área de Concentração: Ciência Animal e Pastagens.

P I R A C I C A B A

Estado de São Paulo - Brasil

Novembro - 1999 
Dados Internacionais de Catalogação na Publicação (CIP) DIVISÃO DE BIBLIOTECA E DOCUMENTAÇÃO - Campus "Luiz de Queiroz"/USP

Morais, Sônia Cristina Daróz de

Avaliação do desempenho e colesterol sérico e muscular de frangos de corte alimentados com niveis crescentes de citrato cúprico na dieta / Sônia Cristina Daróz de Morais. - - Piracicaba, 1999.

74 p. : il.

Dissertação (mestrado) - - Escola Superior de Agricultura Luiz de Queiroz, 1999. Bibliografia.

1. Citrato cúprico 2. Colesterol 3. Desempenho animal 4. Dieta animal 5. Frango de corte 6 . Sulfato de cobre I. Titulo

CDD 636.513 


\section{DEDICO}

Ao meu amado filho, Pedro Henrique, que apesar de tão tenra idade, me ensinou a lutar com perseverança e a ser forte nos momentos mais dificeis com seu sorriso, suas palavras meigas e seu amor sincero. E que tantas vezes teve que abrir mão do nosso convívio para que eu pudesse me dedicar aos estudos.

À minha mãe, Zilda, que esteve sempre ao meu lado me apoiando e sendo, inúmeras vezes, a mãe do meu filho. Com muito amor agradeço.

Aos meus irmãos e inmã, Jorge Augusto, Eduardo Flávio e Regina Lúcia, meus verdadeiros amigos. Pelo incentivo e por seus conselhos tão valiosos.

Aos meus sobrinhos, Felipe, Flávio, Bruno e Giulia, pelo carinho.

Às minhas cunhadas, Cleusa e Cristina, e ao meu cunhado, Luiz Eduardo, pela amizade.

"O Senhor te guiará continuamente, fartará a tua alma até em lugares áridos, e fortificará os teus ossos; serás como um jardim regado, e como um manancial, cujas águas jamais faltam." (Isaias 58:11) 


\section{AGRADECIMENTOS}

Agradeço primeiramente a Deus, pois Ele me deu a oportunidade de realizar mais um sonho e com isso alcançar esta meta.

À Escola Superior de Agricultura "Luiz de Queiroz", Universidade de São Paulo pela oportunidade de realização do curso de mestrado.

Ao meu orientador Prof. Dr. José Fernando Machado Menten pelos valiosos ensinamentos, dedicação e orientação recebida no curso de mestrado.

Ao Prof. Dr. Roberto Dias de Morais e Silva pelo incentivo e por sua amizade e orientação no início do curso.

Ao Prof. Dr. Irineu Umberto Packer, (Departamento de Produção Animal -Setor de Não Ruminantes), à Prof. Dra. Maria Cristina Stolf Nogueira (Departamento de Matemática e Estatística) e à amiga Ana Carolina Espasandin pela colaboração nas análises estatísticas.

A todos os professores do Departamento de Produção Animal -Setor de Não Ruminantes, em especial ao Prof. Dr. Valdomiro Shigueru Miyada e ao Prof. Dr. Luis L. Coutinho pelas colaborações prestadas durante todo o curso de mestrado.

Ao Conselho Nacional de Desenvolvimento Científico e Tecnológico, CNPq pela concessão da bolsa de estudo.

À Fundação de Amparo à Pesquisa do Estado de São Paulo (FAPESP) por financiar a pesquisa.

À Griftin Corporation pela doação do citrato cúprico.

À SUPREMAIS Produtos Bioquímicos Ltda. pelas análises laboratoriais.

Aos diretores da Nutron Alimentos, Antônio Mário Penz Júnior, Luciano Roppa, Abílio César Tardin e Gabriel Jorge Neto pela compreensão e apoio para que eu pudesse concluir meu trabalho. 
Aos meus amigos do curso de mestrado, Mônica Maria de Almeida Brainer e Marcos Martinez do Vale por nossa amizade.

Aos amigos, Juliano Gaiotto, Márcia Christina Iafigliola e Aline Calil, pela colaboração durante toda a fase experimental.

À bibliotecária Eliana M. G. Sabino pela revisão das referências bibliográficas.

Às secretárias do Departamento de Produção Animal -Setor de Não Ruminantes, Cláudia C. de Camargo e Vera Lúcia Graciano pela atenção.

Aos funcionários do Departamento de Produção Animal -Setor de Não Ruminantes que, direta ou indiretamente, cooperaram com este trabalho, em especial a Alexandre Sebastião Soares, José Augusto Alves e Antônio Carlos Oliva.

À todas as pessoas que de alguma forma me ajudaram na realização deste trabalho.

Aos demais colegas do curso de mestrado que fizeram com que o curso se tornasse ainda melhor. Pelo nosso convívio tão agradável que certamente vai deixar muita saudade. 


\section{SUMÁRIO}

Página

LISTA DE FIGURAS.................................................................................... vii

LISTA DE TABELAS ..................................................................................... viii

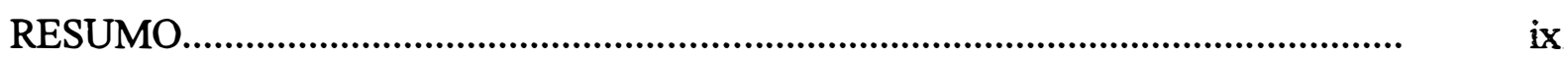

SUMMARY........................................................................................................... xii

1 INTRODUÇÃO................................................................................................

2 REVISÃO DE LITERATURA.................................................................... 3

$2.1 \mathrm{O}$ cobre e suas funções.........................................................................................

2.2 Metabolismo, níveis tóxicos e deficiência de cobre................................................. 5

2.3 Biodisponibilidade do cobre em suas diversas fontes........................................... 8

2.4 Promotores de crescimento: definição e modo de ação.......................................... 10

2.5 Utilização do sulfato e do citrato cúprico............................................................... 11

2.6 Citrato cúprico vs. sulfato cúprico pentahidratado.................................................. 13

2.7 Colesterol: definição e síntese................................................................................... 14

2.8 Reduzindo os níveis de colesterol nos alimentos................................................. 16

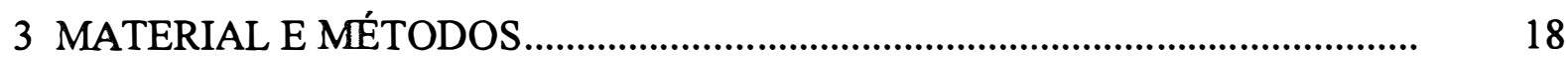

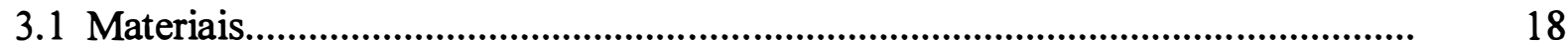

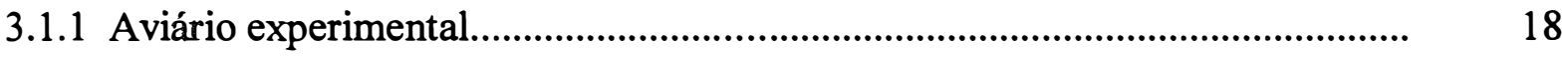

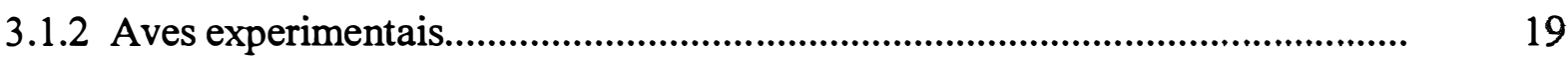

3.1.3 Citrato cúprico................................................................................................. 19

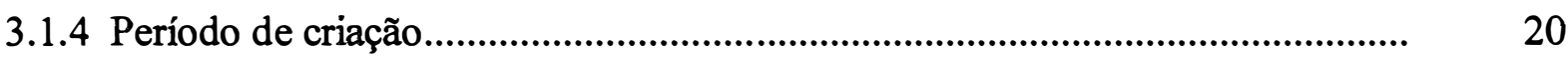

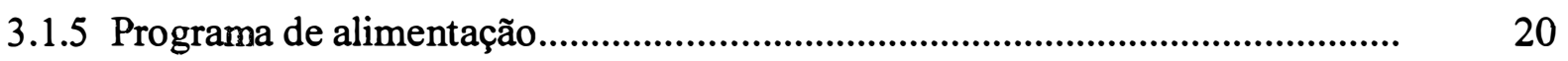

3.1.6 Análises bromatológicas................................................................................... 22

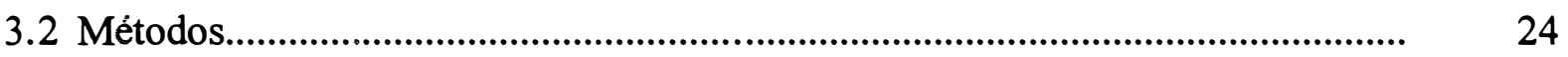

3.2.1 Manejo de equipamentos e aves................................................................. 24

3.2.2 Delineamento experimental................................................................................ 27 
Página

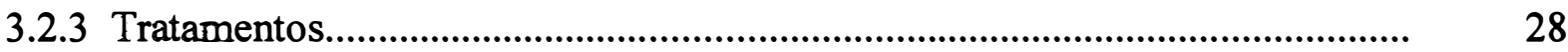

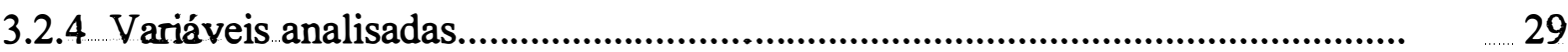

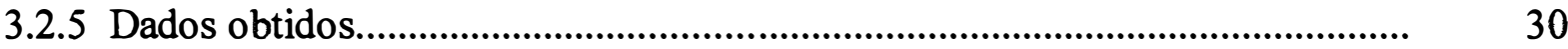

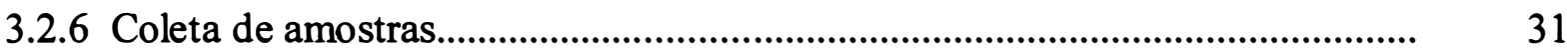

3.2.7 Metodologia de análise do nível de colesterol no soro sangüíneo.................... 32

3.2.8 Metodologia para determinação do nível de colesterol no músculo do peito.........................................................................................

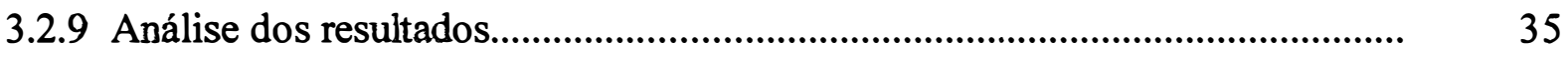

4 RESULTADOS E DISCUSSÃO

4.1 Ganho Médio de Peso (GMP), Consumo Médio de Ração (CMR), Conversão Alimentar (CA) e Mortalidade + Refugagem (M+R) de 1 a 21 dias de idade.

4.2 Ganho Médio de Peso (GMP), Consumo Médio de Ração (CMR), Conversão Alimentar (CA) e Mortalidade + Refugagem (M+R) de 22 a 42 dias de idade.

4.3 Peso Médio (PM), Ganho Médio de Peso (GMP), Consumo Médio de Ração (CMR), Conversão Alimentar (CA) e Mortalidade + Refugagem (M+R), Nível de Colesterol no Soro Sangüíneo (ColS.), Nível de Colesterol na Carne (ColC.), Ganho de Peso Médio Diário (GPMD)

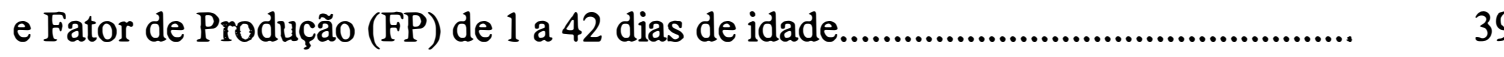

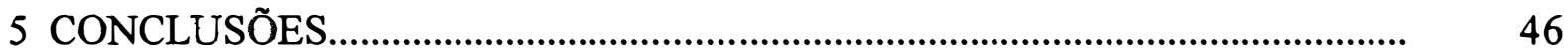

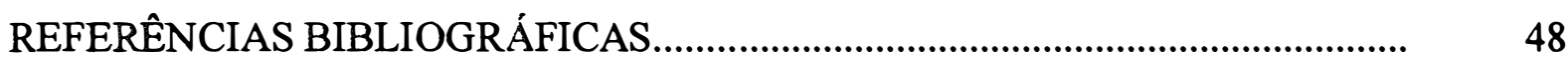

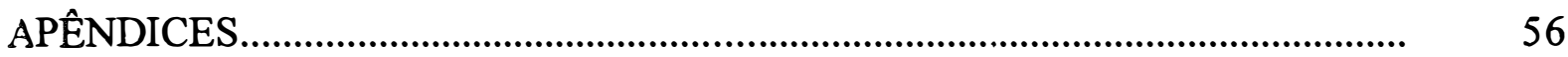




\section{LISTA DE FIGURAS}

Página

1 Vista interna do aviário experimental........................................................... 23

2 Instalação do experimento. Vista de uma unidade experimental.......................... 23

3 Fluxograma para determinação do nível de colesterol no músculo do peito........ 34 


\section{LISTA DE TABELAS}

Página

1 Composição percentual e valores calculados das dietas basais................................. 21

2 Análises bromatológicas de milho e farelo de soja utilizados na ração basal.................................................................................................... 22

3 Efeito dos tratamentos sobre as variáveis GMP, CMR, CA e M+R no período de 1 a 21 dias da criação das aves........................................................................ 37

4 Efeito dos tratamentos sobre as variáveis GMP, CMR, CA e M+R no período

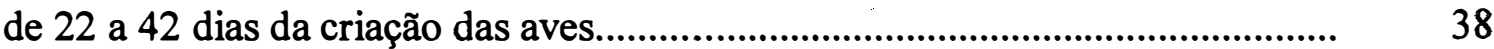

5 Efeito dos tratamentos sobre as variáveis PM, GMP, CMR, CA, M+R, ColS. ColC., GPMD e FP no período

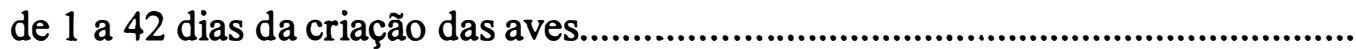




\title{
AVALIAÇÃO DO DESEMPENHO E COLESTEROL SÉRICO E MUSCULAR DE FRANGOS DE CORTE ALIMENTADOS COM NÍVEIS CRESCENTES DE CITRATO CÚPRICO NA DIETA
}

\author{
Autora: SÔNIA CRISTINA DARÓZ DE MORAIS \\ Orientador : Prof. Dr. JOSÉ FERNANDO MACHADO MENTEN
}

\section{RESUMO}

O presente trabalho foi realizado na Escola Superior de Agricultura "Luiz de Queiroz", localizado no município de Piracicaba, SP, no Departamento de Produção Animal - Setor de Não Ruminantes. A fase experimental de campo foi iniciada em 19 de fevereiro e concluída em 02 de abril de 1998.

O objetivo deste experimento foi de avaliar o desempenho de frangos de corte utilizando-se diferentes níveis de citrato cúprico, comparando-os ao sulfato cúprico pentahidratado e a uma dieta basal, a qual não continha nenhuma fonte de cobre $(\mathrm{Cu})$ com finalidade promotora de crescimento.

Foram cinco os tratamentos utilizados, sendo estes os seguintes: tratamento CONTR. (dieta basal), tratamentos CITR. 50, CITR. 100 e CITR. 150, a dieta basal mais níveis de citrato cúprico suprindo 50,100 e $150 \mathrm{mg}$ de $\mathrm{Cu} / \mathrm{kg}$ de ração, respectivamente. O tratamento SULF. 200 era composto pela dieta basal mais $200 \mathrm{mg}$ de $\mathrm{Cu}$ na forma de sulfato cúprico pentahidratado/kg de ração. 
Foram utilizados 1200 pintos sexados da linhagem Hubbard-Peterson, sendo 600 machos e 600 fềmeas, adquiridos de um incubatório comercial, os quais foram criados até 42 dias de idade. Para cada fase de criação foi formulada uma ração basal com a finalidade de atender às exigências nutricionais das aves. A ração era à base de milho e farelo de soja e as fases de criação: inicial ( 1 a 21 dias), crescimento ( 22 a 35 dias) e final (36 a 42 dias).

O delineamento empregado foi de blocos ao acaso, com um arranjo fatorial 5 X 2 ( 5 tratamentos e 2 sexos), e 3 repetições. Foram utilizadas 30 unidades experimentais, com 40 aves cada.

As variáveis analisadas foram: ganho médio de peso (GMP), consumo médio de ração $(C M R)$, conversão alimentar $(C A)$ e mortalidade + refugagem $(M+R)$, nos períodos de 1 a 21 dias, de 22 a 42 dias e de 1 a 42 de criação das aves. As variáveis peso médio (PM), nível de colesterol no soro sangüíneo (ColS.), nível de colesterol na carne (ColC.), ganho de peso médio diário (GPMD) e fator de produção (FP) também foram analisadas com dados obtidos aos 42 dias de criação.

Para a análise estatística foi utilizado o Programa SAS (Statistical Analyses System) de análises estatísticas.

Não houve efeito estatisticamente significativo $(\mathrm{P}>0,05)$ entre os tratamentos, para todas as variáveis analisadas, nos diferentes períodos testados. Quando testou-se sexo, houve diferença significativa $(\mathrm{P}<0,05)$ quando analisadas as variáveis GMP, CMR e CA em todos os períodos e PM, GPMD e FP aos 42 dias.

Para as variáveis $\mathrm{M}+\mathrm{R}$, ColS. e ColC. não houve diferença estatisticamente significativa $(P>0,05)$ quando testado tratamento ou sexo nos diferentes períodos e aos 42 dias, respectivamente.

Houve interação estatisticamente significativa $(\mathrm{P}<0,05)$ entre tratamento e sexo para a variável $M+R$ no período de 1 a 21 dias, porém pode-se considerar um efeito casual, pois não há explicação lógica para o ocorrido.

Neste trabalho não se comprovou a ação promotora de crescimento do $\mathrm{Cu}$; nem tampouco sua ação redutora do nível de colesterol no soro sangüíneo ou na 
carne, contrariando pesquisas anteriores que provaram sua eficácia. Portanto pode-se sugerir que sejam reavaliadas as condições para a utilização do $\mathrm{Cu}$ assim como sua verdadeira ação promotora de crescimento. 


\title{
EVALUATION OF THE PERFORMANCE AND SERUM AND MUSCLE CHOLESTEROL OF BROILER CHICKENS FED INCREASING LEVELS OF DIETARY CUPRIC CITRATE
}

\author{
Author: SÔNIA CRISTINA DARÓZ DE MORAIS \\ Adviser : Prof. Dr. JOSÉ FERNANDO MACHADO MENTEN
}

\section{SUMMARY}

This study was carried out at the Department of Animal Production, University of São Paulo, Piracicaba, SP, from February 19 to April 2, 1998.

The objetive of the experiment was to study the effect of different levels of cupric citrate compared to cupric sulfate pentahydrate and to a basal diet, which did not contain growth promoting levels of copper $(\mathrm{Cu})$.

The treatments included a basal diet (CONTR.) and this diet supplemented with cupric citrate to provide 50,100 or $150 \mathrm{mg} \mathrm{Cu} / \mathrm{kg}$ (CITR. 50, CITR. 100 AND CITR. 150) or with cupric sulfate pentahydrate to provide $200 \mathrm{mg} \mathrm{Cu} / \mathrm{kg}$ (SULF. 200).

Six hundred male and 600 female Hubbard x Peterson day-old chicks were obtained from a commercial hatchery and used in a 42 day experiment. The feeds were based on corn and soybean meal and formulated for starter (1 to 21 days), grower (22 to 35 days) and withdrawal ( 36 to 42 days) periods.

A $5 \times 2$ factorial (diets and sexes) arrangement of treatments in a randomized block design with 3 replicates was used; in each pen were placed 40 birds. 
The variables analysed for the 1-21 days, 22-42 days and 1-42 days were average weigth gain (GMP), average feed intake (CMR), feed conversion (CA) and mortality + culling $(M+R)$. At the end of the 42 day experimental period data of average liveweigth (PM), serum cholesterol (ColS.), muscle cholesterol (ColC.), average daily weight gain (GMPD) and production index (FP) were also collected for analysis.

There were no significant effects of diets for any of the variables studied $(P>0,05)$. Sex differences were significant $(P<0,05)$ for GMP, CMR and CA in all periods and for PM, GPMD and FP at 42 days.

There was no diet or sex effect $(P>0,05)$ for $M+R$, ColS. and ColC., except for a significant diet $x$ sex interaction $(P<0,05)$ for $M+R$, in the 1-21 days.

This study did not confirm previous findings of the growth promoting effect of $\mathrm{Cu}$, as well as the ability of high dietary levels of $\mathrm{Cu}$ to reduce serum and muscle cholesterol of chickens. 


\section{INTRODUÇÃO}

Nas últimas décadas, a indústria avícola alcançou posição de destaque, uma vez que conseguiu aumentar a eficiência e, consequentemente, reduzir o custo para a produção do frango de corte.

Uma das causas para que isto viesse a ocorrer foi a utilização de aditivos na ração das aves, os quais têm a capacidade de aumentar a taxa de crescimento, a eficiência de utilização dos alimentos e reduzir a morbidade e a mortalidade, melhorando assim a eficiência de produção animal.

Dentre os mais diversos aditivos, os agentes antimicrobianos têm sido muito usados na avicultura devido aos resultados obtidos. Entre esses agentes, o cobre $(\mathrm{Cu})$ tem resultado em bons índices de desempenho.

Existem algumas formas de $\mathrm{Cu}$ que podem ser adicionadas à ração animal, o sulfato cúprico pentahidratado $\left(\mathrm{CuSO}_{4} .5 \mathrm{H}_{2} \mathrm{O}\right)$, o óxido cúprico $(\mathrm{CuO})$ e o carbonato cúprico $\left(\mathrm{CuCO}_{3} \mathrm{Cu}(\mathrm{OH})_{2}\right)$ com ação promotora de crescimento (Rostagno et al. 1994). Entretanto, o sulfato cúprico pentahidratado tem sido o mais utilizado, provavelmente, devido à maior disponibilidade do $\mathrm{Cu}$.

Pesti e Bakali (1996) conseguiram obter melhores resultados de desempenho de frangos utilizando cirrato cúprico, com função promotora de crescimento, quando comparado ao sulfato cúprico pentahidratado. Foi possível observar também que o citrato cúprico foi vantajoso, pois além de apresentar resultados satisfatórios a níveis mais baixos que o sulfato cúprico pentahidratado também foi possível diminuir o nível de colesterol no plasma e no músculo das aves. 
Sabendo-se que há necessidade de atender às exigências do consumidor, o qual tem optado por alimentos sempre com níveis mais baixos de colesterol, torna-se necessário pesquisar alternativas que tornem possíveis satisfazer tais exigências.

Segundo Bragagnolo e Rodriguez-Amaya (1993), uma taxa elevada de colesterol no sangue é um dos principais fatores de risco para doenças coronarianas, assim como a hipertensão, o fumo, o estresse e a vida sedentária.

Sendo o $\mathrm{Cu}$ um promotor de crescimento muito utilizado na avicultura e conhecendo-se seus beneficios, tomam-se necessários mais estudos sobre ele e suas diferentes formas para verificar em qual nível utilizado pode-se obter melhores resultados.

Este experimento foi realizado com os seguintes objetivos:

- avaliar o efeito promotor de crescimento de níveis crescentes de citrato cúprico adicionados à ração de frangos de corte, sobre o desempenho das aves, machos e fềmeas; - avaliar a ação de fontes de $\mathrm{Cu}$ sobre a concentração de colesterol no soro sangüíneo e no músculo do peito das aves. 


\section{REVISÃO DE LITERATURA}

\subsection{O cobre e suas funções}

O cobre $(\mathrm{Cu})$ é um micromineral que está presente nos tecidos animais, que foi demonstrado pela primeira vez em 1833 por Boutigny. Porém, sua importância na nutrição animal não foi reconhecida antes de 1928, quando Hart e colaboradores mostraram que ambos, $\mathrm{Cu}$ e ferro ( $\mathrm{Fe}$ ), são necessários para a formação da hemoglobina em ratos (Scott et al., 1982; Maynard et al., 1984; Andriguetto et al., 1986; McDowell, 1992; Ammerman et al., 1995 ).

$\mathrm{O} \mathrm{Cu}$ é um constituinte normal e constante do organismo animal. Fígado, coração, rins, ossos, baço, pêlos e músculos contém altas concentrações de $\mathrm{Cu}$ porém sua maior concentração está no figado (Schaible, 1970). Existem alguns fatores que influenciam a concentração de $\mathrm{Cu}$ nos tecidos, como: espécie, idade (os animais jovens possuem concentrações mais elevadas que os animais adultos), estado nutricional do animal, composição química da dieta e condições de enfermidade. As variações individuais dentro das espécies são muito grandes (Andriguetto et al., 1986; Underwood, 1977).

$\mathrm{O} \mathrm{Cu}$ está presente no plasma sangüineo como parte da proteína plasmática ligadora de $\mathrm{Cu}$, a eritrocupreína, a qual fornece uma ligação entre o metabolismo de $\mathrm{Cu}$ e Fe. 
Além do seu papel no metabolismo do $\mathrm{Fe}$, o $\mathrm{Cu}$ desempenha outras funções básicas, é necessário na respiração celular assim como também é um componente essencial para muitas metaloenzimas, tais como, citocromo-C-oxidase, uricase, tirosinase, lisil oxidase, benzilamina oxidase e diamina oxidase (Scott et al., 1982; McDowell, 1992; Hays e Swenson, 1993; Ammerman et al., 1995). Cu é importante na formação normal do osso, assim como é essencial na atividade osteoblástica e na formação normal de colágeno e elastina (Maynard et al., 1984).

$\mathrm{O} \mathrm{Cu}$ é um elemento que possui propriedades antibacterianas que quando utilizado em altas concentrações na ração animal suprime ou inibe o crescimento de microorganismos (Cromwell, 1991).

Segundo Miller et al. (1991), muitas das funções essenciais do $\mathrm{Cu}$ no metabolismo foram elucidadas, incluindo as seguintes:

1. Cu é parte integrante da ceruloplasmina que atua na liberação do Fe hepático para posterior incorporação da hemoglobina;

2. atividade da lisil oxidase para síntese de desmosina e isodesmosina que atuam nas ligações cruzadas do colágeno e elastina;

3. citocromo oxidase para formação da mielina funcionamento adequado do sistema nervoso central;

4. tirosinase para formação da melanina e pigmentação adequada;

5. superóxido dismutase para conversão de superóxido em peróxido para atividade fagocitária adequada;

6. ambos citocromo oxidase e lisil oxidase para adequado funcionamento cardiovascular. 


\subsection{Metabolismo, níveis tóxicos e deficiência de cobre}

Para a maioria das espécies animais a disponibilidade de $\mathrm{Cu}$ é baixa, sendo sua absorção não mais que 5 a $10 \%$ do $\mathrm{Cu}$ ingerido nas dietas por animais adultos, enquanto que para animais jovens a absorção pode ser de 15 a 30\% (McDowell, 1992).

A absorção do $\mathrm{Cu}$ vai variar de acordo com o nível dietético de outros minerais e substâncias orgânicas, com a acidez do conteúdo intestinal na área de absorção e com a forma química que é administrado (Underwood, 1977).

Estudos em algumas espécies animais têm demonstrado que a absorção do $\mathrm{Cu}$ é influenciada pela forma química e pelo número de substâncias que interagem com outros fatores da dieta. Os fitatos, que são agentes redutores na ração, formam complexos muito estáveis com o $\mathrm{Cu}$ e reduzem a assimilação deste elemento, talvez por converterem a íon cúprico em cuproso, sendo que para ser absorvido o $\mathrm{Cu}$ deve se encontrar no estado cúprico (Rutz, 1994; Ammerman et al., 1995).

Altos níveis de cálcio $(\mathrm{Ca})$, zinco $(\mathrm{Zn})$, cádmio $(\mathrm{Cd})$ e ferro $(\mathrm{Fe})$ diminuem a absorção de $\mathrm{Cu}$ e podem reduzir a concentração de $\mathrm{Cu}$ no plasma. Em algumas circunstâncias, molibdênio (Mo) pode reduzir os níveis de $\mathrm{Cu}$ no sangue (Underwood, 1977; McDowell, 1992).

Aparentemente, o $\mathrm{Zn}$ induz a altas concentrações de metalotioneína na mucosa intestinal e esta proteína liga-se aos íons, intracelularmente, não permitindo sua passagem à circulação porta. A afinidade da metalotioneína pelo $\mathrm{Cu}$ é maior do que pelo $\mathrm{Zn}$, portanto, é esperado que a regulação do transporte de $\mathrm{Cu}$ seja mais controlada que a de Zn (Rutz, 1994; Ammerman et al., 1995).

Nos animais monogástricos, a absorção do $\mathrm{Cu}$ ocorre na parte superior do intestino delgado, onde o pH do conteúdo é sempre ácido (Hays e Swenson, 1993 ).

Starcher (1969) afirma que, nas aves o Cu é absorvido no proventrículo e no duodeno, porém a absorção é cinco vezes maior no duodeno do que no proventrículo. Isto ocorre porque no duodeno existe uma maior concentração de 
metaloproteínas ligadoras de $\mathrm{Cu}$ que desempenham importante papel no processo de absorção.

Segundo McDowell (1992), a absorção do Cu é muito maior durante a deficiência de $\mathrm{Cu}$, que quando o animal encontra-se em um estado nutricional adequado.

$\mathrm{O} \mathrm{Cu}$ parece ser absorvido por dois mecanismos diferentes conforme sua concentração no lúmen. Em baixas concentrações ele é absorvido por transporte ativo, enquanto em concentrações elevadas o $\mathrm{Cu}$ atravessa a mucosa por difusão simples (McDowell, 1992; Macari et al., 1994; Rutz, 1994).

A excreção do $\mathrm{Cu}$ dá-se principalmente pelas fezes, proveniente na sua maior parte do $\mathrm{Cu}$ ingerido e não absorvido e, secundariamente proveniente da bile e da mucosa intestinal. Quantidades médias são excretadas através da urina, leite e pequenas quantidades através da transpiração (Andriguetto et al., 1986; Underwood, 1977; McDowell, 1992).

Certamente que a severidade da intoxicação pelo $\mathrm{Cu}$ depende também da forma química do $\mathrm{Cu}$ ingerido e dos teores de $\mathrm{Cu}, \mathrm{Mo}, \mathrm{Fe}, \mathrm{Zn}$, sulfato, proteínas e antioxidantes presentes na dieta (Andriguetto et al., 1986).

$\mathrm{O}$ consumo prolongado e excessivo de $\mathrm{Cu}$ vai provocar em todos os animais, um elevado acúmulo deste mineral nos tecidos, especialmente no figado, o qual possui capacidade de armazenar o $\mathrm{Cu}$ sem desencadear precocemente um quadro de intoxicação, sendo que esta capacidade varia de acordo com a espécie. Quando a capacidade do figado é extrapolada, este libera rapidamente o $\mathrm{Cu}$ para o sangue, causando então uma crise hemolítica que é caracterizada por hemoglobinemia e hemoglobinúria, associada com severa icterícia. Neste caso, um exame histológico revelará um quadro de necrose hepática. Em aves, a crise hemolítica parece não ocorrer, porém o nível de hemoglobina toma-se bastante reduzido (Andriguetto et al., 1986).

Segundo Underwood (1977), a intoxicação por $\mathrm{Cu}$ pode também ocorrer em suínos que recebem suplementação de $\mathrm{Cu}$ como promotor de crescimento, caso a dieta basal não esteja adequadamente balanceada com outros minerais com os quais o $\mathrm{Cu}$ interage. 
Mehring et al. (1960) avaliaram a tolerância de aves a níveis crescentes de óxido cúprico. Os autores observaram que os níveis mais altos de $\mathrm{Cu}$ utilizados, 588, 832 e 1176 ppm causaram depressão no crescimento e um acúmulo desse mineral no figado e baço das aves.

Em casos de deficiência de $\mathrm{Cu}$ ocorre uma variedade de manifestações clínicas em diferentes espécies, porém a anemia é o sintoma característico de todas as espécies (Scott et al., 1982), pois o $\mathrm{Cu}$ tem um efeito direto sobre o metabolismo do ferro, então, indiretamente afeta a biossíntese de hemoglobina (Ammerman et al., 1995)

Hill e Matrone (1958) confirmaram a presença de anemia quando avaliaram a exigência de $\mathrm{Cu}$ e $\mathrm{Fe}$ de frangos de corte em crescimento e constataram que o nível mais baixo tolerado pelas aves foi de 3,12 ppm para manter os níveis normais de hemoglobina.

Segundo Schaible (1970) a deficiência de $\mathrm{Cu}$ em aves causa retardo no crescimento, produz alta mortalidade, severa fraqueza de pernas e deformidades ósseas e grande incidência de hemorragia subcutânea e hemorragia interna até a morte.

Quando o $\mathrm{Cu}$ é deficiente na dieta, há um decréscimo na absorção do $\mathrm{Fe}$, um rebaixamento da sua taxa total no organismo e um declínio na sua mobilização dos tecidos e o desenvolvimento de uma severa anemia microcítica-hipocrômica. Fracassando a correção do quadro de anemia através do $\mathrm{Fe}$ injetável, prova-se que o $\mathrm{Cu}$ é essencial no aproveitamento de $\mathrm{Fe}$ na síntese hemoglobínica. Existem outros sintomas causados pela deficiência de $\mathrm{Cu}$ como, crescimento retardado, distúrbios ósseos, despigmentação dos pêlos, lãs e penas, desenvolvimento anormal da lã e das penas, desmielinização difusa e simétrica do sistema nervoso central e da medula espinhal, fibrose do miocárdio e distúrbios gastrointestinais como diarréias, podendo causar ainda comprometimento da reprodução (Maynard et al., 1984; Andriguetto et al., 1986; Hays e Swenson, 1993).

Segundo McDowell (1992), alguns estudos demonstraram o efeito da deficiência de $\mathrm{Cu}$ sobre o metabolismo de lipídios. Foi observado que a deficiência de $\mathrm{Cu}$ resulta em elevados níveis de triglicerídeos séricos, fosfolipídeos e colesterol em ratos. Funções alteradas do coração de ratos alimentados com baixos níveis de $\mathrm{Cu}$ são 
associadas com alteração do metabolismo de lipídios e ácidos-graxos de cadeia longa, o que pode ser atribuído ao papel principal do $\mathrm{Cu}$ no sistema da enzima superóxido dismutase.

Apesar de o modo de ação do Cu sobre o metabolismo de lipídios ainda não estar totalmente esclarecido, níveis farmacológicos de $\mathrm{Cu}$ na dieta afetaram claramente o metabolismo de lipídios e o crescimento da aves. Segundo Bakalli et al. (1995), a deficiência de $\mathrm{Cu}$ causa a hipercolesterolemia. Em estudos com frangos de corte esses autores demonstraram que suplementando $250 \mathrm{mg}$ de $\mathrm{Cu} / \mathrm{kg}$ de ração, em adição ao $\mathrm{Cu}$ necessário para atender a exigência nutricional das aves de $8 \mathrm{mg}$ de $\mathrm{Cu} / \mathrm{kg}$ (NRC, 1994), foi possível reduzir o colesterol total do plasma ( $26 \%)$, aumentar o HDL colesterol $(\sim 11 \%)$, reduzir triglicerídeos no plasma $(\sim 43 \%)$, reduzir glutationa no sangue $(\sim 40 \%)$ e reduzir o colesterol do músculo do peito $(\sim 27 \%)$.

\subsection{Biodisponibilidade do cobre em suas diversas fontes}

Segundo Rostagno et al. (1994), o Cu utilizado na nutrição animal pode ser obtido de diferentes fontes como: carbonato cúprico $\left(\mathrm{CuCO}_{3} \mathrm{Cu}(\mathrm{OH})_{2}\right)$ contendo $55,3 \%$ de $\mathrm{Cu}$, óxido cúprico $(\mathrm{CuO})$ contendo $78,3 \%$ de $\mathrm{Cu}$ e sulfato cúprico pentahidratado $\left(\mathrm{CuSO}_{4} .5 \mathrm{H}_{2} \mathrm{O}\right)$ contendo $25,4 \%$ de $\mathrm{Cu}$.

Na nutrição animal, a forma de suplementação de $\mathrm{Cu}$ mais utilizada tem sido o sulfato cúprico pentahidratado (Andriguetto et al., 1986), pois como descrito anteriormente, a disponibilidade do $\mathrm{Cu}$ depende da quantidade e da forma química do elemento no trato digestivo, e o $\mathrm{Cu}$ na forma de sulfato é mais disponível para várias espécies, incluindo ratos, aves e ruminantes (Underwood, 1977), entre as formas de $\mathrm{Cu}$ até então utilizadas. 
Segundo Ammerman et al. (1995), das fontes de $\mathrm{Cu}$ utilizadas como suplemento, muitas são bem absorvidas. O óxido cúprico e sulfito cúprico são exceções, ambos são pobremente absorvidos em todas as espécies. Carbonato cúprico tem absorção intermediána, mas o carbonato cúprico é bem absorvido. Poucas pesquisas com $\mathrm{Cu}$ aminoácidos e $\mathrm{Cu}$ proteinato sugerem absorção relativamente maior de $\mathrm{Cu}$ do que o obtido com sulfato cúprico.

McNaughton et al. (1974), avaliaram a disponibilidade de algumas fontes de $\mathrm{Cu}$ : sulfato cúprico, óxido cuproso $\left(\mathrm{Cu}_{2} \mathrm{O}\right)$ e iodato cuproso. Os autores puderam observar que o conteúdo de hemoglobina, hematócrito e, conteúdo de $\mathrm{Cu}$ no figado foram significativamente aumentados quando utilizado sulfato cúprico, quando comparado aos resultados obtidos das duas outras formas testadas, iodato cuproso ou óxido cuproso. Aumento do ganho de peso e diminuição da mortalidade foi observada quando as aves foram alimentadas com sulfato cúprico ou iodato cuproso quando comparado ao óxido cuproso. Ao final dos experimentos puderam concluir que iodato cuproso e óxido cuproso têm essencialmente igual disponibilidade para as aves, mas a disponibilidade dessas fontes de $\mathrm{Cu}$ é apenas $3 / 4$ que do sulfato cúprico.

Baker et al. (1991) avaliaram a biodisponibilidade de $\mathrm{Cu}$ utilizando as formas óxido cúprico, óxido cuproso e um complexo cobre-lisina ( $\mathrm{Cu}$-lisina). A forma sulfato cúprico pentahidratado foi utilizado como padrão. Avaliando a deposição de $\mathrm{Cu}$ no figado, as formas óxido cuproso, cobre-lisina e sulfato cúprico pentahidratado apresentaram resultados semelhantes, enquanto a forma óxido cúprico não apresentou resposta satisfatória.

Segundo Cachoni (1993), avaliando a biodisponibilidade de $\mathrm{Cu}$ para frangos de corte das fontes sulfato e óxido cúprico, pôde-se observar que, quando avaliada absorção, utilizando-se o $\mathrm{Cu}$ no fígado como parâmetro da estimativa, a forma sulfato foi mais absorvida que a forma óxido.

O figado tem sido o órgão utilizado para avaliar a disponibilidade de $\mathrm{Cu}$, devido a sua maior afinidade pelo $\mathrm{Cu}$ (Cachoni, 1993). Segundo McDowell (1992), a deficiência de $\mathrm{Cu}$ é associada com declínio do elemento no figado, rins ossos, músculo e 
outros tecidos. Igualmente, a toxicidade do $\mathrm{Cu}$ eleva os níveis desse elemento nos tecidos, particularmente o figado. Então, as concentrações de $\mathrm{Cu}$ no figado podem ser o parâmetro de avaliação dos níveis de $\mathrm{Cu}$ no animal.

Ledoux et al. (1989) pesquisaram o feito do $\mathrm{Cu}$ na alimentação de frangos de corte, utilizando níveis de $0,100,200$ ou $300 \mathrm{ppm}$ de $\mathrm{Cu}$ por 22 dias, sobre a composição mineral nos tecidos e puderam concluir que o nível de $\mathrm{Cu}$ encontrado no

figado pode ser utilizado em bioensaios como critério para determinar a biodisponibilidade de $\mathrm{Cu}$ de fontes inorgânicas.

\subsection{Promotores de crescimento: definição e modo de ação}

Sabe-se que o $\mathrm{Cu}$ é um elemento mineral essencial na nutrição dos animais (Mehring Jr. e Brumbaugh, 1960; Ewing, 1963) e que pode ser obtido de várias fontes. Quando utilizado em níveis dietéticos relativamente elevados, tem a capacidade de estimular o desempenho de suínos (Cromwell, 1991). Ou seja, age como promotor de crescimento.

Os promotores de crescimento, por inibirem ou regularem a proliferação microbiana intestinal e seu efeito enterotoxigênio, facilitam a digestão e proporcionam uma melhor assimilação de nutrientes, com resultados imediatos na conversão alimentar e no ganho de peso (Bordin, 1984).

A respeito da atividade promotora de crescimento, foram propostos os seguintes modos de ação (Hays; 1969; Cromwell, 1991) que incluem:

1. efeito metabólico, através do qual os promotores de crescimento afetam diretamente a eficiência dos processos metabólicos no animal;

2. efeito de economia de nutrientes, através do qual o promotor de crescimento pode reduzir a exigência por certos nutrientes na dieta, estimulando o crescimento de 
organismos desejáveis capazes de sintetizar vitaminas ou aminoácidos, deprimindo o crescimento de certos organismos que competem por nutrientes com o animal, aumentando a disponibilidade de nutrientes;

3. efeito no controle de doenças, através da supressão de organismos que causam infecções clínicas e subclínicas.

A utilização desses promotores de crescimento tem sido uma prática comum em todos os países que são grandes produtores de animais, pois o uso desses aditivos na ração além de promover maior crescimento, também melhoram a conversão alimentar e diminuem a mortalidade devido a infecções clínicas e subclínicas (Hays, 1969; Hays e Muir, 1979).

Hoda e Maha (1995) avaliaram a eficiência do $\mathrm{Cu}$ como promotor de crescimento em frangos de corte nas formas de carbonato cúprico, óxido cúprico e sulfato cúprico, aos níveis de 0,75 e 150 ppm. Observaram que ambos níveis de suplementação de carbonato cúprico e $150 \mathrm{ppm}$ de sulfato cúprico aumentaram significativamente o ganho de peso e melhoraram a conversão alimentar, enquanto que o óxido cúprico não apresentou nenhum efeito promotor de crescimento.

Segundo Cromwell (1991), em leitões 250 ppm de $\mathrm{Cu}$ parece ser o nível mais eficiente; 100 a $1250 \mathrm{ppm}$ de $\mathrm{Cu}$ resultou em aproximadamente $75 \%$ a $80 \%$ de resposta máxima. Altos níveis de $\mathrm{Cu}(500 \mathrm{ppm})$, devem ser evitados devido à chance de intoxicação em suínos, resultante de um marcado acúmulo de $\mathrm{Cu}$ no figado.

\subsection{Utilização do sulfato e do citrato cúprico}

O sulfato cúprico é um composto de cor azul, que pode apresentar-se na forma de grandes cristais ou grânulos azuis ou ainda, como um pó azul claro (The Merk Index, 1989). 
O sulfato cúprico tem sido utilizado há muitos anos na avicultura no tratamento de enterites e vários tipos de micoses (Schaible 1970). Os resultados obtidos têm sido suficientemente positivos para que se continue a usá-lo com finalidade terapêutica. Em 1955, alguns pesquisadores na Inglaterra observaram que níveis de 250 ppm de $\mathrm{Cu}$, na forma de sulfato cúprico, aumentaram a taxa de crescimento de leitões, de uma forma muito semelhante a que ocorre quando utilizado antibiótico. Esses resultados foram também confirmados por pesquisadores na Suíça (Scott et al., 1982).

Foram realizados experimentos com perus comparando os efeitos promotores de crescimento de 50 e $100 \mathrm{ppm}$ de $\mathrm{Cu}$ como sulfato cúprico, com uma determinada variedade de antibióticos e outros agentes antimicrobianos. Os resultados mostraram que utilizando $250 \mathrm{mg}$ de sulfato cúprico na ração produziu resposta de crescimento aproximadamente $10 \%$ maior que utilizando apenas a dieta basal. Este resultado foi equivalente ao obtido com a utilização de antibióticos (Scott et al., 1982).

Norwell et al. (1974) estudaram os efeitos de altos níveis de sulfato cúprico na ração de frangos de corte sobre a mortalidade, ganho de peso, peso relativo do figado, resíduo de $\mathrm{Cu}$ nos tecidos e efeitos histopatológicos sobre o figado, pâncreas, duodeno, ilio e papo. Observaram que $720 \mathrm{ppm}$ de $\mathrm{Cu}$ na ração foi prejudicial ao crescimento e que ambos, 480 ppm e 720 ppm, elevaram significativamente os níveis de $\mathrm{Cu}$ no figado de frangos de corte.

Segundo Miller et al. (1991), foram fornecidas dietas para suínos na fase inicial e de crescimento, suplementadas com $250 \mathrm{ppm}$ de $\mathrm{Cu}$ na forma de sulfato cúprico pentahidratado e, consistentemente, resultou em aumento da taxa de crescimento.

Kroger et al. (1997) avaliaram a influência de várias fontes de $\mathrm{Cu}$ (sulfato cúprico, óxido cúprico e $\mathrm{Cu}$ elementar) sobre a performance e rendimento de carcaça de suínos e observaram que, suplementando $200 \mathrm{ppm}$ de $\mathrm{Cu}$ na forma de sulfato cúprico, o ganho de peso foi aumentado em $12 \%$ e melhorou a conversão alimentar em $12,4 \%$. Quando $\mathrm{Cu}$ foi fornecido tanto na forma de sulfato como óxido cúprico no período final de engorda, a ocorrência de Clostridium perfringens na flora intestinal foi menor que nos animais controle. 
$\mathrm{O}$ citrato cúprico é a forma orgânica do $\mathrm{Cu}$, cuja fórmula química é $\mathrm{C}_{6} \mathrm{H}_{4} \mathrm{Cu}_{2} \mathrm{O}_{7}$, o qual pode apresentar-se na forma hemipentahidratado, contendo $35,0 \%$ de $\mathrm{Cu}$, ou na forma anidra com $40,32 \%$ de $\mathrm{Cu}$, com coloração verde-azulada (The Merk Index, 1989).

Pesti e Bakalli (1996) realizaram vários experimentos com a finalidade de comparar a eficácia do $\mathrm{Cu}$ como promotor de crescimento de frangos de corte e para reduzir o nível de colesterol no músculo do peito e no plasma sangüíneo utilizando como fontes de $\mathrm{Cu}$, citrato cúprico e sulfato cúprico pentahidratado. Os autores observaram que utilizando citrato cúprico aos níveis de 63 ou $75 \mathrm{mg} \mathrm{Cu} / \mathrm{kg}$ como promotor de crescimento na ração, este apresentou-se mais eficiente, resultando em melhor desempenho das aves quando comparado ao sulfato cúprico pentahidratado a 125 ou 250 $\mathrm{mg} \mathrm{Cu} / \mathrm{kg}$. Em adição a esses resultados foi observado também que houve uma redução do nível de colesterol no músculo do peito e no plasma das aves suplementadas com citrato cúprico em comparação ao sulfato cúprico pentahidratado.

Ewing et al. (1998) avaliaram os efeitos de sulfato cúprico pentahidratado, citrato cúprico e oxicloreto de cobre sobre o ganho de peso de frangos de corte. Os autores puderam observar que as formas sulfato cúprico pentahidratado e oxicloreto de cobre aumentaram $4,9 \%$ ao ganho de peso, enquanto que o citrato cúprico aumentou em $9,1 \%$, comprovando assim a eficácia do citrato cúprico como promotor de crescimento.

\subsection{Citrato cúprico vs. sulfato cúprico pentahidratado}

Segundo Pesti e Bakalli (1996), o citrato cúprico foi mais eficaz como promotor de crescimento pois utiliza-se níveis mais baixos de $\mathrm{Cu}$ quando comparado ao sulfato cúprico. Os autores afirmam que o motivo pelo qual obteve-se melhor resultado 
com o citrato cúprico como promotor de crescimento é que este provou ser melhor absorvido que o sulfato cúprico, ou pode ser um melhor cofator para um dos mecanismos pelos quais o $\mathrm{Cu}$ pode promover crescimento.

Outro resultado de maior eficiência do citrato cúprico foi obtido por Ewing et al. (1998) já citado anteriormente. Comprovando a melhor resposta de desempenho do citrato.

Brainer (1998) avaliou a eficiência do $\mathrm{Cu}$ como promotor de crescimento de frangos de corte nos períodos de 1-42 dias, 1-22 dias e 22-42 dias, nas formas de citrato cúprico $(75 \mathrm{mg} \mathrm{Cu} / \mathrm{kg})$ e sulfato cúprico pentahidratado $(200 \mathrm{mg}$ $\mathrm{C}(\mathrm{kg}$ ). Porém não observou diferença alguma no desempenho das aves entre as duas formas de $\mathrm{Cu}$ utilizadas.

\subsection{Colesterol: definição e síntese}

O colesterol é um álcool sólido, cuja estrutura se baseia no núcleo ciclopentano peridrofenantreno, sintetizado em todos os tecidos, mas sendo o fígado o principal local de produção. É também ingerido na alimentação, sendo mais abundante em produtos lácteos, came, gema de ovo e crustáceos. Diariamente ingerem-se cerca de 500 a $700 \mathrm{mg}$, metade absorvida no jejuno, sob forma de partículas denominadas micelas, que contém também ácidos graxos, monoglicerídeos e ácidos biliares conjugados. A ingestão de óleos vegetais diminui a absorção intestinal de colesterol por dois motivos: em primeiro lugar, os óleos vegetais contém taxa maior de ácidos graxos insaturados que, por possuírem cadeias curvas, ocupam muito lugar na micela, deslocando das mesmas o colesterol; em segundo lugar, possuem fitoesteróides, de configuração química semelhante ao colesterol e que competem com o mesmo. 
O colesterol sintetizado no figado ou absorvido na dieta circula no plasma e é depositado nos tecidos. Circula no plasma principalmente nas beta lipoproteínas, sendo depositado em vários tecidos, inclusive em tendões e nas paredes das artérias. Integra as membranas celulares e é precursor de todos os outros esteróis do organismo, tais como: corticosteróides, hormônios sexuais, ácido biliares e vitamina D (Pupo, 1979; Mayes, 1994).

As lipoproteínas são classificadas em função da sua densidade, as quais são de quatro tipos (Mateos et al., 1999):

1. Quilomicrons: cuja missão é o transporte de lipídeos, após serem absorvidos no trato intestinal. Compõem-se fundamentalmente de triglicerídeos;

2. VLDL (lipoproteínas de muito baixa densidade): que contém cerca de $50 \%$ de triglicerídeos e cerca de $22 \%$ de colesterol e cuja missão fundamental é o transporte de lipídeos de origem endógena;

3. LDL (lipoproteínas de baixa densidade): que contém cerca de $50 \%$ de colesterol e que possuem um papel importante na regulação do metabolismo do mesmo;

4. HDL (lipoproteínas de alta densidade): cujo papel fisiológico é de transportar o colesterol mobilizado por tecidos periféricos.

Cerca de um grama diário é excretado nas fezes, sob a forma de esteróides neutros e de sais biliares, vindos da bile, que contém colesterol e ácidos biliares (ácidos cólico e quenodesoxicólico formados no figado a partir do colesterol) e transformados na luz intestinal (conjugação com glicina e taurina, dando glico e taurocolatos e quenodesoxicolatos). Os sais biliares são em parte reabsorvidos e novamente ofertados no figado (ciclo êntero-hepático).

Note-se que no figado a produção de colesterol parece ser regulada pela sua própria concentração que inibe, quando alta, a formação de ácido mevalônico a partir de derivados de acetato, passo inicial da síntese de colesterol. Também o aumento da concentração de sais biliares diminui a passagem de colesterol para ácidos biliares (Pupo, 1979). 


\subsection{Reduzindo os níveis de colesterol nos alimentos}

Segundo Bragagnolo e Rodriguez-Amaya (1992), o aumento da taxa de colesterol no sangue é um dos principais fatores de doenças coronarianas em humanos, assim como a hipertensão, o fumo, o estresse e a vida sedentária. As autoras dizem também que, de acordo com os dados do Centro Brasileiro de Classificação de Doenças da Universidade de São Paulo, USP, em 1985 quando foram registradas 788 óbitos, $27,1 \%$ foram causados por doenças cardiovasculares, enquanto que $9 \%$ foram causadas por tumores, como o câncer.

Como tem havido, por parte do consumidor, um aumento da procura por produtos que tenham qualidade superior, do ponto de vista da saúde humana, tem aumentado também o interesse por modificar o perfil lipídico da carne de aves e da gema do ovo (Barlow et al., 1990).

Bakali e Pesti (1995) utilizando sulfato cúprico pentahidratado ao nível de 250 ppm, puderam observar redução do nível de colesterol do plasma sangüíneo e no músculo do peito em $12,9 \%$ e $24,6 \%$ aos 35 dias e em $10,8 \%$ e $16,2 \%$ aos 42 dias, respectivamente.

Pesti e Bakali (1996) suplementando rações de frangos de corte com $125 \mathrm{mg} / \mathrm{kg}$ nas formas de citrato cúprico ou sulfato cúprico pentahidratado, observaram uma redução do nível de colesterol do músculo do peito de $27,84 \mathrm{mg} / 100 \mathrm{~g}$ e 25,32 $\mathrm{mg} / 100 \mathrm{~g}$, respectivamente, quando comparados aos frangos que foram alimentados com a dieta basal, os quais apresentaram um nível de $43,92 \mathrm{mg} / 100 \mathrm{~g}$.

Konjufca et al. (1997) avaliaram os níveis de colesterol na came de frangos de corte utilizando como fontes de $\mathrm{Cu}$ o citrato cúprico e sulfato cúprico pentahidratado, e alho em pó. Ao final de cinco experimentos os autores concluíram que a suplementação de $\mathrm{Cu}$ e alho baixaram os níveis de colesterol no músculo do peito em 24 e $15 \%$ respectivamente, e baixaram também o colesterol no músculo da coxa das aves em 22 e $23 \%$, respectivamente. 
Pesti e Bakali (1998) realizaram dois experimentos com a finalidade de avaliar a hipótese que, níveis farmacológicos de $\mathrm{Cu}$ na dieta poderiam reduzir o colesterol do ovo. Foram utilizados níveis de 0,125 e $250 \mathrm{mg}$ de Cu/kg na forma de sulfato cúprico pentahidratado. Os autores puderam concluir que as concentrações de colesterol na gema do ovo foram diminuindo a partir de $125 \mathrm{mg}$ de $\mathrm{Cu} / \mathrm{kg}$, tendo como média dos dois experimentos 11,7 vs. $8,6 \mathrm{mg} / \mathrm{g}$. Quando as aves foram alimentadas com $250 \mathrm{mg}$ de $\mathrm{Cu} / \mathrm{kg}$, resultou em declínio do colesterol no ovo, porém as diferenças não foram significativas, $7,9 \mathrm{mg} / \mathrm{g}$. Os autores também afirmam que as alterações da concentração de colesterol no plasma foram similares às alterações do colesterol na gema. 


\section{MATERIAL E MÉTODOS}

\subsection{Materiais}

\subsubsection{Aviário experimental}

O experimento foi condurido no aviário experimental do Departamento de Produção Animal - Setor de Não Ruminantes, da Escola Superior de Agricultura "Luiz de Queiroz", localizado no município de Piracicaba, SP.

$\mathrm{O}$ aviário experimental tem $32 \mathrm{~m}$ de comprimento, por $8 \mathrm{~m}$ de largura. $\mathrm{Na}$ lateral possui mureta de alvenaria de $0,6 \mathrm{~m}$ de altura, completada com tela de arame. Coberto com telhas de barro e piso de concreto, com duas portas de acesso. Próximo a cada uma dessas portas existe uma área de $28 \mathrm{~m}^{2}$ a qual é destinada ao armazenamento das rações experimentais e outros equipamentos, e possui um tanque para a lavagem dos materiais.

O aviário experimental é formado por 30 "boxes", os quais são dispostos em três fileiras longitudinais, cada qual contendo 10 "boxes", separadas umas das outras por um corredor de 1,0 $\mathrm{m}$ de largura. Cada "box" possui uma área de $5 \mathrm{~m}^{2}$ com uma porta de acesso lateral. A ilurninação artificial do aviário é feita por 11 
lâmpadas incandescentes de 60 watts cada, localizadas na parte central a uma altura de 2,30 $\mathrm{m}$ do piso.

Nesse experimento, cada "box" alojou 40 aves, as quais foram inicialmente aquecidas por meio de lâmpadas infravermelbas de 250 watts, suspensas a $0,50 \mathrm{~m}$ do piso, havendo uma lâmpada por "box". O controle da temperatura interna do galpão era feito também através de cortinas que eram baixadas quando havia a necessidade de resfriar o galpão.

O material utilizado para compor a cama em cada um dos "boxes" do aviário experimental foi a maravalha de madeira, a qual foi mantida durante todo o período experimental.

\subsubsection{Aves experimentais}

Foram utilizados 1200 pintos de corte de um dia de idade, da linhagem Hubbard-Peterson, sendo 600 machos e 600 fêmeas, adquiridos da Incubadora Pinheiros Ltda., localizada no município de Guareí, SP, a qual forneceu os pintos sexados. Ao nascer as aves foram vacinadas contra a doença de Marek e Bouba aviária.

\subsubsection{Citrato cúprico}

$\mathrm{O}$ citrato cúprico $\left(\mathrm{C}_{6} \mathrm{H}_{4} \mathrm{Cu}_{2} \mathrm{O}_{7}\right)$, utilizado nas rações experimentais foi cedido pela Griffin Corporatin, localizado em Valdosta, Georgia (EUA). Segundo as análises feitas pelo Laboratório de Controle de Qualidade da SUPREMAIS Produtos 
Bioquímicos Ltda., localizado no município de Valinhos, SP, o citrato cúprico é do tipo anidro, contendo $37,38 \%$ de $\mathrm{Cu}$.

\subsubsection{Período de criação}

As aves foram criadas por 42 dias, tendo o experimento iniciado em 19 de fevereiro de 1998 e finalizado em 02 de abril de 1998.

\subsubsection{Programa de alimentação}

O programa de alimentação foi dividido em três fases, com a finalidade de atender as exigências nutricionais de cada fase de crescimento das aves. Este programa constou de uma dieta basal para cada fase, as quais foram formuladas à base de milho e farelo de soja, sendo todas as rações fareladas.

$\mathrm{Na}$ primeira fase, do $1^{\circ}$ ao $21^{\circ}$ dia de idade das aves, foi utilizada a ração inicial. Na segunda fase, do $22^{\circ}$ ao $35^{\circ}$, foi utilizada a ração de crescimento e na terceira fase, do $36^{\circ}$ ao $42^{\circ}$ a ração final. As rações, que estão apresentadas na Tabela 1, foram formuladas de acordo com Rostagno et al. (1994), utilizando-se o programa "Sistema Conversacional para Minimização do Custo da Ração" de Gomide e Rostagno. As rações foram preparadas na fábrica de rações do Departamento de Produção Animai da ESALQ/USP - Piracicaba, Setor de Não Ruminantes.

As fontes de $\mathrm{Cu}$ adicionadas às rações foram: citrato cúprico anidro, contendo $37,38 \%$ de $\mathrm{Cu}$, e sulfato cúprico pentahidratado, contendo $25,0 \%$ de $\mathrm{Cu}$. 
TABELA 1: Composição percentual e valores calculados das dietas basais.

\begin{tabular}{|c|c|c|c|}
\hline \multicolumn{4}{|c|}{ RAÇÕES } \\
\hline INGREDIENTES & $\begin{array}{l}\text { INICIAL } \\
(\%)\end{array}$ & $\begin{array}{c}\text { CRESCIMENTO } \\
\text { (\%) }\end{array}$ & $\begin{array}{l}\text { FINAL } \\
(\%)\end{array}$ \\
\hline Milho & 57,320 & 62,455 & 64,820 \\
\hline Farelo de soja & 36,535 & 32,046 & 29,428 \\
\hline Óleo vegetal & 2,298 & 2,053 & 2,388 \\
\hline Fosfato bicálcico & 1,953 & 1,739 & 1,754 \\
\hline Calcário & 1,123 & 1,024 & 1,039 \\
\hline DL-metionina 99 & 0,161 & 0,123 & 0,110 \\
\hline Sal & 0,300 & 0,300 & 0,300 \\
\hline Cloreto de colina $60 \%$ & 0,080 & 0,040 & 0,020 \\
\hline Suplem. vitamínico ${ }^{\mathrm{a}}$ & 0,120 & 0,100 & 0,080 \\
\hline Suplem. mineral ${ }^{b}$ & 0,060 & 0,060 & 0,060 \\
\hline Anticoccidiano & $0,050^{\mathrm{c}}$ & $0,060^{d}$ & - \\
\hline \multicolumn{4}{|c|}{ VALORES CALCULADOS } \\
\hline Energ. met. (kcal/kg) & 3.000 & 3.050 & 3.100 \\
\hline Proteína bruta (\%) & 21,6324 & 20,0000 & 19,0000 \\
\hline Metionina (\%) & 0,4947 & 0,4365 & 0,4103 \\
\hline Metionina + cistina (\%) & 0,8500 & 0,7700 & 0,7300 \\
\hline Lisina (\%) & 1,1000 & 0,9929 & 0,9289 \\
\hline Cálcio (\%) & 1,0000 & 0,9000 & 0,9000 \\
\hline Fósforo disponível (\%) & 0,4500 & 0,4100 & 0,4100 \\
\hline
\end{tabular}

${ }^{a}$ Cada kg do suplem. vitamínico contém: vit. $\mathrm{A}, 10.000 .000$ U; vit. $\mathrm{D}_{3}, 2.000 .000$ U; vit. $\mathrm{E}$, $30.000 \mathrm{UI}$; vit. $\mathrm{K}_{3}, 3.000 \mathrm{mg}$; vit. $\mathrm{B}_{1}, 2.000 \mathrm{mg}$; vit. $\mathrm{B}_{2}, 6.000 \mathrm{mg}$; vit. $\mathrm{B}_{6}, 4.000 \mathrm{mg}$; vit. $\mathrm{B}_{12}$, $15.000 \mathrm{mcg}$; ác. nicotínico, $50.000 \mathrm{mg}$; ác. pantotênico, $12.000 \mathrm{mg}$; biotina, $100 \mathrm{mg}$; ác. fólico, $1.000 \mathrm{mg}$; selênio, $250 \mathrm{mg}$; veículo q.s.p., $1.000 \mathrm{mg}$.

${ }^{b}$ Cada $\mathrm{kg}$ do suplem. mineral contém: cobalto, $2.000 \mathrm{mg}$; iodo, $2.000 \mathrm{mg}$; manganês, 16.000 $\mathrm{mg}$; ferro, $100.000 \mathrm{mg}$; cobre, $20.000 \mathrm{mg}$; zinco, $100.000 \mathrm{mg}$.

${ }^{c}$ Cada $1.000 \mathrm{~g}$ de anticoccidiano contém: maduramicina 7,5 g; nicarbazina $80 \mathrm{~g}$; veículo q.s.p., $1000 \mathrm{~g}$.

${ }^{\mathrm{d}}$ cada $1.000 \mathrm{~g}$ de anticoccidiano contém: lasalocida sódica $150 \mathrm{~g}$; excipiente q.s.p., $1.000 \mathrm{~g}$. 


\subsubsection{Análises bromatológicas}

- Milho, farelo de soja = foram coletadas amostras de milho e farelo de soja para análises bromatológicas. As análises foram realizadas pelo laboratório de bromatologia do Departamento de Produção Animal da Escola Superior de Agricultura "Luiz de Queiroz".

Os resultados obtidos nas análises bromatológicas de milho e farelo de soja, estão apresentados na Tabela 2

TABELA 2: Análises bromatológicas de milho e farelo de soja utilizados na ração basal.

\begin{tabular}{lcc}
\hline ANÁLISES & MILHO & $\begin{array}{c}\text { FARELO DE } \\
\text { SOJA }\end{array}$ \\
\hline BROMATOLÓGICAS & 89,97 & 89,97 \\
Matéria seca (\%) & 6,64 & 45,87 \\
Proteína bruta (\%) & 2,42 & 4,59 \\
Fibra bruta (\%) & 3,51 & 2,30 \\
Extrato etéreo (\%) & 0,78 & 5,50 \\
Matéria mineral (\%) & 76,62 & 31,71 \\
\hline
\end{tabular}

- Ração = foi coletada amostra de ração da fase final do tratamento CONT. para análise de cobre, sendo esta realizada pelo laboratório de bromatologia da Multimix Produtos e Serviços Agropecuários Ltda., localizado na cidade de Campinas-SP. O resultado obtido a partir desta análise foi de $17 \mathrm{mg}$ de cobre/ $\mathrm{kg}$ de ração. 

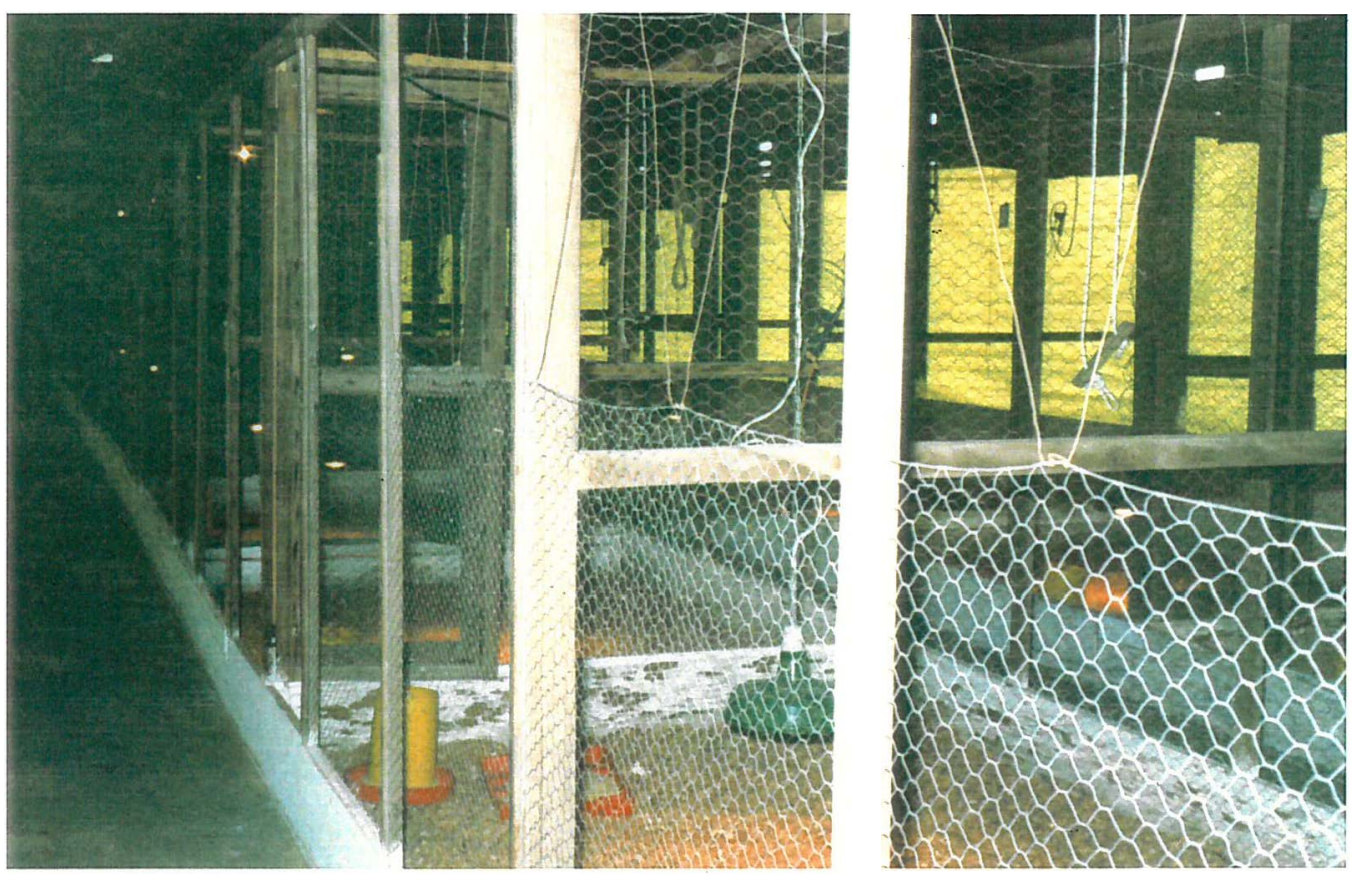

Figura 1: Vista interna do aviário experimental.

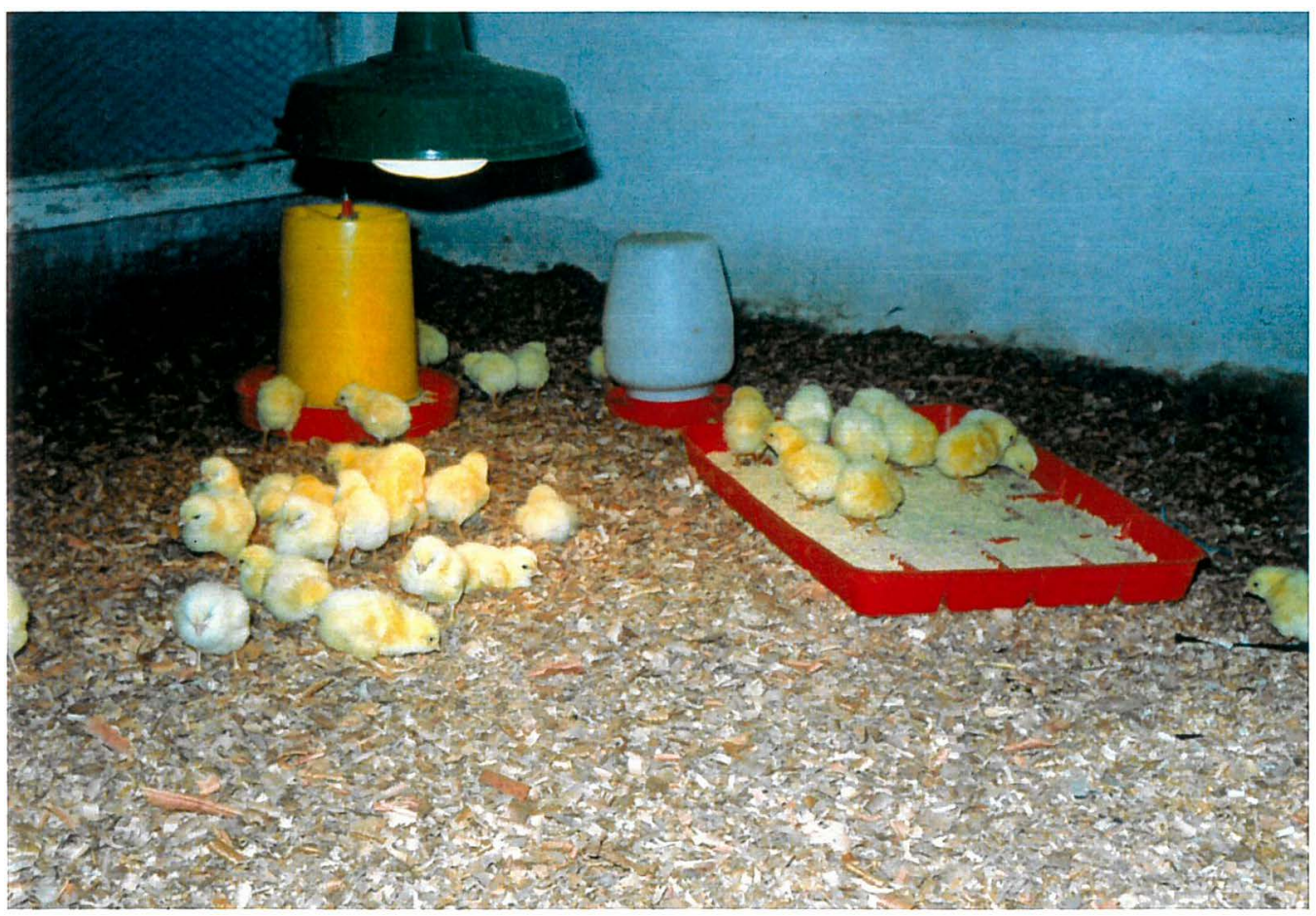

Figura 2: Instalação do experimento. Vista de uma unidade experimental. 


\subsection{Métodos}

\subsubsection{Manejo de equipamentos e aves}

Para o recebimento das aves, o galpão foi lavado com água e desinfetado com Iodo 2,6\% $\left(\right.$ Biocid $^{\circledR}$ ), na proporção de 1:500, sendo este pulverizado por todo o galpão utilizando-se um pulverizador costal. Os equipamentos utilizados no experimento também foram lavados com Biocid ${ }^{\circledR}$, utilizando-se a mesma diluição do produto.

A caixa de água, a qual tem capacidade para 250 litros, foi lavada da seguinte forma. Primeiramente toda a água foi esgotada, depois novamente cheia, foi colocado Biocid $^{\circledast}$, na proporção de 1:1200, ou seja, $160 \mathrm{ml}: 250$ litros de água. Outra vez esvaziada e enxaguada, para depois deixar água a ser utilizada.

Após a lavagem e desinfecção de todo o galpão, assim como os equipamentos, as cortinas foram erguidas e o galpão permaneceu fechado por alguns dias para se fazer o vazio sanitário.

Depois desta etapa, foi colocada a cama de maravalha de madeira tendo esta uma espessura de aproximadamente $8 \mathrm{~cm}$.

Antes do início da distribuição das aves as lâmpadas de aquecimento foram acesas. Foi colocado um bebedouro de pressão infantil por "box", sendo adicionado complexo vitamínico (Vita Gold Potenciado ${ }^{\circledR}$ ) na água de bebida na proporção de $2 \mathrm{ml}$ por litro de água. Em cada bebedouro foi colocado aproximadamente $800 \mathrm{ml}$ de água com o complexo vitamínico. Após o término desta água foi adicionado apenas a água pura, sendo que o mesmo procedimento foi repetido no $2^{\circ}$ dia do experimento. Também foi colocado em cada "box" um comedouro tubular infantil e uma bandeja, contendo ração inicial, de acordo com cada tratamento. 
Logo no início da manhã as aves começaram a ser pesadas e distribuídas aleatoriamente nos "boxes". Em cada "box" foram alojadas 40 aves que foram separadas por sexo e distribuídas de acordo com o sorteio realizado antes do início do experimento, num total de 1200 aves (Apêndice 1).

A partir $3^{\circ}$ dia observou-se 0 início de diarréia nos pintos, provavelmente devido às altas temperaturas naquela época do ano e, conseqüente aumento da ingestão de água. Pôde-se notar também que a incidência de diarréia aumentava ou diminuía, durante todo o período experimental, de acordo com o aumento ou a diminuição da temperatura, respectivamente.

Até $\mathrm{o} 4^{\circ}$ dia do experimento as aves que morreram ou que apresentaram qualquer sinal de desenvolvimento não satisfatório foram trocadas por pintos de mesmo sexo. Porém, a partir do $5^{\circ}$ dia do experimento as aves que morreram, ou refugos, eram pesadas e descartadas.

Observou-se também a incidência de problemas de pernas nas aves, tanto nos machos quanto nas fêmeas, e em alguns casos o problema surgiu logo na $1^{\mathrm{a}}$ semana de idade. A maioria dos casos vieram a surgir a partir da $2^{\mathrm{a}}$ semana, mas quase todas essas aves permaneceram até o final do experimento. Porém quando o problema apresentou maior gravidade impossibilitando que a ave caminhasse até o comedouro ou bebedouro, esta perdia muito peso e era então retirada do experimento. Este fato ocorreu em apenas 4 aves durante todo o período experimental .

Diariamente os bebedouros eram lavados e a ração dos comedouros eram revolvidas. Do $1^{\circ}$ ao $10^{\circ}$ dia do experimento foram mantidos os bebedouros infantis. No $6^{\circ}$ dia foram colocados os bebedouros pendulares e no $7^{\circ}$ dia os bebedouros foram baixados para início da adaptação das aves, os quais permaneceram até o término do experimento.

Com a ração o procedimento foi o seguinte: no $1^{\circ}$ dia do experimento a ração inicial foi colocada nos comedouros tubulares infantis e nas bandejas; no $5^{\circ}$ dia as sobras de ração das bandejas foram pesadas e posteriormente descartadas; no $8^{\circ}$ dia foram colocados os comedouros tubulares e, no $13^{\circ}$ dia os comedouros infantis foram 
retirados dos "boxes" e, as sobras desses comedouros foram pesadas e descartadas em seguida. Os comedouros tubulares permaneceram até o final do experimento. Conforme havia necessidade, os comedouros eram reabastecidos com ração de acordo com o tratamento, sendo que a quantidade de ração colocada era devidamente anotada.

No $12^{\circ}$ dia do experimento foi feita a vacina contra a doença de Newcastle e, no $15^{\circ}$ dia a vacina contra a doença de Gumboro, ambas administradas na água de bebida das aves.

As aves foram criadas em regime de luz contínua, ou seja, 24 horas de luz por dia. As cortinas eram baixadas ou erguidas de acordo com as necessidades de se manter a temperatura interna do galpão adequada.

Diariamente, às 9:00 h, era feita a leitura da temperatura sendo anotadas as temperaturas máximas e mínimas (Apêndice 2). A leitura da temperatura era feita em um termômetro de máxima e mínima colocado em um "box" na área central do aviário, a uma altura de aproximadamente $30 \mathrm{~cm}$ do piso.

Periodicamente a cama era revolvida e em casos de umidade excessiva, devido à diarréia ou chuva, esta era trocada.

Durante o período experimental, todas as aves foram pesadas semanalmente assim como os comedouros, para determinação do peso vivo médio, ganho de peso médio, consumo médio de ração e conversão alimentar. Para se fazer as pesagens foram utilizadas duas balanças, sendo uma com capacidade até $15 \mathrm{~kg}$ com precisão de $0,01 \mathrm{~kg}$ e outra com capacidade até $150 \mathrm{~kg}$ com precisão de $0,1 \mathrm{~kg}$.

No último dia do experimento, ou seja, aos 42 dias, logo após a pesagem das aves e dos comedouros foi tomada aleatoriamente uma ave representativa da média do "box" para a coleta de sangue, a qual foi marcada e, posteriormente, a mesma ave foi abatida por deslocamento cervical e realizada a coleta do músculo do peito. Ambas coletas foram necessárias para determinação do nível de colesterol no soro sangüíneo e no músculo do peito, respectivamente. 


\subsubsection{Delineamento experimental}

O delineamento experimental foi em blocos casualizados em arranjo fatorial $5 \times 2$, constituído de 5 dietas e 2 sexos, com 3 repetições, sendo cada bloco constituído por 10 "boxes" Cada um dos tratamentos foi distribuído nos "boxes" através de sorteio. Foram utilizadas 30 unidades experimentais com 40 aves cada, totalizando 1200 aves, sendo 600 fềmeas e 600 machos.

\section{O modelo matemático adotado foi o seguinte:}

$Y_{i j k}=\mu+\alpha_{i}+\beta_{j}+(\alpha \beta)_{i j}+\gamma_{k}+e_{i j k}$

com:

$\mathrm{i}=1,2,3,4,5 . \quad \mathrm{j}=1,2 . \quad \mathrm{k}=1,2,3$.

onde:

$\mathrm{Y}_{\mathrm{i} j \mathrm{k}}=$ é o valor observado referente ao desempenho de frangos de corte em $\mathrm{kg} / \mathrm{ave}$, do nível i do fator tratamentos, com o nível $\mathrm{j}$ do fator sexo no bloco $\mathrm{k}$;

$\mu=$ é uma constante inerente a todas as observações;

$\alpha_{\mathrm{i}}=$ é o efeito do nível i do fator dietas;

$\beta_{j}=$ é o efeito do nível $j$ do fator sexo;

$(\alpha \beta)_{\mathrm{ij}}=$ é o efeito da interação entre o nível i de tratamentos com o nível j de sexo;

$\gamma_{\mathrm{k}}=$ é o efeito do nível $\mathrm{k}$ do fator blocos, tal que $\gamma_{\mathrm{k}} \cap \mathrm{N}\left(0, \sigma_{y}{ }^{2}\right)$ e independentes;

$e_{i j k}=\cap N\left(0, \sigma^{2}\right)$ independentes. 


\subsubsection{Tratamentos}

O experimento teve apenas uma etapa com duração de 42 dias, onde inicialmente seriam analisados os efeitos de níveis crescentes de citrato cúprico na dieta, sobre o desempenho de frangos de corte, e seus efeitos sobre o nível de colesterol no músculo do peito e no soro do sangue das aves, sendo que estes resultados seriam comparados aos obtidos com a suplementação de sulfato cúprico pentahidratado (controle positivo) e com o tratamento da dieta basal (controle negativo), a qual não foi suplementada com nenhum dos dois compostos testados neste experimento.

Como não houve diferença estatisticamente significativa entre os tratamentos, foi feita então a comparação entre as médias dos tratamentos propostos, aplicando-se o Teste Tukey $(\alpha=0,05)$, utilizando o Programa SAS (Statistical Analyses System) de análises estatísticas.

\section{Tratamentos realizados}

Os tratamentos foram distribuídos nos blocos através de sorteio, sendo estes constituídos da seguinte forma:

- CONT. = Controle negativo. Dieta basal (D.B.) contendo $12 \mathrm{mg}$ de $\mathrm{Cu}$ suplementar/kg de ração.

- CITR. 50 = D.B. suplementada com $50 \mathrm{mg}$ de $\mathrm{Cu} / \mathrm{kg}$ de ração, na forma de citrato cúprico (133,3 mg de citrato cúprico/kg de ração).

- CITR. 100 = D.B. suplementada $100 \mathrm{mg}$ de $\mathrm{Cu} k \mathrm{~kg}$ de ração, na forma de citrato cúprico (267,5 mg de citrato cúprico/ $\mathrm{kg}$ de ração). 
- CITR. 150 = D.B. suplementada $150 \mathrm{mg}$ de $\mathrm{Cu} / \mathrm{kg}$ de ração, na forma de citrato cúprico (401,3 mg de citrato cúprico/kg de ração).

- SULF. 200 = Controle positivo. D.B. suplementada $200 \mathrm{mg}$ de $\mathrm{Cu} / \mathrm{kg}$ de ração, na forma de sulfato cúprico pentahidratado ( $800,0 \mathrm{mg}$ de sulfato de cobre/kg de ração).

\subsubsection{Variáveis analisadas}

- Peso vivo médio = obtido aos 1,21 e 42 dias.

- Ganho médio de peso = obtido nos períodos de 1 a 21 , de 22 a 42 e de 1 a 42 dias.

- Consumo médio de ração = obtido nos períodos de la 21 , de 22 a 42 e de 1 a 42 dias.

- Conversão alimentar = obtido nos períodos de 1 a 21, de 22 a 42 e de 1 a 42 dias.

- Mortalidade + refugagem $=$ obtido nos períodos de 1 a 21 , de 22 a 42 e de 1 a 42 dias.

- Nível de colesterol no soro sangüíneo = obtido aos 42 dias.

- Nível de colesterol no músculo do peito = obtido aos 42 dias.

- Ganho de peso médio diário = obtido aos 42 dias

- Fator de produção = obtido aos 42 dias. 


\subsubsection{Dados obtidos}

- Peso vivo médio $(\mathrm{PVM})=$ este dado foi obtido dividindo-se o peso vivo total da parcela pelo número de aves vivas.

- Ganho médio de peso (GMP) = obtido através da pesagem semanal das aves, subtraindo-se o peso médio semanal das aves do peso médio da semana anterior.

- Consumo médio de ração $(\mathrm{CMR})=$ foi obtido fazendo a pesagem semanal dos comedouros somando-se a sobra de ração da semana anterior. Este resultado era então dividido pelo número de aves vivas. Quando alguma ave do "box" morria ou era refugada, era feita a correção do consumo através da fórmula apresentada a seguir:

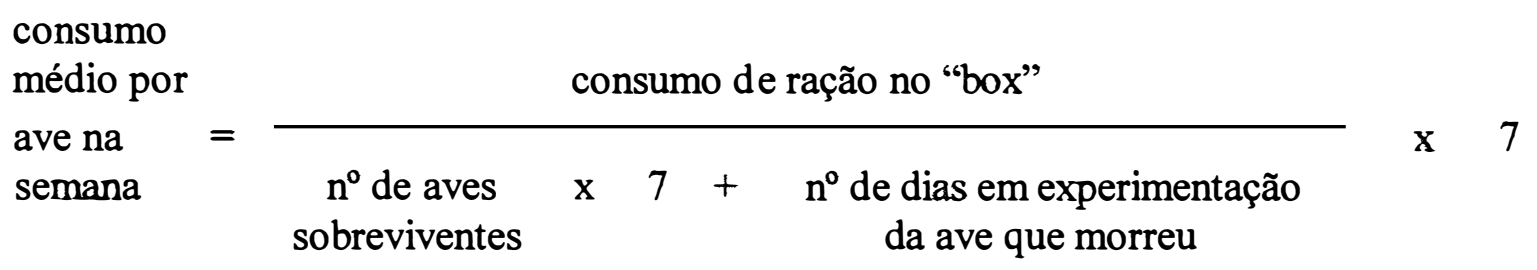

- Conversão alimentar média $(\mathrm{CA})=$ foi calculado dividindo-se o valor obtido no consumo médio de ração da parcela pelo ganho médio de peso.

- Mortalidade + refugagem $(M+R)=$ as aves que morreram, ou refugaram, durante $o$ período experimental eram pesadas e anotado o número do "box" ao qual pertenciam e o dia da semana para que se pudesse fazer a correção do consumo de ração de acordo com o número de aves vivas nos "boxes".

- Nível de colesterol no soro sangüíneo e no músculo do peito = o material foi coletado ao término do experimento. Foi escolhida uma ave por "box" e coletado o sangue. Após este processo, a ave era marcada e posteriormente abatida para a coleta do 
músculo do peito. Em todas as aves foi coletado o lado esquerdo do músculo peitoral torácico.

- Ganho de peso médio diário = este dado foi obtido dividindo-se o ganho médio de peso das aves do "box" de 1 a 42 dias pelo número de dias de criação, neste caso, 42 dias.

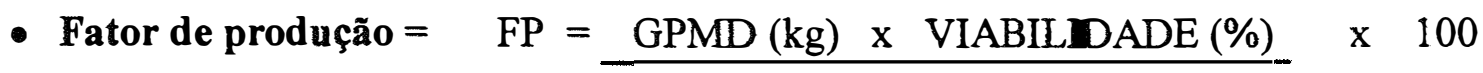
$\mathrm{CA}$

\subsubsection{Coleta das amostras}

- Soro sangüíneo = no último dia do experimento, logo após a pesagem das aves e dos comedouros iniciou-se a coleta de sangue, sem jejum prévio. Foi escolhida uma ave por "box", sendo que a mesma deveria ter, aparentemente, o peso corporal próximo ao peso médio das aves do "box".

A partir disto iniciou-se a coleta do sangue que foi obtido da veia ulnar, localizada na asa da ave, utilizando-se seringas descartáveis e estéreis de $5 \mathrm{ml}$ e agulhas $25 \times 7$. Foram retirados aproximadamente $3 \mathrm{ml}$ de sangue de cada ave. Logo após este processo, o sangue coletado era colocado em um tubo estéril, devidamente identificado. Este sangue foi conservado no gelo enquanto esta etapa era realizada. Ao término desta, o sangue foi mantido em geladeira até o início da centrifugação para a obtenção do soro. Este processo iniciou-se no período da tarde do mesmo dia.

O sangue foi centrifugado a $2000 \mathrm{rpm}$ por $5 \mathrm{~min}$. Separado o soro, este foi retirado e transferido para outro tubo estéril e mantido em geladeira até que fosse encaminhado ao laboratório, para análise de nível de colesterol no soro. 
Esta análise foi realizada pelo Laboratório de Análises Clínicas PREVILAB Ltda., localizado na cidade de Piracicaba -SP. O método utilizado para esta análise foi o Teste Colorimétrico Enzimático - HITACHI - 911.

- Músculo do peito = as aves utilizadas para a coleta do sangue foram marcadas e, posteriormente as mesmas aves foram abatidas por deslocamento cervical, sem jejum prévio. Esta etapa iniciou-se no período da tarde do último dia do experimento.

Após o abate, a ave era colocada em decúbito dorsal, e retirada a pele da região ventral até total exposição do músculo do peito. Era então retirado o lado esquerdo do músculo peitoral torácico. O músculo foi colocado em saco plástico, hermeticamente fechado e conservado em gelo até o término desta etapa. Depois disto, todas as amostras foram conservadas em congelador, a uma temperatura aproximada de $16^{\circ} \mathrm{C}$.

Posteriormente, as amostras foram levadas para o Instituto de Tecnologia de Alimentos (ITAL), localizado no município de Campinas-SP, para ser determinado o nível de colesterol no músculo do peito, através da metodologia de Cromatografia Líquida de Alta Eficiência (CLAE)

\subsubsection{Metodologia de análise do nível de colesterol no soro sangüíneo}

Teste Colorimétrico Enzimático - HTACHI - 911, descrito pelo laboratório "BOEHRINGER MANNHEIM". 


\section{Princípio do teste}

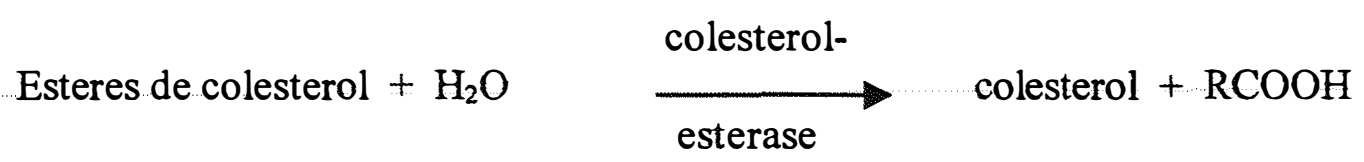

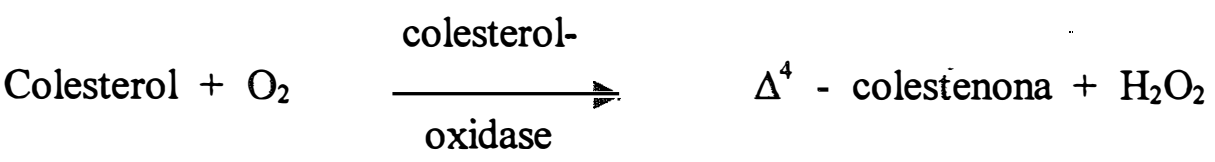
$2 \mathrm{H}_{2} \mathrm{O}_{2}+4$-aminofenazona + fenol $\longrightarrow 4$-(p-benzoquinona-monoimino) - fenazona $+4 \mathrm{H}_{2} \mathrm{O}$

O produto desta última reação é quantificado colorimétricamente, sendo proporcional à concentração de colesterol no soro sangüíneo.

\subsubsection{Metodologia para determinação de colesterol no músculo do peito}

O nível de colesterol no músculo do peito foi determinado através de Cromatografia Líquida de Alta Eficiência (CLAE), segundo o método de Bragagnolo e Rodriguez-Amaya (1997), descrito sumariamente na Figura 1.

Preparo da amostra:

Cada amostra, pesando aproximadamente $500 \mathrm{~g}$, foi triturada separadamente num multiprocessador, até a obtenção de uma massa homogênea. Alíquotas de $10 \mathrm{~g}$, em duplicata foram tomadas para análise. 
Figura 3: Fluxograma para determinação do nível de colesterol no músculo do peito.

Pesagem

pesar $10 \mathrm{~g}$ da

amostra

adicionar $200 \mathrm{ml}$ de clorofórmio-metanol (2:1)

agitar por 2 min com minipimer (Braun)

filtrar para funil de separação de $500 \mathrm{ml}$

Extração

dos

lipídios

lavar com $40 \mathrm{ml}$ de $\mathrm{KCl}$ 0,72\%

separar as fases

lavar com $25 \mathrm{ml}$ de $\mathrm{KCl} \mathrm{0,72 \%}$

separar as fases

completar com clorofórmio em balão volumétrico

de $200 \mathrm{ml}$

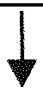

tomar $5 \mathrm{ml}$ do extrato clorofórmico

secar em $\mathrm{N}_{2}$ e banho-maria à $55^{\circ} \mathrm{C}$

Saponificação

adicionar $10 \mathrm{ml}$ de $\mathrm{KOH} 12 \%$ em etanol $90 \%$ agitar em vortex

deixar $15 \mathrm{~min}$ a $80^{\circ} \mathrm{C}$ em banho-maria com agitação

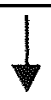

adicionar $5 \mathrm{ml}$ de $\mathrm{H}_{2} \mathrm{O}$

agitar em vortex

esfriar

colocar $10 \mathrm{ml}$ de hexano

agitar em vortex

tomar $5 \mathrm{ml}$ de hexano

agitar em vortex

tomar $5 \mathrm{ml}$

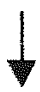


CLAE

\begin{tabular}{|l|}
\multicolumn{1}{|c|}{} \\
secar o extrato de hexano $(10 \mathrm{ml}) \mathrm{em} \mathrm{N}_{2} \mathrm{e}$ \\
banho-maria à $55^{\circ} \mathrm{C}$ \\
diluir em $3 \mathrm{ml}$ da fase móvel \\
agitar \\
deixar $2 \mathrm{~min}$. no ultra-som \\
filtrar em membrana de $0,45 \mu \mathrm{m}$ \\
injetar $20 \mathrm{ml}$ \\
coluna C $18(125 \mathrm{~mm} \mathrm{X} 4,5 \mathrm{~mm}$ X $5 \mu \mathrm{m})$ \\
$\lambda=210 \mathrm{~nm}$ \\
fase móvel: acetonitrila + isopropanol $(70: 30)$ \\
fluxo $=0,80 \mathrm{ml} /$ min. \\
temperatua da coluna $=35^{\circ} \mathrm{C}$ \\
\hline
\end{tabular}

\subsubsection{Análise dos resultados}

Os dados obtidos neste experimento foram tabulados em planilha EXCEL 5.0 e analisados utilizando-se o Programa SAS (Statistical Analyses System) de análises estatísticas.

Os dados de desempenho PVM, GMP, CMR, CA e M+R, foram submetidos à análise da variância nos períodos de 1 a 21 dias, de 22 a 42 dias e no período total de 1 a 42 dias. Suas médias foram comparadas através do teste de Tukey, ao nível de $5 \%$ de significância.

Os resultados de PM, ColS., ColC., GPMD e FP foram obtidos apenas aos 42 dias, porém foram submetidos as mesmas análises dos resultados de desempenho. 


\section{RESULTADOS E DISCUSSÃO}

\subsection{Ganho Médio de Peso (GMP), Consumo Médio de Ração (CMR), Conversão Alimentar (CA) e Mortalidade + Refugagem (M+R) de 1 a 21 dias de idade.}

Os dados originais de peso vivo total e médio obtidos no $7^{\circ}, 14^{0}$ e $21^{0}$ dia do período experimental e GMP, CMR, CA e M+R obtidos na $1^{\mathrm{a}}, 2^{\mathrm{a}}$ e $3^{\mathrm{a}}$ semanas, referentes ao período de 1 a 21 dias encontram-se nos Apêndices 4 , 5 e 6, respectivamente.

As análises da variância para GMP, CMR, $C A$ e $M+R$ no período de 1 a 21 dias encontram-se nos Apêndices 12, 13, 14 e 15 respectivamente.

Na Tabela 3 estão apresentados os resultados obtidos em GMP, CMR, $\mathrm{CA}$ e $\mathrm{M}+\mathrm{R}$ de frangos de corte submetidos aos tratamentos de níveis crescentes de citrato cúprico e sulfato cúprico pentahidratado de 1 a 21 dias. 
TABELA 3: Efeito dos tratamentos sobre as variáveis GMP, CMR, CA e $M+R$ no período de 1 a 21 dias da criação das aves.

\begin{tabular}{llcccc}
\hline & & \multicolumn{4}{c}{ Variáveis } \\
\cline { 3 - 6 } Tratamentos & Sexo & $\begin{array}{c}\text { GMP } \\
(\mathbf{k g})\end{array}$ & $\begin{array}{c}\text { CMR } \\
(\mathbf{k g})\end{array}$ & $\mathbf{C A}$ & $\begin{array}{c}\mathbf{M}^{\mathrm{C}} \mathbf{R}^{\mathrm{c}} \\
(\%)\end{array}$ \\
\hline CONTR. & fêmea & $0,721^{\mathrm{a}}$ & $1,121^{\mathrm{a}}$ & $1,555^{\mathrm{a}}$ & 0,83 \\
& macho & $0,825^{\mathrm{b}}$ & $1,237^{\mathrm{b}}$ & $1,500^{\mathrm{b}}$ & 1,67 \\
CITR. 50 & fêmea & $0,714^{\mathrm{a}}$ & $1,124^{\mathrm{a}}$ & $1,574^{\mathrm{a}}$ & 3,33 \\
& macho & $0,821^{\mathrm{b}}$ & $1,225^{\mathrm{b}}$ & $1,493^{\mathrm{b}}$ & 0,00 \\
CITR. 100 & fêmea & $0,712^{\mathrm{a}}$ & $1,153^{\mathrm{a}}$ & $1,618^{\mathrm{a}}$ & 1,67 \\
& macho & $0,808^{\mathrm{b}}$ & $1,220^{\mathrm{b}}$ & $1,509^{\mathrm{b}}$ & 0,00 \\
CITR. 150 & fêmea & $0,716^{\mathrm{a}}$ & $1,115^{\mathrm{a}}$ & $1,557^{\mathrm{a}}$ & 0,83 \\
& macho & $0,811^{\mathrm{b}}$ & $1,239^{\mathrm{b}}$ & $1,527^{\mathrm{b}}$ & 3,33 \\
SULF. 200 & fêmea & $0,727^{\mathrm{a}}$ & $1,121^{\mathrm{a}}$ & $1,542^{\mathrm{a}}$ & 0,00 \\
& macho & $0,824^{\mathrm{b}}$ & $1,255^{\mathrm{b}}$ & $1,523^{\mathrm{b}}$ & 2,50 \\
\hline Coef. Var. (\%) & & 1,70 & 1,69 & 1,79 & 118,62 \\
\hline
\end{tabular}

${ }^{2, b}$ Médias seguidas de letra de diferentes na coluna diferem entre si pelo teste Tukey $(\mathrm{P}<0,05)$.

'Interação tratamento*sexo $(\mathrm{P}<0,05)$.

Não houve diferença estatisticamente significativa $(P>0,05)$ entre as médias das variáveis GMP, CMR e CA quando analisado tratamento, indicando que os níveis de citrato cúprico assim como o sulfato cúprico pentahidratado não tiveram efeito sobre o desempenho das aves. Para a variável $M+R$ também não houve diferença estatisticamente significativa $(\mathrm{P}>0,05)$.

Quando analisado sexo, houve diferença estatisticamente significativa $(\mathrm{P}<0,05)$ entre as médias das variáveis GMP, CMR e CA. Porém, este resultado já era esperado, uma vez que é conhecido o fato dos machos terem melhor desempenho que as fềmeas. Para a variável $M+R$ não houve diferença estatisticamente significativa $(\mathrm{P}>0,05)$.

Houve uma interação significativa $(\mathrm{P}<0,05)$ entre tratamento e sexo na variável $\mathrm{M}+\mathrm{R}$. Porém, este fato não está ligado a efeito de tratamento ou sexo e pode apenas ser atribuído ao acaso, uma vez que não segue nenhum padrão. 


\subsection{Ganho Médio de Peso (GMP), Consumo Médio de Ração (CMR), Conversão Alimentar (CA) e Mortalidade + Refugagem (M+R) de 22 a} 42 dias de idade.

Os dados originais de peso vivo total e médio obtidos no $28^{\circ}, 35^{\circ}$ e $42^{0}$ dia do período experimental e GMP, CMR, CA e M+R obtidos na $4^{\mathrm{a}}, 5^{\mathrm{a}}$ e $6^{\mathrm{a}}$ semanas, referentes ao período de 22 a 42 dias encontram-se nos Apêndices 7, 8 e 9, respectivamente.

As análises da variância para GMP, CMR, CA e $M+R$ no período de 22 a 42 dias encontram-se nos Apêndices 16, 17, 18 e 19 respectivamente.

Na Tabela 4 estão apresentados os resultados obtidos em GMP, CMR, $\mathrm{CA}$ e $\mathrm{M}+\mathrm{R}$ de frangos de corte submetidos aos tratamentos de níveis crescentes de citrato cúprico e sulfato cúprico pentahidratado de 22 a 42 dias.

TABELA 4: Efeito dos tratamentos sobre as variáveis GMP, CMR, CA e $M+R$ no período de 22 a 42 dias da criação das aves.

\begin{tabular}{llcccc}
\hline & & \multicolumn{4}{c}{ Variáveis } \\
\cline { 3 - 6 } Tratamentos & Sexo & $\begin{array}{c}\text { GMP } \\
\mathbf{( k g )}\end{array}$ & $\begin{array}{c}\text { CMR } \\
\mathbf{( k g )}\end{array}$ & $\mathbf{C A}$ & $\begin{array}{c}\mathbf{M}+\mathbf{R} . \\
\mathbf{( \% )}\end{array}$ \\
\hline \multirow{2}{*}{ CONTR } & fêmea & $1,328^{\mathrm{a}}$ & $2,794^{\mathrm{a}}$ & $2,104^{\mathrm{a}}$ & 2,50 \\
& macho & $1,679^{\mathrm{b}}$ & $3,395^{\mathrm{b}}$ & $2,023^{\mathrm{b}}$ & 1,67 \\
CITR. 50 & fêmea & $1,337^{\mathrm{a}}$ & $2,799^{\mathrm{a}}$ & $2,093^{\mathrm{a}}$ & 1,67 \\
& macho & $1,652^{\mathrm{b}}$ & $3,364^{\mathrm{b}}$ & $2,036^{\mathrm{b}}$ & 1,67 \\
CITR. 100 & fêmea & $1,327^{\mathrm{a}}$ & $2,807^{\mathrm{a}}$ & $2,116^{\mathrm{a}}$ & 0,83 \\
& macho & $1,687^{\mathrm{b}}$ & $3,379^{\mathrm{b}}$ & $2,003^{\mathrm{b}}$ & 5,00 \\
CITR. 150 & fêmea & $1,342^{\mathrm{a}}$ & $2,780^{\mathrm{a}}$ & $2,071^{\mathrm{a}}$ & 1,67 \\
& macho & $1,652^{\mathrm{b}}$ & $3,355^{\mathrm{b}}$ & $2,031^{\mathrm{b}}$ & 1,67 \\
SULF. 200 & fêmea & $1,322^{\mathrm{a}}$ & $2,773^{\mathrm{a}}$ & $2,098^{\mathrm{a}}$ & 1,67 \\
& macho & $1,688^{\mathrm{b}}$ & $3,422^{\mathrm{b}}$ & $2,028^{\mathrm{b}}$ & 2,50 \\
\hline Coef. Var. (\%) & & 2,50 & 1,76 & 1,42 & 88,54 \\
\hline
\end{tabular}

${ }^{\text {a, b }}$ Médias seguidas de letra de diferentes na coluna diferem entre si pelo teste Tukey $(\mathrm{P}<0,05)$. 
Não houve diferença estatisticamente significativa $(P>0,05)$ entre as médias das variáveis GMP, CMR e CA quando analisado tratamento no período de 22 a 42 dias de criação, indicando que os níveis de citrato cúprico assim como o sulfato cúprico pentahidratado não tiveram efeito sobre o desempenho das aves. Para a variável $M+R$ também não houve diferença estatisticamente significativa $(P>0,05)$.

Assim como no período anterior, quando analisado sexo, houve diferença estatisticamente significativa $(P<0,05)$ entre as médias das varáveis GMP, CMR e CA, mas não houve diferença estatisticamente significativa $(P>0,05)$ para a variável $\mathrm{M}+\mathrm{R}$.

\subsection{Peso Médio (PM), Ganho Médio de Peso (GMP), Consumo Médio de Ração (CMR), Conversão Alimentar (CA), Mortalidade + Refugagem $(M+R)$, Nível de Colesterol no Soro Sangüíneo (ColS.), Nível de Colesterol na Carne (ColC.), Ganho de Peso Médio Diário (GPMD) e Fator de Produção (FP) de 1 a 42 dias de idade.}

Os dados originais de peso vivo total e médio obtidos no $42^{\circ}$ dia do período experimental e GMP, CMR, CA, M+R, GPMD e FP obtidos nas seis semanas, referentes ao período de 1 a 42dias encontram-se no Apêndice 9. Os dados originais de ColS. e ColC. obtidos no $42^{\circ}$ dia encontram-se no Apêndice 10 .

As análises da variância para PM, GMP, CMR, CA e M+R, GPMD, FP, ColS. e ColC. aos 42 dias encontram-se nos Apêndices 20 a 28, respectivamente.

Na Tabela 5 estão apresentados os resultados obtidos em PM, GMP, CMR, CA, M+R, ColS., ColC., GPMD e FP de frangos de corte submetidos aos tratamentos de níveis crescentes de citrato cúprico e sulfato cúprico pentahidratado no $42^{0}$ dia do período experimental. 
Não houve diferença estatisticamente significativa $(\mathrm{P}>0,05)$ entre as médias das variáveis PM, GMP, CMR, CA, GPMD e FP quando analisado tratamento, indicando que, novamente, os níveis de citrato cúprico assim como o sulfato cúprico pentahidratado não tiveram efeito sobre o desempenho das aves. Para as variáveis $M+R$, ColS., ColC quando analisado tratamento, este também não apresentou diferença estatisticamente significativa $(\mathrm{P}>0,05)$.

Quando analisado sexo, houve diferença estatisticamente significativa $(\mathrm{P}<0,05)$ entre as médias das variáveis $\mathrm{PM}, \mathrm{GMP}, \mathrm{CMR}, \mathrm{CA}, \mathrm{GPMD}$ e FP, confirmando mais uma vez a diferença de desempenho entre os sexos. Para as variáveis $M+R$, ColS. e ColC não houve diferença estatisticamente significativa $(P>0,05)$. 


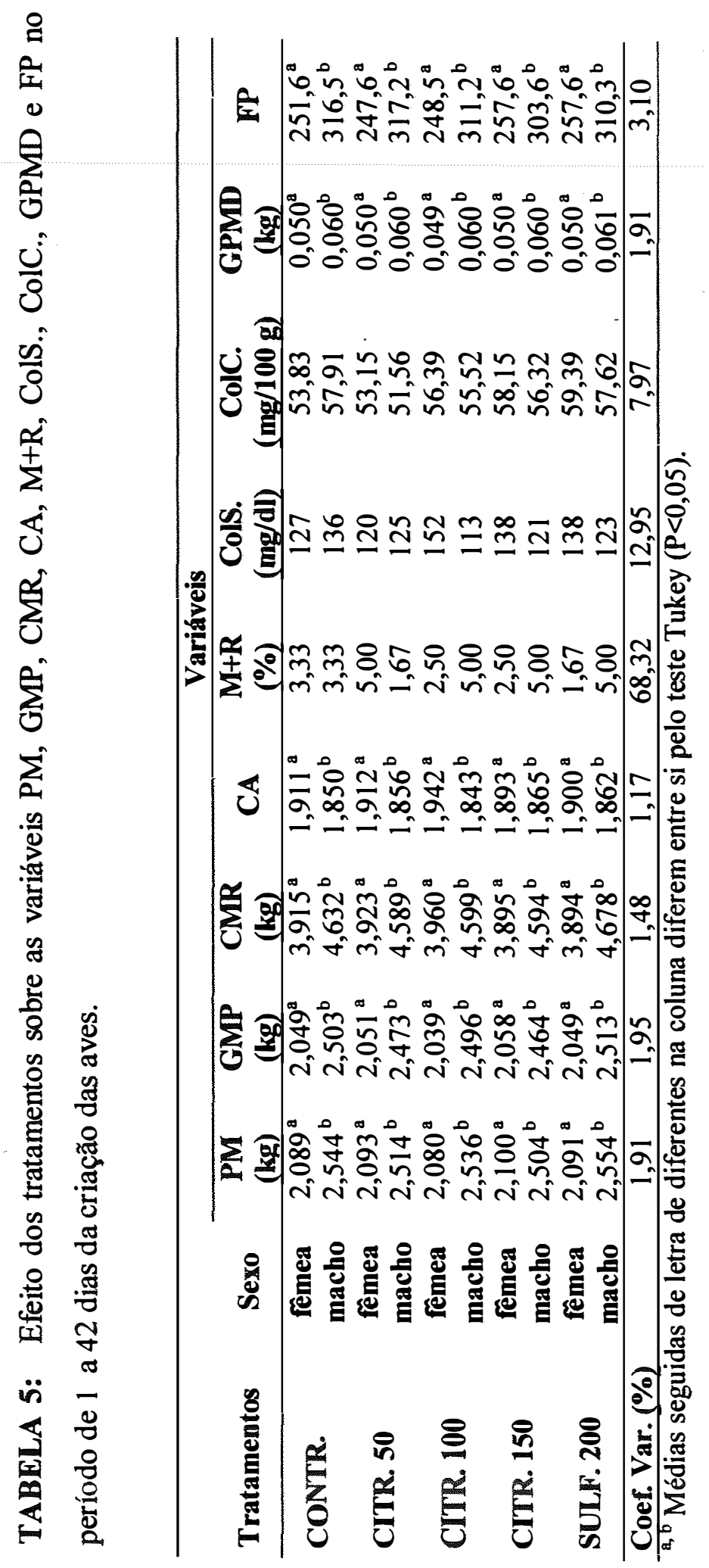


Ewing et al. (1998) observaram aumento no ganho de peso em relação à dieta controle de $9,1 \%$ e $4,9 \%$ quando usaram citrato cúprico e sulfato cúprico pentahidratado, comprovando o efeito promotor de crescimento do citrato cúprico. Tal efeito não foi observado neste experimento. Estes autores também citam que a conversão alimentar das aves foi 5,2\% e 7,6\% melhor quando comparadas às dietas basais em dois experimentos. Neste trabalho, a conversão alimentar foi igual em todos os tratamentos quando analisados os três períodos estudados, de 1 a 21 dias, de 22 a 42 dias e de 1 a 42 dias.

Os autores Pesti e Bakali (1996) também comprovaram o efeito promotor de crescimento do $\mathrm{Cu}$ na ração de frangos de corte e observaram que o citrato cúprico foi mais eficiente a níveis mais baixos que o sulfato cúprico pentahidratado. Apesar de, neste trabalho, terem sido aplicados tratamentos muito semelhantes aos do trabalho citado, não foi observada qualquer diferença de desempenho entre os tratamentos nos períodos estudados.

Zhou et al. (1994) sugeriram que o maior efeito do $\mathrm{Cu}$ como promotor de crescimento deve-se ao estímulo de consumo de alimento. Porém, neste trabalho não foi possível observar diferença de consumo entre os tratamentos aplicados.

No presente trabalho, os efeitos promotores de crescimento do $\mathrm{Cu}$ não puderam ser observados. Diversos autores sugerem que o $\mathrm{Cu}$ possui uma ação muito semelhante à dos agentes antimicrobianos, sendo que um dos mecanismos apontados como responsável pela melhora do desempenho seria a ação sobre microorganismos causadores de doenças, que mesmo sem apresentar sinais clínicos, podem afetar o crescimento dos animais (Cromwell, 1991). Isto se confirma quando observa-se que agentes antimicrobianos têm ação mais evidente como promotor de crescimento quando suínos são alojados em ambientes contaminados, do que quando as instalações são limpas e desinfetadas (Hays, 1969; Cromwell, 1991).

Quando o sistema imunológico é estimulado, resulta em alterações metabólicas que diminuem a eficiência de utilização de nutrientes, provavelmente por alteração na absorção ou na taxa metabólica. Existem diversos mecanismos pelos quais o 
sistema imune, quando estimulado, pode resultar em mudanças no metabolismo e conseqüente redução no crescimento e eficiência alimentar, como a interação com glândulas endócrinas aumentando ou diminuindo a liberação de hormônios, ou mesmo, suas próprias células podem liberar seus hormônios que causam as alterações metabólicas. Evidências indicam que o principal mediador envolvido no estresse imune é a interleucina-1. Foi demonstrado após vários experimentos que, os níveis de interleucina-1 aumentaram após um estresse imunológico, além de que injeções de interleucina-1 resultaram em redução no crescimento, na eficiência alimentar e alterações no metabolismo mineral (Klasing et al., 1987).

Roura et al. (1992) sugeriram que o grau de higiene do ambiente afeta a ação dos antibióticos, os quais agem efetivamente reduzindo o estresse imunológico, através da diminuição da freqüência, duração e/ou intensidade do desafio microbiano e, consequentemente, da resposta imune. Como a intensidade do desafio diminui em um ambiente limpo, pôde-se observar uma redução do efeito positivo dos antibióticos sobre o crescimento em tais ambientes. Porém, em um ambiente com pouca higiene o aumento da taxa de crescimento e da eficiência alimentar, devido aos antibióticos, foi acompanhado pela redução dos níveis de interleucina circulante, o que sugere que os antibióticos reduzem o estresse imunológico.

Provavelmente este mecanismo de ação seja a melhor explicação para os resultados obtidos neste experimento, pois o período de vazio sanitário, assim como as práticas de desinfecção do aviário e equipamentos antes do recebimento dos pintos e o ambiente relativamente livre de desafio microbiano, podem ter reduzido a ativação do sistema imunológico, não sendo possível observar a ação promotora de crescimento do $\mathrm{Cu}$.

Os índices de desempenho obtidos neste estudo constituem uma evidência que as condições gerais de criação foram muito boas, provavelmente com baixo desafio microbiano. O PM aos 42 dias (aproximadamente 2,1 $\mathrm{kg}$ para fêmeas e 2,5 $\mathrm{kg}$ para machos) e a CA (aproximadamente 1,90 para fêmeas e 1,85 para machos) podem ser considerados excelentes. 
Outro parâmetro para avaliar as condições sanitárias do aviário são as taxas de mortalidade + refugagem que podem ser consideradas baixas, sendo estas de apenas $3,5 \%$.

Em estudos recentes Brainer (1998) e Lima (1999) não conseguiram comprovar a ação promotora de crescimento do $\mathrm{Cu}$. As autoras afimam que as ótimas condições higiênicas das instalações talvez tenham sido as causas para que o $\mathrm{Cu}$ não tenha conseguido expressar sua capacidade promotora de crescimento.

Diversas pesquisas confirmam que a deficiência de $\mathrm{Cu}$ causa hipercolesterolemia. Alguns estudos recentes afirmam que em aves alimentadas com altas concentrações de $\mathrm{Cu}$ na dieta, foi possível observar uma redução nos níveis de colesterol no músculo do peito e no plasma sangüíneo (Bakali e Pesti, 1995; Konjufca et al., 1997; Pesti e Bakali, 1998).

Mateos et al. (1999) citam em seu trabalho que ensaios com diversos micronutrientes, entre eles o $\mathrm{Cu}$, têm sido feitos na tentativa de reduzir o nível de colesterol. Porém, não têm conseguido nenhum efeito positivo.

Bakali e Pesti (1995) afirmam que o mecanismo pelo qual o $\mathrm{Cu}$ reduz o colesterol pode ser por reduzir a síntese de colesterol, ou maior degradação, ou maior excreção.

Neste trabalho, quando analisadas as variáveis ColS. e ColC., os resultados obtidos diferem dos trabalhos dos autores citados anteriormente. Este fato provavelmente seja explicado quando verifica-se que não houve diferença estatisticamente significativa de desempenho entre os tratamentos aplicados. Quando as aves têm maior ganho de peso, isto ocorre devido à maior deposição de proteínas, consequentemente há um aumento no tamanho das fibras musculares. Sabe-se que o colesterol está presente nas membranas. Quando ocorre o aumento da fibra muscular, há uma diminuição da concentração de colesterol por grama de tecido muscular. Uma possibilidade para explicar a ausência de efeito sobre o colesterol seria que, neste presente trabalho não houve diferença de desempenho entre os tratamentos aplicados, 
consequentemente também não foi possível identificar diferenças entre os níveis de colesterol no músculo da carne.

Bakali e Pesti (1995) afirmarn em seu trabalho que foi possível reduzir o nível de colesterol no sangue e no músculo do peito das aves em $11,8 \%$ e 20,4\%, respectivamente, utilizando $250 \mathrm{mg} \mathrm{Cu} / \mathrm{kg}$ na forma de sulfato cúprico pentahidratado. Os autores afirmam que é possível reduzir em até $25 \%$ o nível de colesterol do músculo de frangos de corte quando as aves são alimentadas por 42 dias com altos níveis de $\mathrm{Cu}$ na ração.

No presente trabalho, além de não ser possível identificar diferenças entre os tratamentos quanto aos níveis de colesterol na carne, também não foi possível observar diferenças quanto ao nível de colesterol no soro sangüíneo. Isto provavelmente deve-se ao fato que, apesar de ser conhecida a afirmação que a deficiência de Cu causa uma hipercolesterolemia, o inverso pode não ser verdadeiro, ou seja, altos níveis de $\mathrm{Cu}$ não dieta não determinam obrigatoriamente uma hipocolesterolemia.

Observa-se também que, os autores Pesti e Bakali (1996) em seus vários ensaios normalmente obtiveram as seguintes respostas, quanto maior o ganho de peso das aves, menor o nível de colesterol do músculo e, consequentemente, menor nível de colesterol no sangue, supondo que pode haver uma correlação entre os níveis de colesterol citado. Sendo assim, esses resultados estão de acordo com os resultados obtidos no presente trabalho onde pôde-se observar que, na maioria das vezes os níveis de colesterol na carne e no soro mantiveram-se correlacionados. Porém, como não foi possível detectar diferença de desempenho entre os tratamentos, também não foi possível detectar diferenças entre os níveis de colesterol analisados. 


\section{CONCLUSÕES}

De acordo com as condições em que este trabalho foi realizado, podese concluir que:

1. Contrariando pesquisas realizadas anteriormente, neste experimento o $\mathrm{Cu}$, nas formas de citrato cúprico e sulfato cúprico pentahidratado, não foi eficiente como promotor de crescimento para frangos de corte.

2. Avaliando o desempenho das aves, não houve diferença estatisticamente significativa entre os cinco tratamentos realizados nos três períodos analisados, de 1 a 21 dias, de 22 a 42 dias e de 1 a 42 dias.

3. Quando analisado sexo, houve diferença estatisticamente significativa de desempenho em todos os períodos estudados. Porém, este é um resultado esperado, pois sabe-se que o desempenho de machos é melhor que o de fềmeas.

4. Não houve diferença estatisticamente significativa entre os tratamentos quanto aos níveis de colesterol no soro sangüíneo e na carne aos 42 dias de idade, contrariando trabalhos de pesquisa onde foi comprovado que tanto o citrato quanto o sulfato cúprico reduziram o níveis de colesterol no sangue e na carne das aves.

5. A situação real do aviário, ou seja, os cuidados com a desinfecção das instalações e equipamentos antes do período experimental, o baixo desafio microbiano, a baixa 
densidade e a não reutilização da cama, provavelmente não foram favoráveis ao desenvolvimento de doenças ou estresse, sendo que são essas as condições necessárias para que seja possível avaliar o efeito promotor de crescimento do $\mathrm{Cu}$. Talvez sejam essas as razões pelas quais obteve-se ótimo resultado de desempenho das aves, não sendo possível detectar diferenças estatisticamente significativas entre os tratamentos realizados.

6. Tomam-se necessários mais estudos sobre o citrato cúprico para verificar em qual nível utilizado pode-se obter resposta, e se realmente é eficaz para reduzir o nível de colesterol no soro sangüíneo e no músculo do peito das aves.

7. Pode-se afirmar que, para que seja possível avaliar o efeito promotor de crescimento do $\mathrm{Cu}$ é necessário que exista situação adequada, o que não ocorreu neste presente rabalho. 


\section{REFERÊNCIAS BIBLIOGRÁFICAS}

AMMERMAN, C. B.; BAKER, D.H.; LEWIS, A. J. Bioavailability of nutrients for animals: amino acids, minerals, and vitamins. San Diego: Academic Press, 1995. cap. 7, p.127- 149: Copper bioavailability.

ANDRIGUETTO, J. M.; PERLY, L.; MINARDI, I.; GEMAEL, A.; FLEMMING, J. S.; SOUZA, G. A.; BONA FILHO, A. Nutrição animal. 4.ed. São Paulo: Nobel, 1986. cap.6, p.173-255: Os princípios nutritivos e suas finalidades nutricionais.

BAKALLI, R. I.; PESTI, G. M.; RAGLAND, W. L.; KONJUFCA, V. Dietary copper in excess of nutritional requeriment reduces plasma and breast muscle cholesterol of chickens. Poultry Science, v. 74, p.360-365, 1995.

BAKER, D. H.; ODLE, J.; FUNK, M. A.; WIELAND, T. M. Bioavailability of copper in oxide cupric, cuprous oxide, and in a copper-lysine complex. Poultry Science, v. 70, p. 177-179, 1991.

BARLOW, S. M.; YOUNG, F. V. K.; DUTHIE, I. F. Nutritional recommendations for omega-3 polyunsaturated fatty acids and the challenge to the foof industry. Proceeding of the Nutrition Society, v. 49, p. 13-21, 1990. 
BORDIN, E. L. Promotores de crescimento, avaliação anatomopatológica dos resultados da sua utilização. A Hora Veterinária, v. 4, n. 22, p. 17-24, nov./ dez. 1984.

BRAGAGNOLO, N.; RODRIGUES-AMAYA, D.B. Teores de colesterol em cames de frango. Revista de Farmácia e Bioquímica da Universidade de São Paulo, v. 28, n.2, p. 122-131, jul./dez. 1992.

BRAGAGNOLO, N.; RODRIGUES-AMAYA, D.B. Avaliação comparativa de três métodos para determinação de colesterol em gema de ovo. Arquivos de Biologia e Tecnologia, v. 36, n.2, p. 237-251, jun. 1993.

BRAINER, M. M. A. Efeitos de citrato cúprico em diferentes fases de criação como promotor de crescimento de frangos de corte. Piracicaba, 1998. 81p. Dissertação (Mestrado.) - Escola Superior de Agricultura "Luiz de Queiroz", Universidade de São Paulo.

CACHONI, C.C. Biodisponibilidade de cobre de várias fontes comerciais para frangos de corte na fase inicial. Lavras, 1993. 71p. Dissertação (M.S.) - Escola Superior de Agricultura de Lavras.

CROMWELL, G. L; MILLER, E. R; ULTREY, D.E.; LEWIS, A. J. Antimicrobial Agents. In: Swine nutrition. Stoneham: Butterworth-Heinemann, 1991. pt. 3, cap.17, p.297- 314 . 
EWING, H.P.; PESTI, G.M.; BAKALI, R. I.; MENTEN, J. F. M. Studies on the feeding of cupric sulfate pentahydrate, cupric sulfate, and copper oxychloride to broiler chickens. Poultry Science, v. 77, p. 445-448, 1998.

EWING, W. R. Poultry nutrition. 5. ed. Pasadena, Califórnia: Division of Hoffmann-La Roche Inc., 1963. cap.26, p.574-709: Minerals in the poultry ration.

HAYS, V. W. Biological basis for the use of antibiotics in livestock production. In: SYMPOSIUM ON THE USE OF DRUGS IN ANIMAL FEEDS, Washington, 1969. Washington: National Academy of Sciences, 1969. p. 11-30.

HAYS, V. W.; MUIR, W. M. Efficacy and safety of feed additive use of antibacterial drugs in animal production. Canadian Journal of Animal Science, v. 59, p. 447-456, 1979.

HAYS, V. W.; SWENSON, M. J. Ossos e minerais. In: DUKES, H.H. Fisiologia dos an imais domésticos. 11.ed. Rio de Janeiro: Guanabara, 1993. cap.29, p.471-486.

HILL, C. H.; MATRONE, G. Copper and iron requeriments of growing chicks for maximum hemoglobin formation. Poultry Science. v. 37, p. 1211-1212, Sept. 1958.

HODA, A. A.; MAHA, M. H. Potency of copper as growth promoter in broiler chickens. Veterinary Medical Journal, v. 43, n.1, p. 77-85, 1995. 
KLASING, K. C.; LAURIN, D. E.; PENG, R. K.; FRY, D. M. Immunologically mediated growth depression in chicks:influence of feed intake, corticosterone and interleukin-1. Journal of Nutrition, v. 117, p. 1629-1637, 1987.

KONJUFCA, V.N.; PESTI, G. M.; BAKALLI, R. I. Modulation of cholesterol levels in broiler meat by dietary garlic and copper. Poultry Science, v.76, p.1264-1271, Sept. 1997.

KROGER, H.; FEDER, H.; PLISCHKE, R.; AMTSBERG, G. Influence of various $\mathrm{Cu}$ supplements (copper-sulfate, copper-II-oxide e elemental copper) on fattening performance and carcass yields in pigs. Zuchtungskunde, v. 49, n.3, p. 213-224, 1977.

LEDOUX, D. R.; HENRY, P. R.; AMMERMAN, C. B.; MILES, R.D. Effect of dietary copper on tissue mineral composition as an estimate of copper bioavailability in broiler chicks. Nutrition Reports International. v. 39, n.6, p. 1117-1126, 1989.

LIMA, I. A.V. Estudo de altos níveis de cobre orgânico e inorgânico como promotores do crescimento de leitões. Piracicaba, 1999. 51p. Dissertação (Mestrado.) - Escola Superior de Agricultura "Luiz de Queiroz", Universidade de São Paulo.

MACARI, M; FURLAN, R. L.; GONZALES, E. Fisiologia aviária aplicada a frangos de corte. Jaboticabal: FUNEP, 1994. cap.16, p. 269-274: Absorção de minerais. 
MATEOS, G. G.; GROBAS, S.; FONT, S. S.; TORRE, M. A. Nutrición y calidade de los productos avícolas: contenido en colesterol y modificación del perfil lipídico. In: Reunião Anual Sociedade Brasileira de Zootecnia, 36, Porto Alegre, 1999. Anais. Porto Alegre: SBZ, 1999. p. 155- 166.

MAYES, P. A. Colesterol: síntese, transporte \& excreção. In: MURRAY, R. K.; GRANNER, D. K.; MAYES, P. A.; RODWELL, V. W. Harper: bioquímica . 7. ed. São Paulo: Atheneu Editora, 1994. pt. 3, cap. 28, p. 262-274.

MAYNARD, L. A.; LOOSLI, J. K.; HINTZ, H. F.; WARNER, R. G. Nutrição animal. 3.ed. Rio de Janeiro: Livraria Freitas Bastos, 1984. cap.10, p. 260-335: Elementos inorgânicos e seu metabolismo.

McDOWELL, L. R. Minerals in animal and human nutrition. San Diego: Academic Press, 1992. cap. 8, p. 176-204: Copper and molybdenum.

McNAUGHTON, J. L.; DAY, E. J.; DILWORTH, B. C. Iron and copper availability from various sources. Poultry Science, v. 53, p. 1325-1330, July 1974.

MEHRING Jr., A. L.; BRUMBAUGH, J. H.; SUTHERLAND, A. J.; TITUS, H. W. The tolerance of chickens for dietary copper. Poultry Science, v. 39, p.713-719, May 1960.

MERCK \& CO. The Merck index: an encyclopedia of chemicals, drugs, and biologicals. 11.ed. Rahway, 1989. 1v. 
MILLER, E. R; ULTREY, D.E.; LEWIS, A. J. Iron, copper, zinc, manganese, and iodine in swine nutrition. In:Swine nutrition. Stoneham: Butterworth-Heinemann, 1991. pt. 3, cap.15, p.267- 284:

NATIONAL RESEARCH COUNCIL. Nutrient requeriments of poultry. 9.ed. Washington: National Academic Press, 1994. 71p.

NORWELL, M. J.; CALVERT, C. C.; THOMAS, M. C.; GOATCHER, W. D. The effects of copper sulfate suplementation in broiler chicken diets on growth ans selected toxicological parameters. Poultry Science, v.53, p.1641, July 1974.

PESTI, G. M.; BAKALLI, R. I. Studies on the feeding of cupric sulfate pentahydrate and cupric citrate to broiler chickens. Poultry Science, v.75, p.1086-1091, May 1996.

PESTI, G. M.; BAKALLI, R. I. Studies on the effect of feeding cupric sulfate pentahydrate to laying hens on egg cholesterol content. Poultry Science, v.77, p.1540-1545, 1998.

PUPO, A. A. Endocrinologia. In: MARCONDES, M.; SUSTOVICH, D. R.; RAMOS, O. L. Clínica médica, propedêutica e fisiopatologia. 2. ed. Rio de Janeiro: Guanabara Koogan, 1979. cap. 10, p.485- 563

ROSTAGNO, H. S.; SILVA, D. J.; COSTA, P. M. A.; FONSECA, J. B.; SOARES, P. R.; PEREIRA, J. A. A.; SILVA, M. A. Composição de alimentos e exigências nutricionais de aves e suínos: tabelas brasileiras. Viçosa: UFV, 1994. 59p. 
ROURA, E.; HOMEDES, J.; KLASING, K.C. Prevention of immunologic stress contributes to the growth-permitting ability of dietary antibiotics in chicks. Journal of Nutrition, v. 122, p. 2383-2390, 1992.

RUTZ, F. Absorção de minerais e vitaminas. In: FUNDAÇÃO APINCO DE CIÊNCIA E TECNOLOGIA AVÍCOLAS. Fisiologia da digestão e absorção das aves. Campinas, 1994. p. 83-98.

SCHAIBLE, P. J. Poultry: feeds and nutrition. Westport: The Avi Publishing, 1970. cap. 16, p.250-282: Minerals.

SCOOT, M. L.; NESHEIM, M. C.; YOUNG, R. J. Nutrition of the chickens. 3.ed. New York: M.L.Scott Associates, 1982. cap.5, p. 277-382: Essential inorganics elements.

STARCHER, B .C. Studies on the mechanism of copper absorption in the chicken. Journal of Nutrition, v. 97, p. 321-326, 1969.

UNDERWOOD, E. J. Trace elements in human and animal nuttrition. 4.ed. New York: Academic Press, 1977. cap.3, p.56-108: Copper.

ZHOU, W.; KORNEGAY, E T.; LAAR, V. H.; SWINKELS, J. W. G. M.; WELTEN, M. K.; WONG, E. A.; LINDEMANN, M. D. The role of feed consumption and feed efficiency in copper - stimulated growth. Journal Animal Science, v. 72, n. 9, p. 2385-2394, 1994. 


\section{APÊNDICES}


Apêndice 1: Figura esquemática do aviário experimental e distribuição dos tratamentos nos boxes.

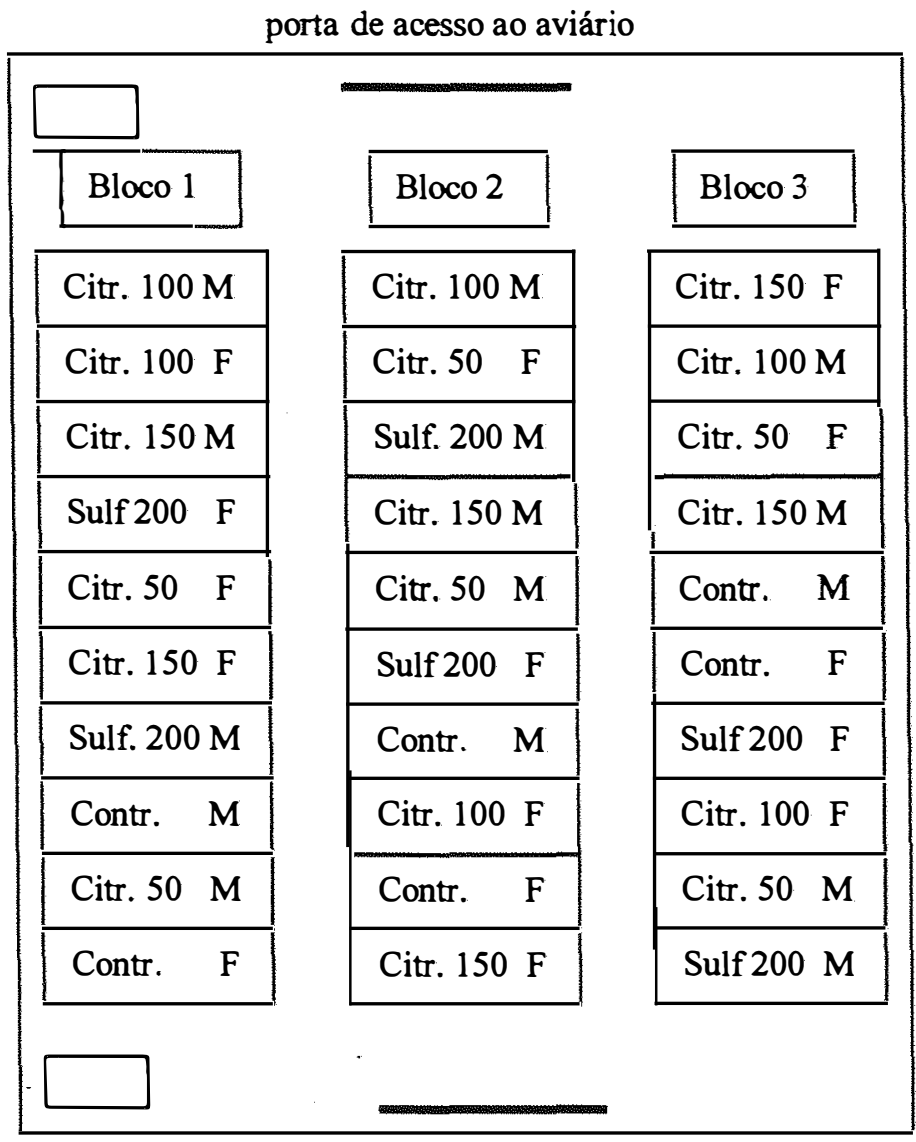

porta de acesso ao aviário 


\section{Tratamentos realizados:}

Contr. = dieta basal (D.B.) contendo $12 \mathrm{mg}$ de $\mathrm{Cu}$ suplementar $/ \mathrm{kg}$ de ração.

Citr. 50 = D.B. suplementada com $50 \mathrm{mg}$ de $\mathrm{Cu} / \mathrm{kg}$ de ração, na forma de citrato cúprico. Citr. 100 = D.B. suplementada com $100 \mathrm{mg}$ de $\mathrm{Cu} / \mathrm{kg}$ de ração, na forma de citrato cúprico.

Citr. 150 = D.B. suplementada com $150 \mathrm{mg}$ de $\mathrm{Cu} / \mathrm{kg}$ de ração, na forma de citrato cúprico.

Sulf. 200 = D.B. suplementada com $200 \mathrm{mg}$ de $\mathrm{Cu} / \mathrm{kg}$ de ração, na forma de sulfato cúprico pentahidratado.

\section{Blocos:}

BLOCO 1 = boxes de 1 a 10;

BLOCO 2 = boxes de 11 a 20;

BLOCO 3 = boxes de 21 a 30.

\section{Sexos:}

$\mathbf{M}=$ macho;

$\mathbf{F}=$ fềmeas. 
Apêndice 2: Temperaturas máximas e mínimas obtidas dentro do aviário durante o período experimental.

\begin{tabular}{|c|c|c|c|c|c|}
\hline Data & $\begin{array}{l}\text { Temp. } \\
\text { mínima } \\
\left({ }^{\circ} \mathrm{C}\right)\end{array}$ & $\begin{array}{l}\text { Temp. } \\
\text { máxima } \\
\left({ }^{\circ} \mathrm{C}\right)\end{array}$ & Data & $\begin{array}{l}\text { Temp. } \\
\text { mínima } \\
\left({ }^{\circ} \mathrm{C}\right)\end{array}$ & $\begin{array}{c}\text { Temp. } \\
\text { máxima } \\
\left({ }^{\circ} \mathrm{C}\right)\end{array}$ \\
\hline $19 / 02$ & 25,0 & 32,0 & $13 / 03$ & 24,0 & 32,0 \\
\hline $20 / 02$ & 23,0 & 34,0 & $14 / 03$ & 20,0 & 29,0 \\
\hline $21 / 02$ & 24,0 & 30,0 & $15 / 03$ & 21,0 & 28,0 \\
\hline $22 / 02$ & 25,0 & 33,0 & $16 / 03$ & 21,0 & 29,0 \\
\hline $23 / 02$ & 25,0 & 30,0 & $17 / 03$ & 22,0 & 29,0 \\
\hline 24/02 & 23,0 & 29,0 & $18 / 03$ & 21,0 & 29,0 \\
\hline 25/ 02 & 24,0 & 29,0 & $19 / 03$ & 22,0 & 31,0 \\
\hline $26 / 02$ & 24,0 & 29,5 & $20 / 03$ & 23,0 & 33,0 \\
\hline $27 / 02$ & 24,0 & 30,0 & $21 / 03$ & 22,0 & 32,0 \\
\hline $28 / 02$ & 23,0 & 29,0 & $22 / 03$ & 22,0 & 29,0 \\
\hline $01 / 03$ & 23,0 & 29,0 & $23 / 03$ & 22,0 & 30,0 \\
\hline $02 / 03$ & 22,0 & 28,5 & $24 / 03$ & 23,5 & 32,5 \\
\hline $03 / 03$ & 22,0 & 31,5 & $25 / 03$ & 20,0 & 29,5 \\
\hline $04 / 03$ & 22,0 & 31,0 & $26 / 03$ & 18,0 & 29,0 \\
\hline $05 / 03$ & 22,0 & 31,0 & $27 / 03$ & 21,0 & 31,0 \\
\hline $06 / 03$ & 23,0 & 33,0 & $28 / 03$ & 21,5 & 32,0 \\
\hline $07 / 03$ & 26,0 & 33,0 & $29 / 03$ & 22,0 & 32,0 \\
\hline 08/ 03 & 23,0 & 33,0 & $30 / 03$ & 21,0 & 27,0 \\
\hline $09 / 03$ & 23,0 & 33,0 & $31 / 03$ & 21,0 & 30,0 \\
\hline $10 / 03$ & 23,0 & 33,0 & $01 / 04$ & 19,0 & 29,0 \\
\hline $11 / 03$ & 22,5 & 32,0 & $02 / 04$ & 18,0 & 27,0 \\
\hline $12 / 03$ & 23,0 & 32,0 & & & \\
\hline
\end{tabular}


Apêndice 3: Variáveis obtidas no $1^{0}$ dia do período experimental.

\begin{tabular}{|c|c|c|c|c|c|}
\hline Tratamento & Sexo & Blocos & $\begin{array}{l}\text { Núm. } \\
\text { Aves }\end{array}$ & $\begin{array}{c}\text { Peso vivo } \\
\text { (kg) }\end{array}$ & $\begin{array}{c}\text { Peso médio } \\
(\mathbf{k g}) \\
\end{array}$ \\
\hline \multirow{3}{*}{ CONTR } & & 1 & 40 & 1,680 & 0,042 \\
\hline & fêmea & 2 & 40 & 1,650 & 0,041 \\
\hline & & 3 & 40 & 1,680 & 0,042 \\
\hline \multirow[t]{2}{*}{ Média } & & & & 1,670 & 0,042 \\
\hline & & 1 & 40 & 1,660 & 0,042 \\
\hline \multirow[t]{2}{*}{ CONTR } & macho & 2 & 40 & 1,680 & 0,042 \\
\hline & & 3 & 40 & 1,690 & 0,042 \\
\hline \multirow[t]{2}{*}{ Média } & & & & 1,677 & 0,042 \\
\hline & & 1 & 40 & 1,670 & 0,042 \\
\hline \multirow[t]{2}{*}{ CITR 50} & fêmea & 2 & 40 & 1,680 & 0,042 \\
\hline & & 3 & 40 & 1,650 & 0,041 \\
\hline \multirow[t]{2}{*}{ Média } & & & & 1,667 & 0,042 \\
\hline & & 1 & 40 & 1,680 & 0,042 \\
\hline \multirow[t]{2}{*}{ CITR. 50} & macho & 2 & 40 & 1,690 & 0,042 \\
\hline & & 3 & 40 & 1,680 & 0,042 \\
\hline \multirow[t]{2}{*}{ Média } & & & & 1,683 & 0,042 \\
\hline & & 1 & 40 & 1,670 & 0,042 \\
\hline \multirow[t]{2}{*}{ CITR 100} & fêmea & 2 & 40 & 1,680 & 0,042 \\
\hline & & 3 & 40 & 1,610 & 0,04 \\
\hline \multirow[t]{2}{*}{ Média } & & & & 1,653 & 0,041 \\
\hline & & 1 & 40 & 1,690 & 0,042 \\
\hline \multirow[t]{2}{*}{ CITR 100} & macho & 2 & 40 & 1,630 & 0,041 \\
\hline & & 3 & 40 & 1,690 & 0,042 \\
\hline \multirow[t]{2}{*}{ Média } & & & & 1,670 & 0,042 \\
\hline & & 1 & 40 & 1,690 & 0,042 \\
\hline \multirow[t]{2}{*}{ CITR. 150} & fêmea & 2 & 40 & 1,670 & 0,042 \\
\hline & & 3 & 40 & 1,660 & 0,042 \\
\hline \multirow[t]{2}{*}{ Média } & & & & 1,673 & 0,042 \\
\hline & & 1 & 40 & 1,650 & 0,041 \\
\hline \multirow[t]{2}{*}{ CITR 150} & macho & 2 & 40 & 1,680 & 0,042 \\
\hline & & 3 & 40 & 1,640 & 0,041 \\
\hline \multirow[t]{2}{*}{ Média } & & & & 1,657 & 0,041 \\
\hline & & 1 & 40 & 1,690 & 0,042 \\
\hline \multirow[t]{2}{*}{ SULF. 200} & fêmea & 2 & 40 & 1,670 & 0,042 \\
\hline & & 3 & 40 & 1,640 & 0,041 \\
\hline \multirow[t]{2}{*}{ Média } & & & & 1,667 & 0,042 \\
\hline & & 1 & 40 & 1,670 & 0,042 \\
\hline \multirow[t]{2}{*}{ SULF. 200} & macho & 2 & 40 & 1,640 & 0,041 \\
\hline & & 3 & 40 & 1,660 & 0,042 \\
\hline Média & & & & 1,657 & 0,042 \\
\hline
\end{tabular}


Apêndice 4: Resultados de peso vivo total e médio obtidos no $7^{0}$ dia do período experimental, ganho médio de peso (GMP), consumo médio de ração (CMR), conversão alimentar $(\mathrm{CA})$ e mortalidade + refugagem $(\mathrm{M}+\mathrm{R})$ na $1^{\mathrm{a}}$ semana.

\begin{tabular}{|c|c|c|c|c|c|c|c|c|c|}
\hline Tratamento & Sexo & Blocos & $\begin{array}{l}\text { Núm. } \\
\text { aves }\end{array}$ & $\begin{array}{l}\text { Peso vivo } \\
\text { (kg) }\end{array}$ & $\begin{array}{l}\text { Peso médio } \\
\text { (kg) }\end{array}$ & $\begin{array}{c}\text { GMP } \\
\text { (kg) }\end{array}$ & $\begin{array}{c}\text { CMR } \\
\text { (kg) }\end{array}$ & CA & $\begin{array}{c}\text { Mort } \\
+ \\
\text { refug. }\end{array}$ \\
\hline & & 1 & 40 & 6,660 & 0,167 & 0,125 & 0,157 & 1,256 & 0 \\
\hline \multirow[t]{2}{*}{ CONTR } & fêmea & 2 & 40 & 6,770 & 0,169 & 0,128 & 0,170 & 1,328 & 0 \\
\hline & & 3 & 40 & 6,880 & 0,172 & 0,130 & 0,165 & 1,269 & 0 \\
\hline \multirow[t]{2}{*}{ Média } & & & & 6,770 & 0,169 & 0,128 & 0,164 & 1,284 & 0 \\
\hline & & 1 & 40 & 6,860 & 0,172 & 0,130 & 0,178 & 1,369 & 0 \\
\hline \multirow[t]{2}{*}{ CONTR } & macho & 2 & 40 & 7,110 & 0,178 & 0,136 & 0,178 & 1,309 & 0 \\
\hline & & 3 & 40 & 7,160 & 0,179 & 0,137 & 0,173 & 1,263 & 0 \\
\hline \multirow[t]{2}{*}{ Média } & & & & 7,043 & 0,176 & 0,134 & 0,176 & 1,314 & 0 \\
\hline & & 1 & 40 & 6,870 & 0,172 & 0,130 & 0,174 & 1,338 & 0 \\
\hline \multirow[t]{2}{*}{ CITR. 50} & fêmea & 2 & 40 & 6,970 & 0,174 & 0,132 & 0,171 & 1,295 & 0 \\
\hline & & 3 & 40 & 6,810 & 0,170 & 0,129 & 0,165 & 1,279 & 0 \\
\hline \multirow[t]{2}{*}{ Média } & & & & 6,883 & 0,172 & 0,130 & 0,170 & 1,304 & 0 \\
\hline & & 1 & 40 & 7,240 & 0,181 & 0,139 & 0,175 & 1,259 & 0 \\
\hline \multirow[t]{2}{*}{ CITR. 50} & macho & 2 & 40 & 7,120 & 0,178 & 0,136 & 0,175 & 1,287 & 0 \\
\hline & & 3 & 40 & 7,240 & 0,181 & 0,139 & 0,172 & 1,237 & 0 \\
\hline \multirow[t]{2}{*}{ Média } & & & & 7,200 & 0,180 & 0,138 & 0,174 & 1,261 & 0 \\
\hline & & 1 & 40 & 6,690 & 0,167 & 0,126 & 0,165 & 1,310 & 0 \\
\hline \multirow{2}{*}{ CITR. 100} & fêmea & 2 & 40 & 6,890 & 0,172 & 0,130 & 0,169 & 1,300 & 0 \\
\hline & & 3 & 40 & 6,670 & 0,167 & 0,127 & 0,160 & 1,260 & 0 \\
\hline \multirow{2}{*}{ Média } & & & & 6,750 & 0,169 & 0,128 & 0,165 & 1,290 & 0 \\
\hline & & 1 & 40 & 6,930 & 0,173 & 0,131 & 0,176 & 1,344 & 0 \\
\hline \multirow[t]{2}{*}{ CITR 100} & macho & 2 & 40 & 6,940 & 0,174 & 0,133 & 0,178 & 1,338 & 0 \\
\hline & & 3 & 40 & 7,190 & 0,180 & 0,138 & 0,174 & 1,261 & 0 \\
\hline \multirow[t]{2}{*}{ Média } & & & & 7,020 & 0,176 & 0,134 & 0,176 & 1,314 & 0 \\
\hline & & 1 & 40 & 6,730 & 0,168 & 0,126 & 0,165 & 1,310 & 0 \\
\hline \multirow[t]{2}{*}{ CITR 150} & fêmea & 2 & 40 & 6,760 & 0,169 & 0,127 & 0,169 & 1,331 & 0 \\
\hline & & 3 & 40 & 6,880 & 0,172 & 0,131 & 0,164 & 1,252 & 0 \\
\hline \multirow[t]{2}{*}{ Média } & & & & 6,790 & 0,170 & 0,128 & 0,166 & 1,297 & 0 \\
\hline & & 1 & 40 & 7,060 & 0,177 & 0,135 & 0,176 & 1,304 & 0 \\
\hline \multirow[t]{2}{*}{ CITR. 150} & macho & 2 & 40 & 7,420 & 0,186 & 0,144 & 0,179 & 1,243 & 0 \\
\hline & & 3 & 40 & 7,190 & 0,180 & 0,139 & 0,181 & 1,302 & 0 \\
\hline \multirow[t]{2}{*}{ Média } & & & & 7,223 & 0,181 & 0,139 & 0,179 & 1,283 & 0 \\
\hline & & 1 & 40 & 6,790 & 0,170 & 0,128 & 0,176 & 1,375 & 0 \\
\hline \multirow[t]{2}{*}{ SULF. 200} & fêmea & 2 & 40 & 6,710 & 0,168 & 0,126 & 0,169 & 1,341 & 0 \\
\hline & & 3 & 40 & 6,830 & 0,171 & 0,130 & 0,168 & 1,292 & 0 \\
\hline \multirow[t]{2}{*}{ Média } & & & & 6,777 & 0,170 & 0,128 & 0,171 & 1,336 & 0 \\
\hline & & 1 & 40 & 7,160 & 0,179 & 0,137 & 0,172 & 1,255 & 0 \\
\hline \multirow{2}{*}{ SULF. 200} & macho & 2 & 40 & 7,080 & 0,177 & 0,136 & 0,184 & 1,353 & 0 \\
\hline & & 3 & 40 & 7,070 & 0,177 & 0,135 & 0,177 & 1,311 & 0 \\
\hline Média & & & & 7,103 & 0,178 & 0,136 & 0,178 & 1,307 & 0 \\
\hline
\end{tabular}


Apên dice 5: Resultados de peso vivo total e médio obtidos no $14^{0}$ dia do período experimental, ganho médio de peso (GMP), consumo médio de ração (CMR), conversão alimentar $(\mathrm{CA})$ e mortalidade + refugagem $(\mathrm{M}+\mathrm{R})$ na $2^{\mathrm{a}}$ semana.

\begin{tabular}{|c|c|c|c|c|c|c|c|c|c|}
\hline Tratamento & Sexo & Blocos & $\begin{array}{l}\text { Núm. } \\
\text { aves }\end{array}$ & $\begin{array}{l}\text { Peso vivo } \\
\text { (kg) }\end{array}$ & $\begin{array}{l}\text { Peso médio } \\
\text { (kg) }\end{array}$ & $\begin{array}{c}\text { GMP } \\
\text { (kg) }\end{array}$ & $\begin{array}{c}\text { CMR } \\
\text { (kg) }\end{array}$ & CA & $\begin{array}{c}\text { Mort } \\
+ \\
\text { refug }\end{array}$ \\
\hline & & 1 & 40 & 16,500 & 0,413 & 0,246 & 0,360 & 1,463 & 0 \\
\hline \multirow[t]{2}{*}{ CONTR. } & fềmea & 2 & 40 & 16,900 & 0,423 & 0,253 & 0,376 & 1,486 & 0 \\
\hline & & 3 & 40 & 16,800 & 0,420 & 0,248 & 0,391 & 1,577 & 0 \\
\hline \multirow[t]{2}{*}{ Média } & & & & 16,733 & 0,418 & 0,249 & 0,376 & 1,509 & 0 \\
\hline & & 1 & 40 & 17,800 & 0,445 & 0,274 & 0,402 & 1,467 & 0 \\
\hline \multirow[t]{2}{*}{ CONTR. } & macho & 2 & 40 & 18,500 & 0,463 & 0,285 & 0,404 & 1,418 & 0 \\
\hline & & 3 & 40 & 18,600 & 0,465 & 0,286 & 0,411 & 1,437 & 0 \\
\hline \multirow[t]{2}{*}{ Média } & & & & 18,300 & 0,458 & 0,282 & 0,406 & 1,441 & 0 \\
\hline & & 1 & 39 & 16,600 & 0,426 & 0,254 & 0,383 & 1,508 & 1 \\
\hline \multirow[t]{2}{*}{ CITR. 50} & fềmea & 2 & 38 & 15,900 & 0,418 & 0,244 & 0,380 & 1,557 & 2 \\
\hline & & 3 & 40 & 16,900 & 0,423 & 0,252 & 0,377 & 1,496 & 0 \\
\hline \multirow[t]{2}{*}{ Média } & & & & 16,467 & 0,422 & 0,250 & 0,380 & 1,520 & 1,0 \\
\hline & & 1 & 40 & 18,200 & 0,455 & 0,274 & 0,393 & 1,434 & 0 \\
\hline \multirow[t]{2}{*}{ CITR. 50} & macho & 2 & 40 & 18,400 & 0,460 & 0,282 & 0,399 & 1,415 & 0 \\
\hline & & 3 & 40 & 18,700 & 0,468 & 0,287 & 0,410 & 1,429 & 0 \\
\hline \multirow[t]{2}{*}{ Média } & & & & 18,433 & 0,461 & 0,281 & 0,401 & 1,426 & 0 \\
\hline & & 1 & 40 & 16,500 & 0,413 & 0,245 & 0,372 & 1,518 & 0 \\
\hline \multirow[t]{2}{*}{ CITR. 100} & fềmea & 2 & 40 & 17,000 & 0,425 & 0,253 & 0,377 & 1,490 & 0 \\
\hline & & 3 & 40 & 17,400 & 0,435 & 0,268 & 0,394 & 1,470 & 0 \\
\hline \multirow[t]{2}{*}{ Média } & & & & 16,967 & 0,424 & 0,255 & 0,381 & 1,493 & 0 \\
\hline & & 1 & 40 & 18,000 & 0,450 & 0,277 & 0,401 & 1,448 & 0 \\
\hline \multirow[t]{2}{*}{ CITR. 100} & macho & 2 & 40 & 18,000 & 0,450 & 0,277 & 0,396 & 1,430 & 0 \\
\hline & & 3 & 40 & 18,700 & 0,468 & 0,288 & 0,410 & 1,424 & 0 \\
\hline \multirow[t]{2}{*}{ Média } & & & & 18,233 & 0,456 & 0,281 & 0,402 & 1,434 & 0 \\
\hline & & 1 & 40 & 16,500 & 0,413 & 0,244 & 0,375 & 1,537 & 0 \\
\hline \multirow[t]{2}{*}{ CITR 150} & fềmea & 2 & 39 & 16,270 & 0,417 & 0,248 & 0,391 & 1,577 & 1 \\
\hline & & 3 & 40 & 17,030 & 0,426 & 0,254 & 0,358 & 1,409 & 0 \\
\hline \multirow[t]{2}{*}{ Média } & & & & 16,600 & 0,418 & 0,249 & 0,375 & 1,508 & 0,33 \\
\hline & & 1 & 40 & 17,800 & 0,445 & 0,269 & 0,393 & 1,461 & 0 \\
\hline \multirow[t]{2}{*}{ CITR. 150} & macho & 2 & 38 & 17,900 & 0,471 & 0,286 & 0,406 & 1,420 & 2 \\
\hline & & 3 & 40 & 18,400 & 0,460 & 0,280 & 0,400 & 1,429 & 0 \\
\hline \multirow[t]{2}{*}{ Média } & & & & 18,033 & 0,459 & 0,278 & 0,400 & 1,436 & 0,66 \\
\hline & & 1 & 40 & 17,100 & 0,428 & 0,258 & 0,373 & 1,446 & 0 \\
\hline \multirow[t]{2}{*}{ SULF. 200} & fềmea & 2 & 40 & 16,800 & 0,420 & 0,252 & 0,392 & 1,556 & 0 \\
\hline & & 3 & 40 & 17,100 & 0,428 & 0,257 & 0,384 & 1,494 & 0 \\
\hline \multirow[t]{2}{*}{ Média } & & & & 17,000 & 0,425 & 0,256 & 0,383 & 1,498 & 0 \\
\hline & & 1 & 40 & 18,100 & 0,453 & 0,274 & 0,399 & 1,456 & 0 \\
\hline \multirow[t]{2}{*}{ SULF. 200} & macho & 2 & 40 & 18,400 & 0,460 & 0,283 & 0,432 & 1,527 & 0 \\
\hline & & 3 & 39 & 17,800 & 0,456 & 0,280 & 0,414 & 1,479 & 1 \\
\hline Média & & & & 18,100 & 0,456 & 0,279 & 0,415 & 1,487 & 0,33 \\
\hline
\end{tabular}


Apêndice 6: Resultados de peso vivo total e médio obtidos no $21^{0}$ dia do período experimental, ganho médio de peso (GMP), consumo médio de ração (CMR), conversão alimentar $(\mathrm{CA})$ e mortalidade + refugagem $(\mathrm{M}+\mathrm{R})$ na $3^{\mathrm{a}}$ semana.

\begin{tabular}{|c|c|c|c|c|c|c|c|c|c|}
\hline Tratamento & Sexo & Blocos & $\begin{array}{l}\text { Núm. } \\
\text { aves }\end{array}$ & $\begin{array}{l}\text { Peso vivo } \\
\text { (kg) }\end{array}$ & $\begin{array}{c}\text { Peso médio } \\
\text { (kg) }\end{array}$ & $\begin{array}{c}\text { GMP } \\
(\mathrm{kg})\end{array}$ & $\begin{array}{c}\text { CMR } \\
(\mathbf{k g})\end{array}$ & CA & $\begin{array}{c}\text { Mort. } \\
+ \\
\text { refug }\end{array}$ \\
\hline \multirow{3}{*}{ CONTR. } & & 1 & 40 & 30,000 & 0,750 & 0,338 & 0,586 & 1,734 & 0 \\
\hline & fềmea & 2 & 39 & 30,400 & 0,779 & 0,357 & 0,587 & 1,644 & 1 \\
\hline & & 3 & 40 & 30,300 & 0,758 & 0,338 & 0,572 & 1,692 & 0 \\
\hline \multirow[t]{2}{*}{ Média } & & & & 30,233 & 0,762 & 0,344 & 0,582 & 1,690 & 0,33 \\
\hline & & 1 & 39 & 33,100 & 0,849 & 0,404 & 0,646 & 1,599 & 1 \\
\hline \multirow[t]{2}{*}{ CONTR. } & macho & 2 & 40 & 35,200 & 0,880 & 0,418 & 0,657 & 1,572 & 0 \\
\hline & & 3 & 39 & 33,900 & 0,869 & 0,404 & 0,662 & 1,639 & 1 \\
\hline \multirow[t]{2}{*}{ Média } & & & & 34,067 & 0,866 & 0,409 & 0,655 & 1,603 & 0,66 \\
\hline & & 1 & 39 & 29,900 & 0,767 & 0,341 & 0,589 & 1,727 & 0 \\
\hline \multirow[t]{2}{*}{ CITR. 50} & fềmea & 2 & 37 & 27,800 & 0,751 & 0,333 & 0,573 & 1,721 & 1 \\
\hline & & 3 & 40 & 30,000 & 0,750 & 0,328 & 0,561 & 1,710 & 0 \\
\hline \multirow[t]{2}{*}{ Média } & & & & 29,233 & 0,756 & 0,334 & 0,574 & 1,719 & 0,33 \\
\hline & & 1 & 40 & 34,200 & 0,855 & 0,400 & 0,631 & 1,578 & 0 \\
\hline \multirow[t]{2}{*}{ CITR. 50} & macho & 2 & 40 & 34,600 & 0,865 & 0,405 & 0,655 & 1,617 & 0 \\
\hline & & 3 & 40 & 34,700 & 0,868 & 0,400 & 0,665 & 1,663 & 0 \\
\hline \multirow[t]{2}{*}{ Média } & & & & 34,500 & 0,863 & 0,402 & 0,650 & 1,619 & 0 \\
\hline & & 1 & 40 & 29,500 & 0,738 & 0,325 & 0,579 & 1,782 & 0 \\
\hline \multirow[t]{2}{*}{ CITR. 100} & fềmea & 2 & 39 & 29,900 & 0,767 & 0,342 & 0,618 & 1,807 & 1 \\
\hline & & 3 & 39 & 29,500 & 0,756 & 0,321 & 0,624 & 1,944 & 1 \\
\hline \multirow[t]{2}{*}{ Média } & & & & 29,633 & 0,754 & 0,329 & 0,607 & 1,814 & 0,66 \\
\hline & & 1 & 40 & 33,700 & 0,843 & 0,393 & 0,624 & 1,588 & 0 \\
\hline \multirow[t]{2}{*}{ CITR. 100} & macho & 2 & 40 & 33,300 & 0,833 & 0,383 & 0,646 & 1,687 & 0 \\
\hline & & 3 & 40 & 34,900 & 0,873 & 0,405 & 0,654 & 1,615 & 0 \\
\hline \multirow[t]{2}{*}{ Média } & & & & 33,967 & 0,849 & 0,394 & 0,641 & 1,630 & 0 \\
\hline & & 1 & 40 & 30,000 & 0,750 & 0,338 & 0,564 & 1,669 & 0 \\
\hline \multirow[t]{2}{*}{ CITR. 150} & fềmea & 2 & 39 & 30,000 & 0,769 & 0,352 & 0,594 & 1,688 & 0 \\
\hline & & 3 & 40 & 30,100 & 0,753 & 0,327 & 0,564 & 1,725 & 0 \\
\hline \multirow[t]{2}{*}{ Média } & & & & 30,033 & 0,757 & 0,339 & 0,574 & 1,694 & 0 \\
\hline & & 1 & 40 & 33,300 & 0,833 & 0,388 & 0,647 & 1,668 & 0 \\
\hline \multirow[t]{2}{*}{ CITR. 150} & macho & 2 & 38 & 33,100 & 0,871 & 0,400 & 0,682 & 1,705 & 0 \\
\hline & & 3 & 38 & 32,400 & 0,853 & 0,393 & 0,653 & 1,662 & 2 \\
\hline \multirow[t]{2}{*}{ Média } & & & & 32,933 & 0,852 & 0,394 & 0,661 & 1,678 & 0,66 \\
\hline & & 1 & 40 & 30,800 & 0,770 & 0,343 & 0,552 & 1,609 & 0 \\
\hline \multirow[t]{2}{*}{ SULF. 200} & fềmea & 2 & 40 & 30,300 & 0,758 & 0,338 & 0,569 & 1,683 & 0 \\
\hline & & 3 & 40 & 31,100 & 0,778 & 0,350 & 0,581 & 1,660 & 0 \\
\hline \multirow[t]{2}{*}{ Média } & & & & 30,733 & 0,768 & 0,344 & 0,567 & 1,651 & 0 \\
\hline & & 1 & 39 & 34,000 & 0,872 & 0,419 & 0,645 & 1,539 & 1 \\
\hline \multirow[t]{2}{*}{ SULF. 200} & macho & 2 & 39 & 33,300 & 0,854 & 0,394 & 0,665 & 1,688 & 1 \\
\hline & & 3 & 39 & 34,000 & 0,872 & 0,415 & 0,678 & 1,634 & 0 \\
\hline Média & & & & 33,767 & 0,866 & 0,409 & 0,663 & 1,620 & 0,66 \\
\hline
\end{tabular}


Apêndice 7: Resultados de peso vivo total e médio obtidos no $28^{0}$ dia do período experimental, ganho médio de peso (GMP), consumo médio de ração (CMR), conversão alimentar (CA) e mortalidade + refugagem $(M+R)$ na $4^{\text {a }}$ semana.

\begin{tabular}{|c|c|c|c|c|c|c|c|c|c|}
\hline Tratamento & Sexo & Blocos & $\begin{array}{l}\text { Núm. } \\
\text { aves }\end{array}$ & $\begin{array}{l}\text { Peso vivo } \\
\text { (kg) }\end{array}$ & $\begin{array}{l}\text { Peso médio } \\
\text { (kg) }\end{array}$ & $\begin{array}{c}\text { GMP } \\
\text { (kg) }\end{array}$ & $\begin{array}{c}\text { CMR } \\
\text { (kg) }\end{array}$ & CA & $\begin{array}{c}\text { Mort. } \\
+ \\
\text { refug. }\end{array}$ \\
\hline \multirow{3}{*}{ CONTR } & \multirow{3}{*}{ fêmea } & 1 & 40 & 48,100 & 1,203 & 0,453 & 0,808 & 1,784 & 0 \\
\hline & & 2 & 39 & 49,300 & 1,264 & 0,485 & 0,854 & 1,761 & 0 \\
\hline & & 3 & 39 & 47,430 & 1,216 & 0,459 & 0,801 & 1,745 & 1 \\
\hline Média & & & & 48,277 & 1,228 & 0,466 & 0,821 & 1,763 & 0,33 \\
\hline \multirow{3}{*}{ CONTR } & \multirow{3}{*}{$\begin{array}{c}\text { mach } \\
\quad 0\end{array}$} & 1 & 39 & 55,200 & 1,415 & 0,567 & 0,950 & 1,675 & 0 \\
\hline & & 2 & 39 & 57,200 & 1,467 & 0,587 & 0,983 & 1,675 & 1 \\
\hline & & 3 & 39 & 56,200 & 1,441 & 0,572 & 0,988 & 1,727 & 0 \\
\hline \multirow[t]{2}{*}{ Média } & & & & 56,200 & 1,441 & 0,575 & 0,974 & 1,692 & 0,33 \\
\hline & & 1 & 39 & 47,800 & 1,226 & 0,459 & 0,793 & 1,728 & 0 \\
\hline \multirow[t]{2}{*}{ CITR 50} & fêmea & 2 & 37 & 44,600 & 1,205 & 0,454 & 0,816 & 1,797 & 0 \\
\hline & & 3 & 39 & 47,000 & 1,205 & 0,455 & 0,804 & 1,767 & 1 \\
\hline \multirow[t]{2}{*}{ Média } & & & & 46,467 & 1,212 & 0,456 & 0,804 & 1,764 & 0,33 \\
\hline & & 1 & 40 & 56,900 & 1,423 & 0,568 & 0,944 & 1,662 & 0 \\
\hline \multirow[t]{2}{*}{ CITR 50} & mach & 2 & 40 & 57,200 & 1,430 & 0,565 & 0,980 & 1,735 & 0 \\
\hline & & 3 & 40 & 57,400 & 1,435 & 0,568 & 0,961 & 1,692 & 0 \\
\hline \multirow[t]{2}{*}{ Média } & & & & 57,167 & 1,429 & 0,567 & 0,962 & 1,696 & 0 \\
\hline & & 1 & 40 & 47,000 & 1,175 & 0,438 & 0,775 & 1,769 & 0 \\
\hline \multirow[t]{2}{*}{ CITR 100} & fềmea & 2 & 38 & 47,000 & 1,237 & 0,470 & 0,843 & 1,794 & 1 \\
\hline & & 3 & 39 & 47,200 & 1,210 & 0,454 & 0,813 & 1,791 & 0 \\
\hline \multirow[t]{2}{*}{ Média } & & & & 47,067 & 1,207 & 0,454 & 0,810 & 1,785 & 0,33 \\
\hline & & 1 & 40 & 55,400 & 1,385 & 0,543 & 0,933 & 1,718 & 0 \\
\hline \multirow[t]{2}{*}{ CITR 100} & $\operatorname{mach}$ & 2 & 38 & 53,600 & 1,411 & 0,578 & 0,957 & 1,656 & 2 \\
\hline & & 3 & 40 & 58,200 & 1,455 & 0,583 & 1,024 & 1,756 & 0 \\
\hline \multirow[t]{2}{*}{ Média } & & & & 55,733 & 1,417 & 0,568 & 0,971 & 1,710 & 0,66 \\
\hline & & 1 & 40 & 47,800 & 1,195 & 0,445 & 0,790 & 1,775 & 0 \\
\hline \multirow[t]{2}{*}{ CITR 150} & fêmea & 2 & 39 & 48,700 & 1,249 & 0,479 & 0,836 & 1,745 & 0 \\
\hline & & 3 & 39 & 47,500 & 1,218 & 0,465 & 0,802 & 1,725 & 1 \\
\hline \multirow[t]{2}{*}{ Média } & & & & 48,000 & 1,221 & 0,463 & 0,809 & 1,748 & 0,33 \\
\hline & & 1 & 40 & 54,900 & 1,373 & 0,540 & 0,958 & 1,774 & 0 \\
\hline \multirow[t]{2}{*}{ CITR. 150} & 0 & 2 & 38 & 54,200 & 1,426 & 0,555 & 0,991 & 1,786 & 0 \\
\hline & & 3 & 38 & 54,100 & 1,424 & 0,571 & 0,956 & 1,674 & 0 \\
\hline \multirow[t]{2}{*}{ Média } & & & & 54,400 & 1,408 & 0,555 & 0,968 & 1,745 & 0 \\
\hline & & 1 & 39 & 47,900 & 1,228 & 0,451 & 0,799 & 1,772 & 1 \\
\hline \multirow[t]{2}{*}{ SULF. 200} & fềmea & 2 & 40 & 47,800 & 1,195 & 0,425 & 0,780 & 1,835 & 0 \\
\hline & & 3 & 40 & 49,000 & 1,225 & 0,468 & 0,808 & 1,726 & 0 \\
\hline \multirow[t]{2}{*}{ Média } & & & & 48,233 & 1,216 & 0,448 & 0,796 & 1,778 & 0,33 \\
\hline & & 1 & 39 & 56,400 & 1,446 & 0,574 & 0,978 & 1,704 & 0 \\
\hline \multirow[t]{2}{*}{ SULF. 200} & mach & 2 & 39 & 55,800 & 1,431 & 0,559 & 0,946 & 1,692 & 0 \\
\hline & & 3 & 39 & 55,800 & 1,431 & 0,577 & 0,997 & 1,728 & 0 \\
\hline Média & & & & 56,000 & 1,436 & 0,570 & 0,974 & 1,708 & 0 \\
\hline
\end{tabular}


Apêndice 8: Resultados de peso vivo total e médio obtidos no $35^{\circ}$ dia do período experimental, ganho médio de peso (GMP), consumo médio de ração (CMR), conversão alimentar $(\mathrm{CA})$ e mortalidade + refugagem $(\mathrm{M}+\mathrm{R})$ na $5^{\mathrm{a}}$ semana.

\begin{tabular}{|c|c|c|c|c|c|c|c|c|c|}
\hline Tratamento & Sexo & Blocos & $\begin{array}{l}\text { Núm. } \\
\text { aves }\end{array}$ & $\begin{array}{l}\text { Peso vivo } \\
\text { (kg) }\end{array}$ & $\begin{array}{l}\text { Peso médio } \\
\text { (kg) }\end{array}$ & $\begin{array}{c}\text { GMP } \\
\text { (kg) }\end{array}$ & $\begin{array}{c}\text { CMR } \\
\text { (kg) }\end{array}$ & CA & $\begin{array}{c}\text { Mort. } \\
+ \\
\text { refug. }\end{array}$ \\
\hline & & 1 & 40 & 64,700 & 1,618 & 0,415 & 0,918 & 2,212 & 0 \\
\hline \multirow[t]{2}{*}{ CONTR. } & fềmea & 2 & 39 & 65,700 & 1,685 & 0,421 & 0,946 & 2,247 & 0 \\
\hline & & 3 & 38 & 62,100 & 1,634 & 0,418 & 0,926 & 2,215 & 1 \\
\hline \multirow[t]{2}{*}{ Média } & & & & 64,167 & 1,645 & 0,418 & 0,930 & 2,225 & 0,33 \\
\hline & & 1 & 39 & 75,500 & 1,936 & 0,521 & 1,131 & 2,171 & 0 \\
\hline \multirow[t]{2}{*}{ CONTR } & macho & 2 & 39 & 78,500 & 2,013 & 0,546 & 1,149 & 2,104 & 0 \\
\hline & & 3 & 38 & 74,700 & 1,966 & 0,525 & 1,110 & 2,114 & 1 \\
\hline \multirow[t]{2}{*}{ Média } & & & & 76,233 & 1,972 & 0,531 & 1,130 & 2,130 & 0,33 \\
\hline & & 1 & 39 & 63,900 & 1,638 & 0,413 & 0,921 & 2,230 & 0 \\
\hline \multirow[t]{2}{*}{ CITR. 50} & fềmea & 2 & 36 & 58,200 & 1,617 & 0,411 & 0,906 & 2,204 & 1 \\
\hline & & 3 & 39 & 62,700 & 1,608 & 0,403 & 0,895 & 2,221 & 0 \\
\hline \multirow[t]{2}{*}{ Média } & & & & 61,600 & 1,621 & 0,409 & 0,907 & 2,218 & 0,33 \\
\hline & & 1 & 40 & 76,800 & 1,920 & 0,498 & 1,095 & 2,199 & 0 \\
\hline \multirow[t]{2}{*}{ CITR. 50} & macho & 2 & 40 & 77,900 & 1,948 & 0,518 & 1,125 & 2,172 & 0 \\
\hline & & 3 & 40 & 78,000 & 1,950 & 0,515 & 1,115 & 2,165 & 0 \\
\hline \multirow[t]{2}{*}{ Média } & & & & 77,567 & 1,939 & 0,510 & 1,112 & 2,179 & 0 \\
\hline & & 1 & 40 & 62,900 & 1,573 & 0,398 & 0,875 & 2,198 & 0 \\
\hline \multirow[t]{2}{*}{ CITR 100} & fêmea & 2 & 38 & 63,900 & 1,682 & 0,445 & 0,958 & 2,153 & 0 \\
\hline & & 3 & 39 & 63,100 & 1,618 & 0,408 & 0,918 & 2,250 & 0 \\
\hline \multirow[t]{2}{*}{ Média } & & & & 63,300 & 1,624 & 0,417 & 0,917 & 2,200 & 0 \\
\hline & & 1 & 39 & 75,500 & 1,936 & 0,551 & 1,110 & 2,015 & 1 \\
\hline \multirow[t]{2}{*}{ CITR 100} & macho & 2 & 38 & 74,100 & 1,950 & 0,539 & 1,126 & 2,089 & 0 \\
\hline & & 3 & 40 & 79,800 & 1,995 & 0,540 & 1,135 & 2,102 & 0 \\
\hline \multirow[t]{2}{*}{ Média } & & & & 76,467 & 1,960 & 0,543 & 1,124 & 2,068 & 0,33 \\
\hline & & 1 & 39 & 63,100 & 1,618 & 0,423 & 0,900 & 2,128 & 1 \\
\hline \multirow[t]{2}{*}{ CITR 150} & fêmea & 2 & 39 & 65,800 & 1,687 & 0,438 & 0,933 & 2,130 & 0 \\
\hline & & 3 & 39 & 63,800 & 1,636 & 0,418 & 0,923 & 2,208 & 0 \\
\hline \multirow[t]{2}{*}{ Média } & & & & 64,233 & 1,647 & 0,426 & 0,919 & 2,155 & 0,33 \\
\hline & & 1 & 40 & 75,700 & 1,893 & 0,520 & 1,085 & 2,087 & 0 \\
\hline \multirow[t]{2}{*}{ CITR. 150} & macho & 2 & 37 & 72,700 & 1,965 & 0,539 & 1,116 & 2,071 & 1 \\
\hline & & 3 & 37 & 73,900 & 1,997 & 0,574 & 1,170 & 2,038 & 1 \\
\hline \multirow[t]{2}{*}{ Média } & & & & 74,100 & 1,952 & 0,544 & 1,124 & 2,065 & 0,66 \\
\hline & & 1 & 39 & 63,900 & 1,638 & 0,410 & 0,903 & 2,202 & 0 \\
\hline \multirow[t]{2}{*}{ SULF. 200} & fêmea & 2 & 39 & 63,000 & 1,615 & 0,420 & 0,895 & 2,131 & 1 \\
\hline & & 3 & 40 & 64,600 & 1,615 & 0,390 & 0,888 & 2,277 & 0 \\
\hline \multirow[t]{2}{*}{ Média } & & & & 63,833 & 1,623 & 0,407 & 0,895 & 2,203 & 0,33 \\
\hline & & 1 & 39 & 77,100 & 1,977 & 0,531 & 1,162 & 2,188 & 0 \\
\hline \multirow[t]{2}{*}{ SULF. 200} & macho & 2 & 38 & 75,600 & 1,989 & 0,559 & 1,134 & 2,029 & 1 \\
\hline & & 3 & 39 & 75,100 & 1,926 & 0,495 & 1,103 & 2,228 & 0 \\
\hline Média & & & & 75,933 & 1,964 & 0,528 & 1,133 & 2,148 & 0,33 \\
\hline
\end{tabular}




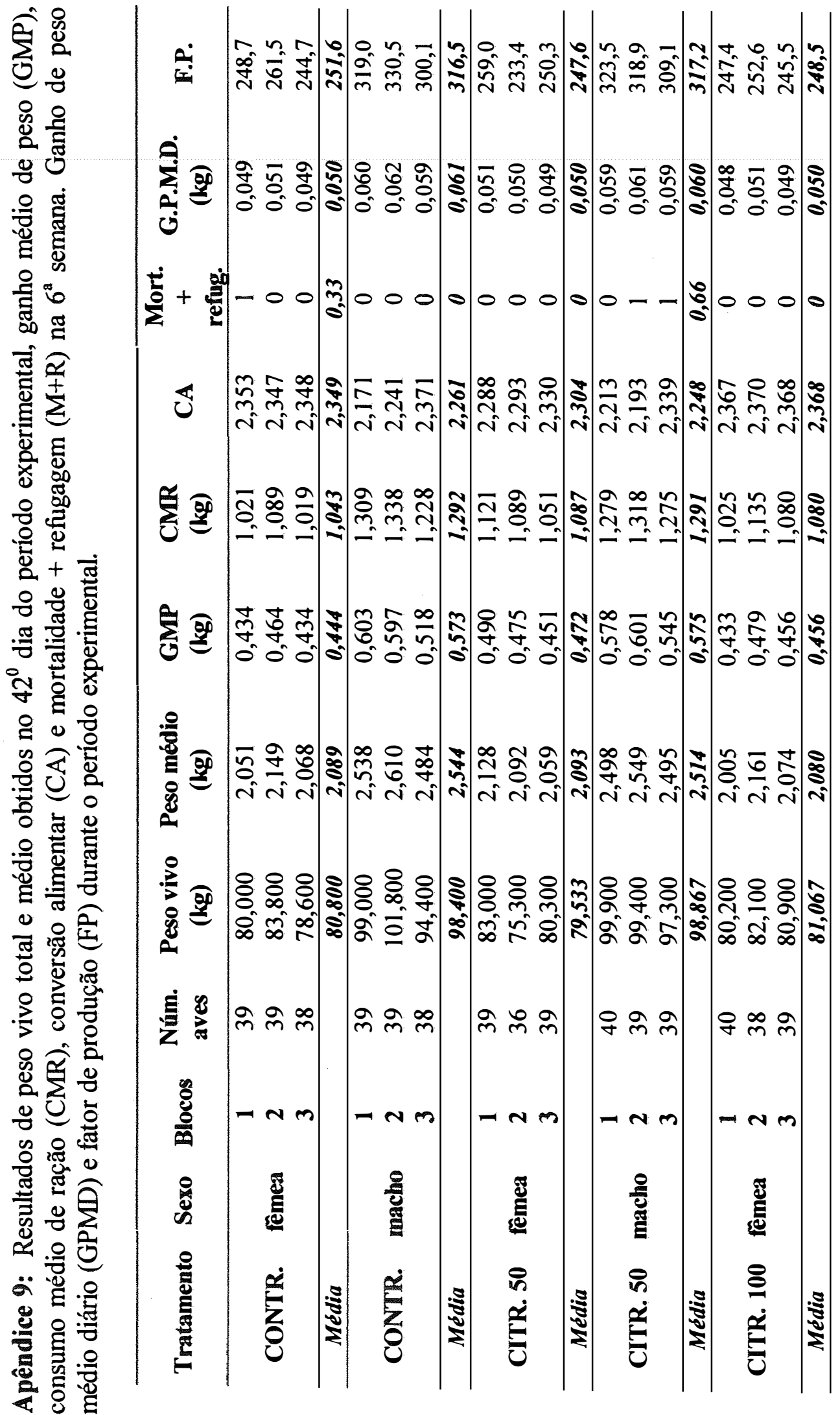




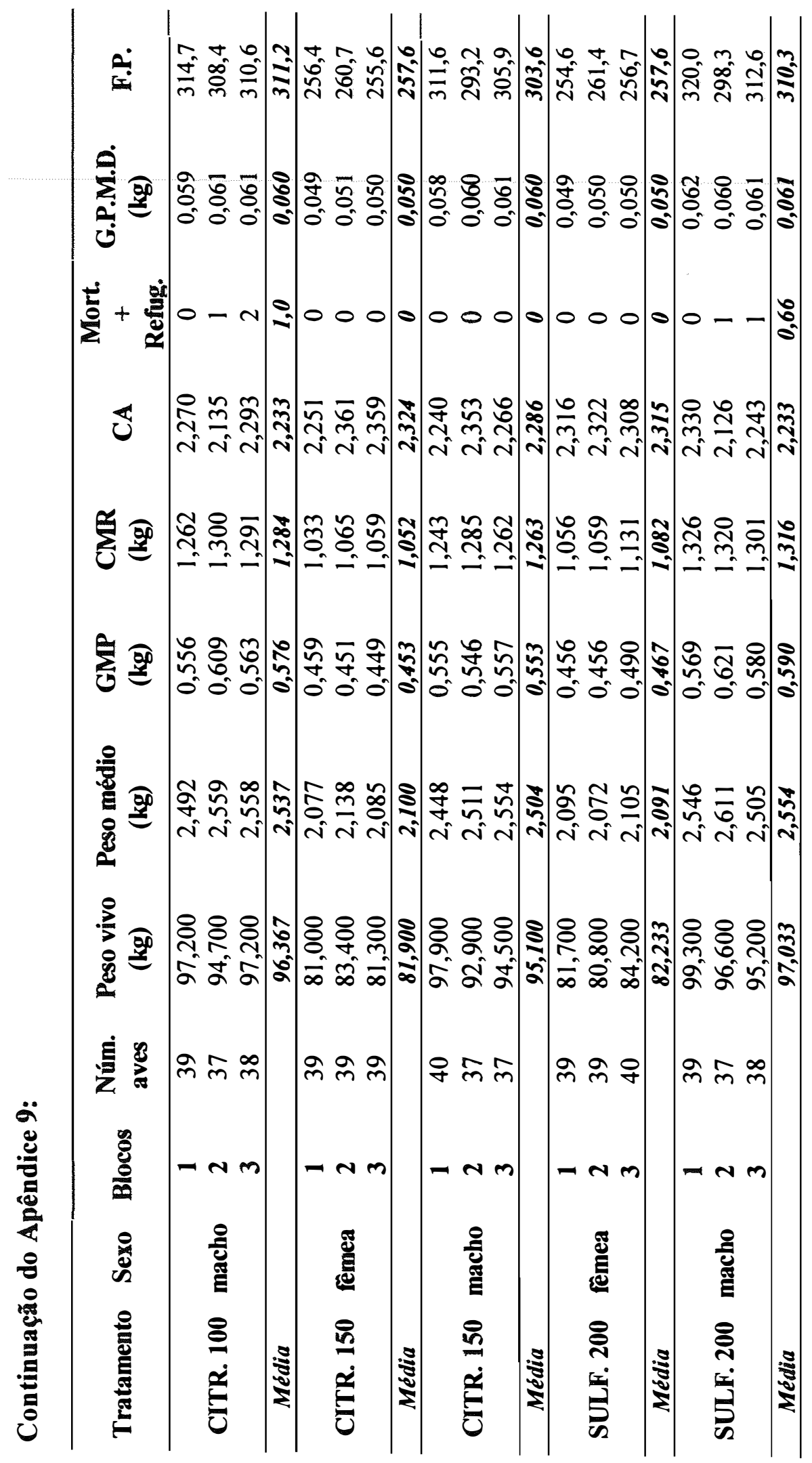


Apêndice 10: Níveis de colesterol no soro sangüíneo (ColS.) e no músculo do peito (ColC.) das aves, obtidos aos 42 dias do período experimental.

\begin{tabular}{|c|c|c|c|c|}
\hline Tratamento & Sexo & Blocos & $\begin{array}{c}\text { ColS. } \\
\text { (mg/dl) }\end{array}$ & $\begin{array}{c}\text { ColC. } \\
(\mathrm{mg} / 100 \mathrm{~g})\end{array}$ \\
\hline & & 1 & 132 & 49,44 \\
\hline \multirow[t]{2}{*}{ CONTR. } & fêmea & 2 & 120 & 54,45 \\
\hline & & 3 & 128 & 57,60 \\
\hline \multirow[t]{2}{*}{ Média } & & & 127 & 53,83 \\
\hline & & 1 & 148 & 54,40 \\
\hline \multirow[t]{2}{*}{ CONTR. } & macho & 2 & 141 & 60,48 \\
\hline & & 3 & 119 & 58,85 \\
\hline \multirow[t]{2}{*}{ Média } & & & 136 & 57,91 \\
\hline & & 1 & 129 & 47,10 \\
\hline \multirow[t]{2}{*}{ CTTR. 50} & fêmea & 2 & 120 & 54,83 \\
\hline & & 3 & 111 & 57,53 \\
\hline \multirow[t]{2}{*}{ Média } & & & 120 & 53,15 \\
\hline & & 1 & 122 & 50,21 \\
\hline \multirow[t]{2}{*}{ CITR. 50} & macho & 2 & 124 & 47,61 \\
\hline & & 3 & 130 & 56,86 \\
\hline \multirow[t]{2}{*}{ Média } & & & 125 & 51,56 \\
\hline & & 1 & 188 & 59,36 \\
\hline \multirow{2}{*}{ CITR. 100} & fêmea & 2 & 118 & 53,11 \\
\hline & & 3 & 150 & 56,71 \\
\hline \multirow[t]{2}{*}{ Média } & & & 152 & 56,39 \\
\hline & & 1 & 105 & 56,04 \\
\hline \multirow[t]{2}{*}{ CITR. 100} & macho & 2 & 110 & 51,12 \\
\hline & & 3 & 124 & 59,39 \\
\hline \multirow[t]{2}{*}{ Média } & & & 113 & 55,52 \\
\hline & & 1 & 133 & 57,02 \\
\hline \multirow[t]{2}{*}{ CITR. 150} & fêmea & 2 & 140 & 60,75 \\
\hline & & 3 & 140 & 56,67 \\
\hline \multirow[t]{2}{*}{ Média } & & & 138 & 58,15 \\
\hline & & 1 & 123 & 57,96 \\
\hline \multirow[t]{2}{*}{ CITR. 150} & macho & 2 & 129 & 48,49 \\
\hline & & 3 & 111 & 62,51 \\
\hline \multirow[t]{2}{*}{ Média } & & & 121 & 56,32 \\
\hline & & 1 & 121 & 62,77 \\
\hline \multirow[t]{2}{*}{ SULF. 200} & fềmea & 2 & 169 & 57,74 \\
\hline & & 3 & 124 & 57,67 \\
\hline \multirow[t]{2}{*}{ Média } & & & 138 & 59,39 \\
\hline & & 1 & 121 & 59,12 \\
\hline \multirow[t]{2}{*}{ SULF. 200} & macho & 2 & 137 & 61,91 \\
\hline & & 3 & 112 & 51,82 \\
\hline Média & & & 123 & 57,62 \\
\hline
\end{tabular}


Apêndice 11: Mortalidade + refugagem $(M+R)$ das aves durante o período experimental.

\begin{tabular}{|c|c|c|c|c|c|c|c|c|c|c|}
\hline \multirow[t]{2}{*}{ Semana } & \multicolumn{2}{|c|}{$\begin{array}{l}\text { Tratamento } \\
\text { CONTR. }\end{array}$} & \multicolumn{2}{|c|}{$\begin{array}{c}\text { Tratamento } \\
\text { CITR } 50\end{array}$} & \multicolumn{2}{|c|}{$\begin{array}{c}\text { Tratamento } \\
\text { CITR } 100 \\
\end{array}$} & \multicolumn{2}{|c|}{$\begin{array}{c}\text { Tratamento } \\
\text { CITR 150 }\end{array}$} & \multicolumn{2}{|c|}{$\begin{array}{l}\text { Tratamento } \\
\text { SULF. } 200\end{array}$} \\
\hline & $\mathbf{F}$ & $\mathbf{M}$ & $\mathbf{F}$ & $\mathbf{M}$ & $\mathbf{F}$ & $\mathbf{M}$ & $\mathbf{F}$ & $\mathbf{M}$ & $\mathbf{F}$ & $\mathbf{M}$ \\
\hline 1 & 0 & 0 & 0 & 0 & 0 & 0 & 0 & 0 & 0 & 0 \\
\hline 2 & 0 & 0 & 3 & 0 & 0 & 0 & 1 & 2 & 0 & 1 \\
\hline 3 & 1 & 2 & 1 & 0 & 2 & 0 & 0 & 2 & 0 & 2 \\
\hline 4 & 1 & 1 & 1 & 0 & 1 & 2 & 1 & 0 & 1 & 0 \\
\hline 5 & 1 & 1 & 1 & 0 & 0 & 1 & 1 & 2 & 1 & 1 \\
\hline 6 & 1 & 0 & 0 & 2 & 0 & 3 & 0 & 0 & 0 & 2 \\
\hline Total/ sexo & 4 & 4 & 6 & 2 & 3 & 6 & 3 & 6 & 2 & 6 \\
\hline Total/ trat. & \multicolumn{2}{|c|}{8} & \multicolumn{2}{|c|}{8} & \multicolumn{2}{|c|}{9} & \multicolumn{2}{|c|}{9} & \multicolumn{2}{|c|}{8} \\
\hline
\end{tabular}

Apêndice 12: Análise da variância do ganho médio de peso (GMP) de 1 a 21 dias de idade ${ }^{l}$.

\begin{tabular}{lccccc}
\hline Causas de variação & G.L. & $\begin{array}{c}\text { Soma de } \\
\text { quadrados }\end{array}$ & $\begin{array}{c}\text { Quadrado } \\
\text { médio }\end{array}$ & F & Pr > F \\
\hline Blocos & 2 & 0,00071460 & 0,00035730 & 2,09 & 0,1529 \\
Tratamentos & 4 & 0,00098400 & 0,00024600 & 1,44 & 0,2621 \\
Sexo & 1 & 0,07460053 & 0,07460053 & 436,06 & 0,0001 \\
Trat. ${ }^{*}$ Sexo & 4 & 0,00014547 & 0,00003637 & 0,21 & 0,9280 \\
Resíduo & 18 & 0,00307940 & 0,00017108 & & \\
\hline Total & 29 & 0,07952400 & & & \\
\hline
\end{tabular}


Apêndice 13: Análise da variância do consumo médio de ração (CMR) de 1 a 21 dias de idade ${ }^{1}$.

\begin{tabular}{lccccc}
\hline Causas de variação & G.L. & $\begin{array}{c}\text { Soma de } \\
\text { quadrados }\end{array}$ & $\begin{array}{c}\text { Quadrado } \\
\text { médio }\end{array}$ & F & Pr > F \\
\hline Blocos & 2 & 0,00529887 & 0,00264943 & 6,66 & 0,0068 \\
Tratamentos & 4 & 0,00084780 & 0,00021195 & 0,53 & 0,7134 \\
Sexo & 1 & 0,08802083 & 0,08802083 & 221,23 & 0,0001 \\
Trat.*Sexo & 4 & 0,00410367 & 0,00102592 & 2,58 & 0,0726 \\
Resíduo & 18 & 0,00716180 & 0,00039788 & & \\
\hline Total & 29 & 0,10543297 & & & \\
\hline
\end{tabular}

${ }^{1}$ Coeficiente de variação: $1,69 \%$

Apêndice 14: Análise da variância da conversão alimentar (CA) de 1 a 21 dias de idade .

\begin{tabular}{lccccc}
\hline Causas de variação & G.L. & $\begin{array}{c}\text { Soma de } \\
\text { quadrados }\end{array}$ & $\begin{array}{c}\text { Quadrado } \\
\text { médio }\end{array}$ & F & Pr > F \\
\hline Blocos & 2 & 0,00204347 & 0,00102173 & 1,34 & 0,2867 \\
Tratamentos & 4 & 0,00483347 & 0,00120837 & 1,58 & 0,2213 \\
Sexo & 1 & 0,02581333 & 0,02581333 & 33,85 & 0,0001 \\
Trat. *Sexo & 4 & 0,00829267 & 0,00207317 & 2,72 & 0,624 \\
Resíduo & 18 & 0,01372453 & 0,00076247 & & \\
\hline Total & 29 & 0,05470747 & & & \\
\hline Coeficiente de variação: $1,79 \%$ &
\end{tabular}

Apêndice 15: Análise da variância de mortalidade + refugagem $(M+R)$ de 1 a 21 dias de idade $^{l}$.

\begin{tabular}{lccccc}
\hline Causas de variação & G.L. & $\begin{array}{c}\text { Soma de } \\
\text { Quadrados }\end{array}$ & $\begin{array}{c}\text { Quadrado } \\
\text { médio }\end{array}$ & F & Pr > F \\
\hline Blocos & 2 & 11,66666667 & 5,83333333 & 2,07 & 0,1557 \\
Tratamentos & 4 & 5,41666667 & 1,35416667 & 0,48 & 0,7504 \\
Sexo & 1 & 0,20833333 & 0,20833333 & 0,07 & 0,7890 \\
Trat. * Sexo & 4 & 40,41666667 & 10,10416667 & 3,58 & 0,0258 \\
Resíduo & 18 & 50,83333333 & 2,82407407 & & \\
\hline Total & 29 & 108,54166667 & & & \\
\hline${ }^{1}$ Coeficiente de variação: $118,62 \%$
\end{tabular}


Apêndice 16: Análise da variância do ganho médio de peso (GMP) de 22 a 42 dias de idade'.

\begin{tabular}{lccccc}
\hline Causas de variação & G.L. & $\begin{array}{c}\text { Soma de } \\
\text { quadrados }\end{array}$ & $\begin{array}{c}\text { Quadrado } \\
\text { médio }\end{array}$ & F & Pr > F \\
\hline Blocos & 2 & 0,00845227 & 0,00422613 & 3,01 & 0,0745 \\
Tratamentos & 4 & 0,00068813 & 0,00017203 & 0,12 & 0,9726 \\
Sexo & 1 & 0,86972213 & 0,86972213 & 619,47 & 0,0001 \\
Trat. ${ }^{\text {Sexo }}$ & 4 & 0,00412720 & 0,00103180 & 0,73 & 0,5801 \\
Resíduo & 18 & 0,02527173 & 0,00140399 & & \\
\hline Total & 29 & 0,90826147 & & & \\
\hline
\end{tabular}

${ }^{1}$ Coeficiente de variação: $2,49 \%$

Apêndice 17: Análise da variância do consumo médio de ração (CMR) de 22 a 42 dias de idade ${ }^{1}$.

\begin{tabular}{lccccc}
\hline Causas de variação & G.L. & $\begin{array}{c}\text { Soma de } \\
\text { quadrados }\end{array}$ & $\begin{array}{c}\text { Quadrado } \\
\text { médio }\end{array}$ & F & Pr > F \\
\hline Blocos & 2 & 0,04564647 & 0,02282323 & 7,69 & 0,0039 \\
Tratamentos & 4 & 0,00367280 & 0,00091820 & 0,31 & 0,8680 \\
Sexo & 1 & 2,63381070 & 2,63381070 & 887,07 & 0,0001 \\
Trat. *Sexo & 4 & 0,00715880 & 0,00178970 & 0,60 & 0,6656 \\
Resíduo & 18 & 0,05344420 & 0,00296912 & & \\
\hline Total & 29 & 2,74373297 & & & \\
\hline
\end{tabular}

${ }^{1}$ Coeficiente de variação: $1,76 \%$

Apêndice 18: Análise da variância da conversão alimentar (CA) de 22 a 42 dias de idade ${ }^{1}$.

\begin{tabular}{lccccc}
\hline Causas de variação & G.L. & $\begin{array}{c}\text { Soma de } \\
\text { quadrados }\end{array}$ & $\begin{array}{c}\text { Quadrado } \\
\text { médio }\end{array}$ & F & Pr > F \\
\hline Blocos & 2 & 0,00362007 & 0,00181003 & 2,11 & 0,1498 \\
Tratamentos & 4 & 0,00072653 & 0,00018163 & 0,21 & 0,9283 \\
Sexo & 1 & 0,03895203 & 0,03895203 & 45,48 & 0,0001 \\
Trat, ${ }^{\star S e x o ~}$ & 4 & 0,00449547 & 0,00112387 & 1,31 & 0,3030 \\
Resíduo & 18 & 0,0154127 & 0,00085640 & & \\
\hline Total & 29 & 0,06320937 & & & \\
\hline
\end{tabular}

${ }^{1}$ Coeficiente de variação: $1,42 \%$ 
Apêndice 19: Análise da variância de mortalidade + refugagem $(\mathrm{M}+\mathrm{R})$ de 22 a 42 dias de idade ${ }^{1}$.

\begin{tabular}{lccccc}
\hline Causas de variação & G.L. & $\begin{array}{c}\text { Soma de } \\
\text { Quadrados }\end{array}$ & $\begin{array}{c}\text { Quadrado } \\
\text { médio }\end{array}$ & F & Pr > F \\
\hline Blocos & 2 & 5,41666667 & 2,70833333 & 0,80 & 0,4664 \\
Tratamentos & 4 & 6,25000000 & 1,56250000 & 0,46 & 0,7646 \\
Sexo & 1 & 5,20833333 & 5,20833333 & 1,53 & 0,2319 \\
Trat.*Sexo & 4 & 22,91666667 & 5,72916667 & 1,68 & 0,1975 \\
Resíduo & 18 & 61,25000000 & 3,40277778 & & \\
\hline Total & 29 & 101,04166667 & & & \\
\hline
\end{tabular}

${ }^{1}$ Coeficiente de variação: $88,54 \%$

Apêndice 20: Análise da variância do peso médio (PM) aos 42 dias de idade ${ }^{1}$.

\begin{tabular}{lccccc}
\hline Causas de variação & G.L. & $\begin{array}{c}\text { Soma de } \\
\text { quadrados }\end{array}$ & $\begin{array}{c}\text { Quadrado } \\
\text { médio }\end{array}$ & F & Pr > F \\
\hline Blocos & 2 & 0,01168687 & 0,00584343 & 2,98 & 0,0765 \\
Tratamentos & 4 & 0,00181153 & 0,00045288 & 0,23 & 0,9176 \\
Sexo & 1 & 1,45156003 & 1,45156003 & 739,05 & 0,0001 \\
Trat. ${ }^{*}$ Sexo & 4 & 0,00398913 & 0,00099728 & 0,51 & 0,7307 \\
Resíduo & 18 & 0,03535380 & 0,00196410 & & \\
\hline Total & 29 & 1,50440137 & & & \\
\hline${ }^{1}$ Coeficiente de variação: $1,91 \%$ &
\end{tabular}

Apêndice 21: Análise da variância do ganho médio de peso (GMP) de 1 a 42 dias de idade ${ }^{1}$.

\begin{tabular}{lccccc}
\hline Causas de variação & G.L. & $\begin{array}{c}\text { Soma de } \\
\text { quadrados }\end{array}$ & $\begin{array}{c}\text { Quadrado } \\
\text { médio }\end{array}$ & F & Pr > F \\
\hline Blocos & 2 & 0,01143247 & 0,00571623 & 2,93 & 0,0792 \\
Tratamentos & 4 & 0,00185913 & 0,00046478 & 0,24 & 0,9131 \\
Sexo & 1 & 1,45376053 & 1,45376053 & 744,76 & 0,0001 \\
Trat. ${ }^{*}$ Sexo & 4 & 0,00382980 & 0,00095745 & 0,49 & 0,7427 \\
Resíduo & 18 & 0,03513553 & 0,00195197 & & \\
\hline Total & 29 & 1,50601747 & & & \\
\hline
\end{tabular}

Toeficiente de variação: $1,94 \%$ 
Apêndice 22: Análise da variância do consumo médio de ração (CMR) de 1 a 42 dias de idade $^{l}$.

\begin{tabular}{lccccc}
\hline Causas de variação & G.L. & $\begin{array}{c}\text { Soma de } \\
\text { quadrados }\end{array}$ & $\begin{array}{c}\text { Quadrado } \\
\text { médio }\end{array}$ & F & Pr > F \\
\hline Blocos & 2 & 0,08015940 & 0,04007970 & 10,00 & 0,0012 \\
Tratamentos & 4 & 0,00707233 & 0,00176808 & 0,44 & 0,7773 \\
Sexo & 1 & 3,68480653 & 3,68480653 & 919,31 & 0,0001 \\
Trat. *Sexo & 4 & 0,01815980 & 0,00453995 & 1,13 & 0,3725 \\
Resíduo & 18 & 0,07214793 & 0,00400822 & & \\
\hline Total & 29 & 3,86234600 & & & \\
\hline 'Coeficiente de variação: $1,48 \%$ &
\end{tabular}

Apêndice 23: Análise da variância da conversão alimentar (CA) de 1 a 42 dias de idade ${ }^{1}$.

\begin{tabular}{lccccc}
\hline Causas de variação & G.L. & $\begin{array}{c}\text { Soma de } \\
\text { quadrados }\end{array}$ & $\begin{array}{c}\text { Quadrado } \\
\text { médio }\end{array}$ & F & Pr > F \\
\hline Blocos & 2 & 0,00230587 & 0,00115293 & 2,36 & 0,1225 \\
Tratamentos & 4 & 0,00065920 & 0,00016480 & 0,34 & 0,8487 \\
Sexo & 1 & 0,02368830 & 0,02368830 & 48,59 & 0,0001 \\
Trat. ${ }^{*}$ Sexo & 4 & 0,00450987 & 0,00112747 & 2,31 & 0,0971 \\
Resíduo & 18 & 0,00877613 & 0,00048756 & & \\
\hline Total & 29 & 0,03993937 & & & \\
\hline
\end{tabular}

${ }^{1}$ Coeficiente de variação: $1,17 \%$

Apêndice 24: Análise da variância de mortalidade + refugagem $(\mathrm{M}+\mathrm{R})$ de 1 a 42 dias de idade ${ }^{3}$.

\begin{tabular}{lccccc}
\hline Causas de variação & G.L. & $\begin{array}{c}\text { Soma de } \\
\text { quadrados }\end{array}$ & $\begin{array}{c}\text { Quadrado } \\
\text { médio }\end{array}$ & F & Pr > F \\
\hline Blocos & 2 & 26,25000000 & 13,12500000 & 2,30 & 0,1294 \\
Tratamentos & 4 & 1,25000000 & 0,31250000 & 0,05 & 0,9939 \\
Sexo & 1 & 7,50000000 & 7,50000000 & 1,31 & 0,2671 \\
Trat. ${ }^{\star}$ Sexo & 4 & 44,58333333 & 11,14583333 & 1,95 & 0,1458 \\
Resíduo & 18 & 102,91666667 & 5,71759259 & & \\
\hline Total & 29 & 182,50000000 & & & \\
\hline
\end{tabular}

Toeficiente de variação: $68,32 \%$ 
Apêndice 25: Análise da variância de ganho de peso médio diário (GPMD) aos 42 dias de idade ${ }^{1}$.

\begin{tabular}{lccccc}
\hline Causas de variação & G.L. & $\begin{array}{c}\text { Soma de } \\
\text { quadrados }\end{array}$ & $\begin{array}{c}\text { Quadrado } \\
\text { médio }\end{array}$ & F & Pr > F \\
\hline Blocos & 2 & 0,00000887 & 0,00000443 & 4,03 & 0,0358 \\
Tratamentos & 4 & 0,00000113 & 0,00000028 & 0,26 & 0,9012 \\
Sexo & 1 & 0,00082163 & 0,00082163 & 746,94 & 0,0001 \\
Trat. ${ }^{*}$ Sexo & 4 & 0,00000353 & 0,00000088 & 0,80 & 0,5391 \\
Resíduo & 18 & 0,00001980 & 0,00000110 & & \\
\hline Total & 29 & 0,00085497 & & & \\
\hline
\end{tabular}

${ }^{1}$ Coeficiente de variação: $1,91 \%$

Apêndice 26: Análise da variância de fator de produção (FP) aos 42 dias de idade ${ }^{1}$.

\begin{tabular}{lccccc}
\hline Causas de variação & G.L. & $\begin{array}{c}\text { Soma de } \\
\text { quadrados }\end{array}$ & $\begin{array}{c}\text { Quadrado } \\
\text { médio }\end{array}$ & F & Pr > F \\
\hline Blocos & 2 & 204,64266667 & 102,32133333 & 1,34 & 0,2869 \\
Tratamentos & 4 & 88,10800000 & 22,02700000 & 0,29 & 0,8817 \\
Sexo & 1 & 26278,88033333 & 26278,88033333 & 343,95 & 0,0001 \\
Trat.*Sexo & 4 & 553,78800000 & 138,44700000 & 1,81 & 0,1705 \\
Resíduo & 18 & 1375,25066667 & 76,40281481 & & \\
\hline Total & 29 & 28500,66966667 & & & \\
\hline
\end{tabular}

${ }^{1}$ Coeficiente de variação: $3,09 \%$

Apêndice 27: Análise da variância do nível de colesterol no soro sangüíneo (ColS.) aos 42 dias de idade ${ }^{l}$.

\begin{tabular}{lccccc}
\hline Causas de variação & G.L. & $\begin{array}{c}\text { Soma de } \\
\text { quadrados }\end{array}$ & $\begin{array}{c}\text { Quadrado } \\
\text { médio }\end{array}$ & F & Pr > F \\
\hline Blocos & 2 & 300,20000000 & 150,10000000 & 0,54 & 0,5945 \\
Tratamentos & 4 & 361,46666667 & 90,36666667 & 0,32 & 0,8593 \\
Sexo & 1 & 929,63333333 & 929,63333333 & 3,32 & 0,0853 \\
Trat. *Sexo & 4 & 2264,53333333 & 566,13333333 & 2,02 & 0,1347 \\
Resíduo & 18 & 5046,46666667 & 280,35925926 & & \\
\hline Total & 29 & $\mathbf{8 9 0 2 , 3 0 0 0 0 0 0 0}$ & & & \\
\hline
\end{tabular}

Coeficiente de variação: $12,95 \%$ 
Apêndice 28: Análise da variância de nível de colesterol no músculo do peito (ColC.) aos 42 dias de idade ${ }^{1}$.

\begin{tabular}{lccccc}
\hline Causas de variação & G.L. & $\begin{array}{c}\text { Soma de } \\
\text { quadrados }\end{array}$ & $\begin{array}{c}\text { Quadrado } \\
\text { médio }\end{array}$ & F & $\operatorname{Pr}>$ F \\
\hline Blocos & 2 & 37,73318000 & 18,86659000 & 0,95 & 0,4061 \\
Tratamentos & 4 & 126,52595333 & 31,63148833 & 1,59 & 0,2202 \\
Sexo & 1 & 1,19201333 & 1,19201333 & 0,06 & 0,8094 \\
Trat.* Sexo & 4 & 38,47835333 & 9,61958833 & 0,48 & 0,7478 \\
Resíduo & 18 & 358,29922000 & 19,90551222 & & \\
\hline Total & 29 & 562,22872000 & & & \\
\hline
\end{tabular}

${ }^{1}$ Coeficiente de variação: $7,97 \%$ 